\title{
Drinking more water as a primary care preventive intervention : the effects on elderly male bladder function, headache and general health
}

Citation for published version (APA):

Spigt, M. G. (2004). Drinking more water as a primary care preventive intervention : the effects on elderly male bladder function, headache and general health. [Doctoral Thesis, Maastricht University]. Universiteit Maastricht. https://doi.org/10.26481/dis.20041203ms

Document status and date:

Published: 01/01/2004

DOI:

$10.26481 /$ dis.20041203ms

Document Version:

Publisher's PDF, also known as Version of record

Please check the document version of this publication:

- A submitted manuscript is the version of the article upon submission and before peer-review. There can be important differences between the submitted version and the official published version of record.

People interested in the research are advised to contact the author for the final version of the publication, or visit the DOI to the publisher's website.

- The final author version and the galley proof are versions of the publication after peer review.

- The final published version features the final layout of the paper including the volume, issue and page numbers.

Link to publication

\footnotetext{
General rights rights.

- You may freely distribute the URL identifying the publication in the public portal. please follow below link for the End User Agreement:

www.umlib.nl/taverne-license

Take down policy

If you believe that this document breaches copyright please contact us at:

repository@maastrichtuniversity.nl

providing details and we will investigate your claim.
}

Copyright and moral rights for the publications made accessible in the public portal are retained by the authors and/or other copyright owners and it is a condition of accessing publications that users recognise and abide by the legal requirements associated with these

- Users may download and print one copy of any publication from the public portal for the purpose of private study or research.

- You may not further distribute the material or use it for any profit-making activity or commercial gain

If the publication is distributed under the terms of Article 25fa of the Dutch Copyright Act, indicated by the "Taverne" license above, 


\title{
Drinking more water as a primary care preventive
}

\section{intervention; the effects on elderly male bladder}

\author{
function, headache and general health
}

\author{
Proefschrift
}

ter verkrijging van de graad van doctor aan de Universiteit Maastricht, op gezag van de Rector Magnificus, Prof. Mr. G.P.M.F. Mols volgens het besluit van het College van Decanen in het openbaar te verdedigen op vrijdag 3 december 2004 om 12:00 uur

door

\section{Marcus Gerardus Spigt}


Promotores:

Prof. Dr. J.A. Knottnerus

Prof. Dr. C.P. van Schayck

Prof. Dr. Ph.E. van Kerrebroeck

Beoordelingscommissie:

Prof. Dr. M. Prins (voorzitter)

Prof. Dr. J.H.L.R. Bosch (Universiteit Utrecht)

Prof. Dr. J.P. van Hoof

Prof. Dr. H. Kuipers

Prof. Dr. W.A. Stalman (Vrije Universiteit Amsterdam)

The studies in this thesis were financed by the Netherlands Organisation for Health Research and Development (ZonMw) 
The studies presented in this thesis were conducted at the Care and Public Health Research Institute (CAPHRI), which participates in the Netherlands School of Primary Care research (CaRe), acknowledged in 1995 by the Royal Dutch Academy of Science (KNAW).

Finacial support for the printing of this thesis was kindly provided by Yamanouchi Europe B.V.. 


\section{Contents}

Chapter 1 Introduction

Page 7

Chapter 2 Pathophysiological aspects of bladder dysfunction: A new hypothesis for the prevention of 'prostatic' symptoms

Page 17

Chapter 3 The short-term effects of increased urine output on male bladder function and lower urinary tract symptoms

Chapter 4 A randomised trial on the effects of increased fluid intake/urine output on male lower urinary tract function

Chapter 5 The validity and ethics of giving placebo in a randomised non-pharmacological trial

Chapter 6 The effects of long-term increased water intake on blood sodium, glomerular filtration rate, blood pressure and quality of life in an elderly male population (55-75 years)

Chapter 7 Increasing the daily water intake for the prophylactic treatment of headache; A pilot trial Page 103

Chapter 8 General discussion

Page 115

Summary

Page 133

Samenvatting

Page 141

Dankwoord

Page 149

De auteur

Page 156 


\section{Chapter 1}

\section{Introduction}




\section{Introduction}

\section{Lower urinary tract symptoms (LUTS)}

The primary aim of the research was to find a preventive intervention for LUTS in elderly men. This disorder manifests itself as symptoms such as weak stream, incomplete emptying of the bladder, (urge) incontinence, and frequent voiding during the day and night. LUTS are present in approximately $20-30 \%$ of the elderly men. ${ }^{1-3}$

Most men associate their symptoms with ageing and do not consider the symptoms serious. ${ }^{3-5}$ These men are often right because, although they generally worsen over time, ${ }^{6}$ LUTS are seldom life-threatening. However, a reduced functioning of the lower urinary tract can seriously alter a persons overall sense of well-being. ${ }^{7-9}$ For instance, frequent urination during the night disturbs the patients' sleep, resulting in reduced overall well-being and fatigue during the day. ${ }^{10,11}$ In addition, the inability to postpone voiding during the day and the possibility of wetting themselves, turns many daily activities into complicated and stressful events. The consequential avoidance of these activities limit the persons' participation in social and outdoor activities. ${ }^{9,12}$ Moreover, a progressed state of the disorder, often involving chronic urinary retention potentially leading to severe renal complications, can necessitate frequent catheterisation which has an obvious impact on quality of life of the elderly. ${ }^{13}$

\section{Prostatic obstruction?}

For years, it has been assumed that a large prostate resulting in an anatomic urethral obstruction was the primary cause of male LUTS. The prostate is situated below the bladder and surrounds the urethra (see fig 1). The anatomic situation of the prostate makes it imaginable that an enlargement of the prostate, which is present in $90 \%$ of men above 80 years, ${ }^{14}$ was held responsible for the LUTS of elderly men. The formerly used terms 'prostatism', or 'benign prostatic hyperplasia (BPH)' refer to that assumption. However, several cross-sectional studies failed to confirm this 'prostate hypothesis'. 1,15-17 Even stronger, it showed that many men with a large prostate and evident urethral obstruction, do not complain of being bothered by LUTS. ${ }^{18,19}$ 


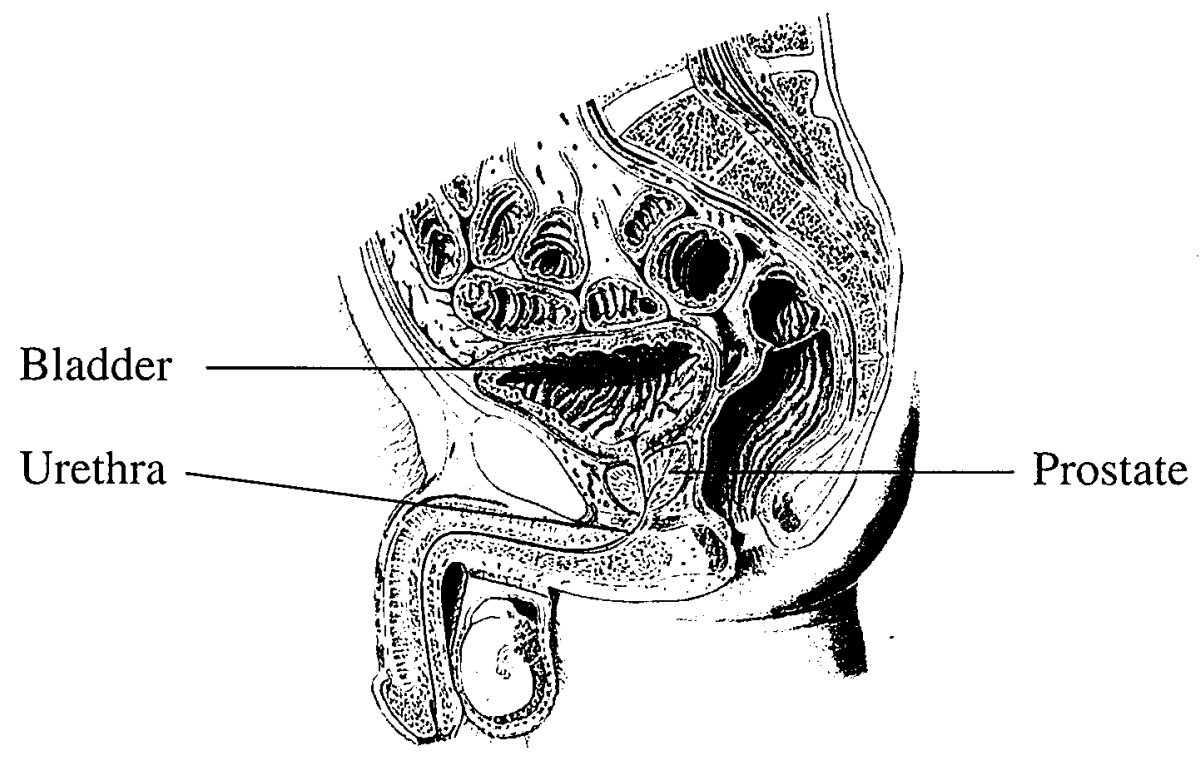

Figure 1: The anatomic location of the prostate*

*From: Sobotta; Atlas van de menselijke anatomie. Houten/Zaventem 1994

\section{A new approach for the prevention of LUTS}

The poor relationship between prostate size and symptom severity made us look critically to the current pathophysiological concepts. This formed the basis of our hypothesis for a new approach in the prevention of LUTS. In short we hypothesised that, because the bladder function is crucial in the micturition process, improving the bladder function should be a key approach in the prevention of LUTS. Since animal studies have shown that bladder function can be improved by increasing the urine output $^{20,21}$ - a matter of physiological adaptation (training) - we hypothesised that increasing the urine output in humans might be an effective approach in the prevention of LUTS. Increased urine output in humans can be achieved by increasing the fluid intake. Accordingly, our approach to prevent LUTS was to drink large amounts of water.

The hypothesis behind drinking water for the prevention of LUTS is described in detail in chapter 2. After formulating the hypothesis the 
next step was to study it. Since no human research had been performed on this topic we first carried out a pilot study. This pilot study is described in chapter 3.

The results form the pilot study were very encouraging. We observed a gradual and large increase in some very important effect measures. This encouraged us to proceed with this line of research resulting in a large randomised trial. This trial, and the results from it, are described in chapter 4 . Chapter 5 addresses the research methodology of the trial, in particular the choice and the evaluation of our unusual choice to give the control group a placebo. This was unusual because the placebo could clearly be distinguished from the intervention. Therefore, we could not inform the participants that they would have a chance of receiving a placebo. In chapter 5 we report on the evaluation of the validity and ethicality of this design.

\section{Drinking water in a broader perspective}

Initially water was only important to us because it was the method to achieve increased urine output in the trial on LUTS. However, during our research we started to learn more about the general health effects of water. Much is claimed both by the supporters as well as the opponents of drinking water. The supporters claim that a decreased water consumption is associated with decubitus ulcer, ${ }^{22,23}$ constipation, ${ }^{24-26}$ urolithiasis, ${ }^{27,28}$ headache, ${ }^{29}$ and even bladder, ${ }^{30-32}$ colorectal $^{33,34}$ and breast cancer. ${ }^{35,36}$ The opponents worry about people exaggerating their fluid intake risking their lives because of a possible hyponatreamia. $37-44$

In view of the fact that water plays such a crucial physiological role in the human body, it is amazing that so little is known about the general health effects of decreased or increased fluid intake. Both the supporters and the opponents rely predominantly on clinical impressions, case reports and theory. Therefore, in order to add scientific evidence to this discussion, we monitored the general health effects of increased fluid intake in the trial on increased fluid intake and LUTS. The results of this monitoring are described in chapter 6.

One example of a potential positive health effect is described in more detail in this thesis. In the pilot study on increase fluid intake and LUTS, where the participants had to drink two litres of water 
additionally to what they normally consumed for a period of two months, one participant stated that his headache relieved as a result of this increased water intake. This observation formed the basis of another pilot study on drinking water and headache. This pilot study is described in chapter 7 . 


\section{References:}

1. Bosch JL, Hop WC, Kirkels WJ and Schröder FH: The International Prostate Symptom Score in a community-based sample of men between 55 and 74 years of age: prevalence and correlation of symptoms with age, prostate volume, flow rate and residual urine volume. Br J Urol. 75: 622-30, 1995.

2. Berges RR, Pientka L, Hofner K, Senge T and Jonas U: Male lower urinary tract symptoms and related health care seeking in Germany. Eur Urol. 39: 682-7, 2001.

3. Wolfs GG, Knottnerus JA, Van der Horst FG, Visser AP and Janknegt RA: Determinants of doctor consultation for micturition problems in an elderly male population. Eur Urol. 33: 1-10, 1998.

4. Cunningham Burley S, Allbutt H, Garraway WM, Lee AJ and Russell EB: Perceptions of urinary symptoms and health-careseeking behaviour amongst men aged 40-79 years. Br J Gen Pract. 46: 349-52, 1996.

5. Jolleys JV, Donovan JL, Nanchahal K, Peters TJ and Abrams P: Urinary symptoms in the community: how bothersome are they? Br J Urol. 74: 551-5, 1994.

6. Temml C, Brossner C, Schatzl G, Ponholzer A, Knoepp L and Madersbacher S: The natural history of lower urinary tract symptoms over five years. Eur Urol. 43: 374-80, 2003.

7. Blanker MH, Driessen LF, Bosch JL, Bohnen AM, Thomas S, Prins A, Bernsen RM and Groeneveld FP: Health status and its correlates among Dutch community-dwelling older men with and without lower urogenital tract dysfunction. Eur Urol. 41: 602-7, 2002.

8. Garraway WM, Russell EB, Lee RJ, Collins GN, McKelvie GB, Hehir M, Rogers AC and Simpson RJ: Impact of previously unrecognized benign prostatic hyperplasia on the daily activities of middle-aged and elderly men. Br J Gen Pract. 43: 318-21, 1993.

9. Calais Da Silva F, Marquis P, Deschaseaux P, Gineste JL, Cauquil $\mathrm{J}$ and Patrick DL: Relative importance of sexuality and quality of life in patients with prostatic symptoms. Results of an international study. Eur Urol. 31: 272-80, 1997. 
10. Asplund R: Nocturia, nocturnal polyuria, and sleep quality in the elderly. J Psychosom Res. 56: 517-25, 2004.

11. van Dijk L, Kooij DG, Schellevis FG, Kaptein AA, Boon TA and Wooning M: Nocturia: impact on quality of life in a Dutch adult population. BJU Int. 93: 1001-4, 2004.

12. Donovan JL, Kay HE, Peters TJ, Abrams P, Coast J, Matos Ferreira A, Rentzhog L, Bosch JL, Nordling J, Gajewski JB et al.: Using the ICSQoL to measure the impact of lower urinary tract symptoms on quality of life: evidence from the ICS-'BPH' Study. International Continence Society--Benign Prostatic Hyperplasia. Br J Urol. 80: 712-21, 1997.

13. Sutaria PM and Staskin DR: Hydronephrosis and renal deterioration in the elderly due to abnormalities of the lower urinary tract and ureterovesical junction. Int Urol Nephrol. 32: 119-26, 2000.

14. Berry SJ, Coffey DS, Walsh PC and Ewing LL: The development of human benign prostatic hyperplasia with age. J Urol. 132: 4749, 1984.

15. Venrooij van GE and Boon TA: The value of symptom score, quality of life score, maximal urinary flow rate, residual volume and prostate size for the diagnosis of obstructive benign prostatic hyperplasia: a urodynamic analysis. J Urol. 155: 2014-8, 1996.

16. Eckhardt MD, van Venrooij GE and Boon TA: Symptoms and quality of life versus age, prostate volume, and urodynamic parameters in 565 strictly selected men with lower urinary tract symptoms suggestive of benign prostatic hyperplasia. Urology. 57: 695-700, 2001.

17. De la Rosette JJ, Witjes WP, Schäfer W, Abrams P, Donovan JL, Peters TJ, Millard RJ, Frimodt Moller C and Kalomiris P: Relationships between lower urinary tract symptoms and bladder outlet obstruction: results from the ICS-"BPH" study. Neurourol Urodyn. 17: 99-108, 1998.

18. Botker Rasmussen I, Bagi P and Jorgensen JB: Is bladder outlet obstruction normal in elderly men without lower urinary tract symptoms? Neurourol Urodyn. 18: 545-51, 1999. 
19. Walker RM, Romano G, Davies AH, Theodorou NA, Springall RG and Carter SS: Pressure flow study data in a group of asymptomatic male control patients 45 years old or older. J Urol. 165: 683-7, 2001.

20. Tammela TL, Longhurst PA, Wein AJ and Levin RM: The effect of furosemide-induced diuresis on rabbit micturition and bladder contractile function. J Urol. 150: 204-8, 1993.

21. Ohnishi N, Horan P, Levin SS and Levin RM: Sucrose diuresis protects rat bladder from outlet partial obstruction-induced contractile dysfunction. Urology. 54: 183-7, 1999.

22. Casimiro C, Garcia de Lorenzo A and Usan L: Prevalence of decubitus ulcer and associated risk factors in an institutionalized Spanish elderly population. Nutrition. 18: 408-14, 2002.

23. Stotts NA and Hopf HW: The link between tissue oxygen and hydration in nursing home residents with pressure ulcers: preliminary data. J Wound Ostomy Continence Nurs. 30: 18490, 2003.

24. Arnaud MJ: Mild dehydration: a risk factor of constipation? Eur J Clin Nutr. 57 Suppl 2: S88-95, 2003.

25. Towers AL, Burgio KL, Locher JL, Merkel IS, Safaeian M and Wald A: Constipation in the elderly: influence of dietary, psychological, and physiological factors. J Am Geriatr Soc. 42: 701-6, 1994.

26. Wilson JA: Constipation in the elderly. Clin Geriatr Med. 15: 499-510, 1999.

27. Embon OM, Rose GA and Rosenbaum T: Chronic dehydration stone disease. Br J Urol. 66: 357-62, 1990.

28. Borghi L, Meschi T, Amato F, Briganti A, Novarini A and Giannini A: Urinary volume, water and recurrences in idiopathic calcium nephrolithiasis: a 5-year randomized prospective study. J Urol. 155: 839-43, 1996.

29. Blau JN, Kell CA and Sperling JM: Water-deprivation headache: a new headache with two variants. Headache. 44: 79-83, 2004.

30. Michaud DS, Spiegelman D, Clinton SK, Rimm EB, Curhan GC, Willett WC and Giovannucci EL: Fluid intake and the risk of bladder cancer in men. N Engl J Med. 340: 1390-7, 1999. 
31. Wilkens LR, Kadir MM, Kolonel LN, Nomura AM and Hankin JH: Risk factors for lower urinary tract cancer: the role of total fluid consumption, nitrites and nitrosamines, and selected foods. Cancer Epidemiol Biomarkers Prev. 5: 161-6, 1996.

32. Bitterman WA, Farhadian H, Abu Samra C, Lerner D, Amoun H, Krapf D and Makov UE: Environmental and nutritional factors significantly associated with cancer of the urinary tract among different ethnic groups. Urol Clin North Am. 18: 501-8, 1991.

33. Tang R, Wang JY, Lo SK and Hsieh LL: Physical activity, water intake and risk of colorectal cancer in Taiwan: a hospital-based case-control study. Int J Cancer. 82: 484-9, 1999.

34. Shannon J, White E, Shattuck AL and Potter JD: Relationship of food groups and water intake to colon cancer risk. Cancer Epidemiol Biomarkers Prev, 5: 495-502, 1996.

35. Bar David Y, Gesundheit B, Urkin J and Kapelushnik J: Water intake and cancer prevention. J Clin Oncol. 22: 383-5, 2004.

36. Stookey JD: Another look at: fuel + $2-\rightarrow \mathrm{CO} 2+\mathrm{H} 2 \mathrm{O}$. Developing a water-oriented perspective. Med Hypotheses. 52: 285-90, 1999.

37. Burke MP and Opeskin K: Sudden death from hyponatremia and hypokalemia in a woman with Gardner syndrome. Am J Forensic Med Pathol. 22: 84-7, 2001.

38. Garigan TP and Ristedt DE: Death from hyponatremia as a result of acute water intoxication in an Army basic trainee. Mil Med. 164: 234-8, 1999.

39. Goldman MB: Moderate hyponatremia and death in a polydipsic schizophrenic on lithium. Biol Psychiatry. 36: 485-6, 1994.

40. McRae RG, Weissburg AJ and Chang $\mathrm{KW}$ : Iatrogenic hyponatremia: a cause of death following pediatric tonsillectomy. Int J Pediatr Otorhinolaryngol. 30: 227-32, 1994.

41. Anonymous: Death in a 56-year-old man with hyponatremia, fluid retention, and multiple cancers. Am J Med. 84: 727-35, 1988.

42. Ashraf $N$, Locksley $R$ and Arieff AI: Thiazide-induced hyponatremia associated with death or neurologic damage in outpatients. Am J Med. 70: 1163-8, 1981. 
43. van Assen $\mathrm{S}$ and Mudde $\mathrm{AH}$ : Severe hyponatraemia in an amiloride/hydrochlorothiazide-treated patient. Neth J Med. 54: 108-13, 1999.

44. Fox BD: Crash diet potomania. Lancet. 359: 942, 2002. 


\title{
Chapter 2
}

\section{Pathophysiological aspects of bladder} dysfunction: A new hypothesis for the prevention of 'prostatic' symptoms

\author{
M.G. (Mark) Spigt ${ }^{1}$ \\ C.P. (Onno) van Schayck ${ }^{1}$ \\ Ph.E. (Philip) van Kerrebroeck ${ }^{2}$ \\ R. (Ron) van Mastrigt ${ }^{3}$ \\ J.A. (André) Knottnerus ${ }^{1}$
}

Affiliations:

1. University of Maastricht, Research institute Caphri, Department of General Practice

2. University Hospital Maastricht, Department of Urology

3. Erasmus Medical Centre, Department of Urology, Sector Furore

Spigt $M G$, van Schayck $C P$, van Kerrebroeck $P E$, van Mastrigt $R$, Knottnerus JA. Pathophysiological aspects of bladder dysfunction: a new hypothesis for the prevention of 'prostatic' symptoms. Med Hypotheses 2004; 62; 3: 448-52. 


\section{Abstract}

This article reviews the literature on the pathophysiology of male Lower Urinary Tract Symptoms (LUTS) with the intention of developing a new preventive intervention for this bothersome disease. Traditionally, male voiding dysfunction has been thought to arise from Bladder Outlet Obstruction (BOO) caused by prostatic enlargement. Many years of research, however, have shown that a clear relationship between the size of the prostate and the occurrence or severity of symptoms is doubtful. Because of its crucial role in urination, it is increasingly being accepted that the clinical manifestation of voiding dysfunction relies on the functional behaviour of the bladder. Several animal studies have shown that bladder performance can be improved by increasing urine output. Contrary to alterations observed in pathologic situations, an increased urine output provides a physiologic stimulus for animal bladder function improvement. We hypothesise that a trained bladder should be less susceptible to the harmful effects of ageing and obstruction. Future symptoms may thus be prevented. In humans an increased urine output can be achieved by drinking additional water, which could be an adequate preventive intervention. 


\section{Introduction}

Elderly men often experience a decreased ability to store and void urine. Commonly reported symptoms are frequent urination, nocturnal voiding, straining to urinate, urge to urinate, a sensation of incomplete emptying and a hesitant, weak or intermittent stream. ${ }^{1}$ Approximately $30 \%$ of men aged 50 or over are affected by Lower Urinary Tract Symptoms (LUTS). ${ }^{2,3}$ Moreover, the incidence of LUTS is expected to increase as a result of the ageing of the population.

Treatment options that have been introduced to relieve symptoms are: phytotherapy, pharmacotherapy, surgical procedures, and minimally invasive techniques. However, prevention will become more and more important in order to control the health care costs of the ageing population. Although common among other specialities, preventive health care is relatively rare in urology. ${ }^{4}$ As regards LUTS, this may partly be due to the fact that there is still no comprehensive explanation for the declining function of the lower urinary tract among older men. This article reviews the current state of knowledge on the pathophysiology of LUTS, and tries to develop a hypothesis for a possible way to prevent the development of LUTS in elderly men. 


\section{Bladder outlet obstruction?}

Traditionally, male voiding dysfunction has been thought to arise from Bladder Outlet Obstruction (BOO). An obstructed outlet into the urethra was assumed to be a reasonable explanation for frequently reported symptoms like poor flow, straining and hesitancy. The BOO hypothesis has greatly influenced the development of treatment strategies in the past decades. Alpha-adrenergic blockers are currently the treatment of first choice for moderate symptoms. They have been shown to be effective ${ }^{5-7}$ although it is uncertain if relieving BOO is the sole source of improvement. ${ }^{8}$ Trans Urethral Resection of the Prostate (TURP) has been the gold standard in the treatment of more severe LUTS. To be effective, however, it was assumed that this intervention should only be applied to patients who are indeed anatomically obstructed.

Since the grade of obstruction could only be measured via urodynamic investigation, many researchers have attempted to find ways to measure this grade non-invasively. Ultrasonically determined prostate size, urinary flow and symptom severity have been correlated with the grade of obstruction in numerous cross-sectional studies. On the whole, however, the conclusions of most correlational studies did not meet the expectations. In fact, most of these studies provided evidence that in symptomatic men, the grade of obstruction could not be satisfactorily predicted by assessing symptom severity or prostate size. ${ }^{9,10}$ Moreover, $\mathrm{BOO}$ as defined by the current standards appears to be a common phenomenon not only in symptomatic, but also in asymptomatic elderly men. ${ }^{11,12}$ In addition, when symptom scores were applied to women, the type and severity of symptoms seemed much the same as in men. ${ }^{13-15}$ These findings have raised doubts about the validity of the BOO hypothesis as the sole causative factor in LUTS. 


\section{Bladder dysfunction as a lead for preventive strategies}

Given that lower urinary tract function involves the storage and voiding of urine, proper functioning of this system largely depends on bladder performance. Clinical manifestation of voiding dysfunction is therefore said to rely, fundamentally, on the functional behaviour of the bladder. ${ }^{16,17}$ This would make the bladder an efficient target for preventive medicine. In order to gain insight into bladder physiology and pathophysiology, we searched the literature to identify factors that could alter bladder function.

\section{Determinants of problematic voiding}

Voiding requires a strong and sustained contraction of the detrusor, until the bladder is completely emptied. Many researchers have studied the effects of outlet obstruction on bladder morphology and physiology, using various animal models of obstruction. These studies have shown that the obstructed animal detrusor responds to experimentally induced obstruction with a surprisingly fast hypertrophy of muscle cells, together with an increase in intercellular collagen. ${ }^{18-24}$ These studies show that experimentally induced obstruction is deleterious to the animal detrusor. It has been suggested that the increase in collagen is the main reason why the contractility of the detrusor is affected, despite the presumed stronger contractile ability of the hypertrophic smooth muscle cells. ${ }^{25}$ The latter probably also holds for the human bladder, although the human condition is different as the obstruction develops gradually. Depending on the severity and duration of obstruction, some bladders may be able to adapt to the obstruction (compensation) while others may respond with a decline in bladder function (decompensation). It is unknown, however, which factors determine a successful or unsuccessful adaptation.

Another cause of impaired bladder contractility is ageing. General features of the ageing process are a decrease in muscle mass and strength and a slowing of muscle contraction. ${ }^{26,27}$ There is increasing evidence that bladder contractility also declines with increasing age. ${ }^{28-30} \mathrm{As}$ in $\mathrm{BOO}$, an increase in collagen relative to muscle tissue is assumed to be 
the main cause of the decreased contractility. ${ }^{31}$ In addition, there seems to be a reduction in the number of nerve fibres, ${ }^{32}$ and a degeneration of the cell membrane of the smooth muscles in the elderly bladder. ${ }^{25}$

Finally, decreased muscle activity leads to muscle weakening, ${ }^{33}$ and there are no reasons to believe that this general rule does not hold for the detrusor muscle. Indeed, in animal studies, Chun et al., Lipski et al., and Machado et al. have shown that inactivity affects bladder contractility. ${ }^{34-36}$ They studied the effects of urinary diversion on bladder function, and found a significant decrease in bladder contractility after the bladder had been bypassed. These studies are quite rigorous illustrations of the adaptation of the bladder to a decreased load. To what extent the human bladder adapts to smaller changes in urine output remains unknown.

\section{Determinants of problematic urine storage}

Uncomplicated storage of urine requires a compliant and relaxing bladder during filling. Bladder compliance describes the relationship between the change in bladder volume and the change in detrusor pressure. The relative increase in collagen over muscle tissue referred to above is assumed to be an important factor contributing to a noncompliant (fibrous) bladder. Since, as described above, collagen deposition may occur in cases of $\mathrm{BOO}, \mathrm{BOO}$ could potentially decrease bladder compliance. Indeed, it has been shown that compliance decreases after experimentally induced obstruction. ${ }^{22}$ Poor compliance also seems to be related to inactivity, as was shown by the urinary diversion studies. In humans, there is some evidence that poor compliance correlates with increasing age, ${ }^{37,38}$ with increasing severity of LUTS, ${ }^{39,40}$ and with the grade of obstruction. ${ }^{37}$

Besides compliance, relaxation of the detrusor is crucial for unproblematic urine storage. The appearance of detrusor activity before the permission to void is given is denominated as detrusor overactivity. ${ }^{41}$ Clinically, the typical patient with detrusor overactivity presents with complaints of urgency, frequency, and/or incontinence. ${ }^{42}$ Some authors have found that bladder overactivity is related to ageing and $\mathrm{BOO},{ }^{43,44}$ but more research is needed on this topic. 


\section{The pathophysiologic mechanism behind bladder dysfunction}

To find clues for preventive interventions, it is important to understand the pathophysiologic mechanism through which the above determinants affect the bladder. Several investigators have demonstrated that detrusor blood flow is reduced with increasing age and in the presence of BOO. ${ }^{45,46}$ It has been suggested that the resulting hypoxia and metabolic depletion directly damage the neuronal and muscular tissues, leading to denervation, collagen deposition, decreased compliance, and impaired contractility. The mechanism through which inactivity may lead to bladder dysfunction seems clear. It is a general physical rule that body tissue that is not being used is restructured to a lower level. ${ }^{33}$ The observed dysfunction of the bladder after experimentally induced inactivity suggests that, as regards muscle degeneration, the bladder behaves much like skeletal muscle. Considering this, improving detrusor blood flow or increasing bladder activity could be effective approaches in the prevention of LUTS. 


\section{A non-invasive and non-pharmacological preventive intervention}

Bladder inactivity is probably the easiest factor to intervene, and there is some evidence that increasing bladder activity leads to bladder function improvement. The studies into the effects of diversion and $\mathrm{BOO}$, for example, have shown that the harmful effects of bladder inactivity and outlet obstruction are, to a certain extend, reversible after undiversion of the bladder. Besides, several animal studies have shown that the bladder is not only able to regain or maintain its normal performance, but that it may even exceed it. Tamela et al. ${ }^{47}$ investigated the effects of diuresis on bladder function and found that, within two weeks, a diuretics-induced 3-fold increase in urine output in rabbits caused a $100 \%$ increase in contractility, a $50 \%$ increase in bladder weight and an increase in the capacity and compliance of the bladder. The nature of this adaptive response to an increased urine output appears to be essentially different from the observed adaptation to BOO. Levin ${ }^{18}$ concludes that, whereas $\mathrm{BOO}$ induces a non-uniform enlargement of the bladder with the associated contractile dysfunctions, diuresis-induced hypertrophy stimulates DNA synthesis in all tissue compartments, leading to improved bladder function. In agreement with this, Ohnishi et $a l .{ }^{48}$ found that diuresis-induced bladder hypertrophy protected the rat bladder from the morphologic defects that usually follow obstruction. It seems that, contrary to the alterations observed in the pathologic obstructive situation, an increase in urine output provides a physiologic stimulus for bladder function improvement.

Regular use of skeletal muscle is essential for unproblematic functioning. The similarities between the bladder and skeletal muscle in terms of muscle adaptation suggest that regular exercise is crucial for proper bladder functioning as well, and that, in fact, an increase in workload should lead to functional improvement, which may prevent future pathology. In humans, an increased urine output can be achieved by increased fluid intake. We therefore hypothesise that an improved bladder function can be achieved by drinking additional water. 


\section{Discussion}

A few aspects should be kept in mind when studying the effects of increased fluid intake. Firstly, the idea of increasing fluid intake may seem paradoxical for the prevention of so-called irritative symptoms (urgency, frequency and nocturia). Daytime and night time frequency is determined by both diuresis and bladder function. Increased diuresis may therefore result in an increased voiding frequency. However, increased diuresis does not have to result in an increased number of voidings during the day or night, provided bladder capacity is also enlarged. Future research in a mildly symptomatic or asymptomatic population must show whether the advantages of increased fluid intake outweigh the practical disadvantages.

Besides these LUTS-related considerations, there are some general health-related aspects that need to be considered when studying the effects of increased fluid intake in elderly men. There is evidence to suggest that elderly individuals are not as well able to regulate their body fluids as younger individuals, probably due to a decreased kidney function. In addition, one could speculate that increased fluid intake might be harmful to a deteriorated haemodynamic system. In the case of increased fluid intake, this may, for instance, lead to oedema and/or risky drops in blood sodium levels. However, such problems may only become apparent in pathologic conditions or when body fluid homeostasis is challenged by abnormal conditions. Renal and haemodynamic pathology should therefore be excluded, and too high increases in fluid intake should be avoided in any case. Within the range from dehydration to overhydration there may, however, be sufficient room to increase the daily fluid intake in order to improve bladder function without causing health problems. To what extent the fluid intake must be raised to improve bladder function is unknown, and how far it can be raised safely in a healthy population is also uncertain. Possible adverse effects should, therefore, be carefully monitored when studying the effects of increased water intake. 


\section{References:}

1. AHCPR: Benign prostatic hyperplasia: diagnosis and treatment. Guideline overview. Agency for Health Care Policy and Research. 86: 489, 548-9, 1994.

2. Bosch JL, Hop WC, Kirkels WJ and Schröder FH: The International Prostate Symptom Score in a community-based sample of men between 55 and 74 years of age: prevalence and correlation of symptoms with age, prostate volume, flow rate and residual urine volume. Br J Urol. 75: 622-30, 1995.

3. Wolfs GG, Knottnerus JA and Janknegt RA: Prevalence and detection of micturition problems among 2,734 elderly men. J Urol. 152: 1467-70, 1994.

4. Roehrborn CG: Acute relief or future prevention: is Urology ready for preventive health care? Urology. 56: 12-9, 2000.

5. Debruyne FM: Alpha blockers: are all created equal? Urology. 56: 20-2, 2000.

6. Vallancien G: Alpha-blockers in benign prostatic hyperplasia. Urology. 54: 773-5, 1999.

7. Barry MJ and Roehrborn CG: Benign prostatic hyperplasia. BMJ. 323: 1042-6, 2001.

8. Michel MC, Schafers RF and Goepel M: Alpha-blockers and lower urinary tract function: more than smooth muscle relaxation? BJU Int. 86 Suppl 2: 23-8; discussion 28-30, 2000.

9. Barry MJ, Cockett AT, Holtgrewe HL, McConnell JD, Sihelnik SA and Winfield HN: Relationship of symptoms of prostatism to commonly used physiological and anatomical measures of the severity of benign prostatic hyperplasia. J Urol. 150: 351-8, 1993.

10. De la Rosette JJ, Witjes WP, Schäfer W, Abrams P, Donovan JL, Peters TJ, Millard RJ, Frimodt Moller $\mathrm{C}$ and Kalomiris P: Relationships between lower urinary tract symptoms and bladder outlet obstruction: results from the ICS-"BPH" study. Neurourol Urodyn. 17: 99-108, 1998.

11. Botker Rasmussen I, Bagi P and Jorgensen JB: Is bladder outlet 
obstruction normal in elderly men without lower urinary tract symptoms? Neurourol Urodyn. 18: 545-51, 1999.

12. Walker RM, Romano G, Davies AH, Theodorou NA, Springall RG and Carter SS: Pressure flow study data in a group of asymptomatic male control patients 45 years old or older. J Urol. 165: 683-7, 2001.

13. Lepor $\mathrm{H}$ and Machi G: Comparison of AUA symptom index in unselected males and females between fifty-five and seventy-nine years of age. Urology. 42: 36-40, 1993.

14. Chai TC, Belville WD, McGuire EJ and Nyquist L: Specificity of the American Urological Association voiding symptom index: comparison of unselected and selected samples of both sexes. J Urol. 150: 1710-3, 1993.

15. Chancellor $\mathrm{MB}$ and Rivas DA: American Urological Association symptom index for women with voiding symptoms: lack of index specificity for benign prostate hyperplasia. J Urol. 150: 1706-8, 1993.

16. Elbadawi A, Yalla SV and Resnick NM: Structural basis of geriatric voiding dysfunction. I. Methods of a prospective ultrastructural/urodynamic study and an overview of the findings. J Urol. 150: 1650-6, 1993.

17. Azadzoi KM, Tarcan T, Kozlowski R, Krane RJ and Siroky MB: Overactivity and structural changes in the chronically ischemic bladder. J Urol. 162: 1768-78, 1999.

18. Levin RM, Monson FC, Haugaard N, Buttyan R, Hudson A, Roelofs $M$, Sartore $S$ and Wein AJ: Genetic and cellular characteristics of bladder outlet obstruction. Urol Clin North Am. 22: 263-83, 1995.

19. Gosling JA, Kung LS, Dixon JS, Horan P, Whitbeck C and Levin RM: Correlation between the structure and function of the rabbit urinary bladder following partial outlet obstruction. J Urol. 163: 1349-56, 2000.

20. Buttyan R, Chen MW and Levin RM: Animal models of bladder outlet obstruction and molecular insights into the basis for the development of bladder dysfunction. Eur Urol. 32 Suppl 1: 32-9, 1997. 
21. Levin RM, Levin SS, Zhao $Y$ and Buttyan R: Cellular and molecular aspects of bladder hypertrophy. Eur Urol. 32 Suppl 1: 15-21, 1997.

22. Kok DJ, Wolffenbuttel KP, Minekus JP, van Mastrigt R and Nijman JM: Changes in bladder contractility and compliance due to urethral obstruction: a longitudinal followup of guinea pigs. J Urol. 164: 1021-4, 2000.

23. Mauroy B: Bladder consequences of prostatic obstruction. Eur Urol. 32 Suppl 1: 3-8, 1997.

24. Saito M, Ohmura M and Kondo A: Effects of long-term partial outflow obstruction on bladder function in the rat. Neurourol Urodyn. 15: 157-65, 1996.

25. Elbadawi A: Voiding dysfunction in benign nrostatic hyperplasia: trends, controversies and recent revelations. II. Pathology and pathophysiology. Urology. 51: 73-82, 1998.

26. Starling RD, Ades PA and Poehlman ET: Physical activity, protein intake, and appendicular skeletal muscle mass in older men. Am J Clin Nutr. 70: 91-6, 1999.

27. Margreth A, Damiani E and Bortoloso E: Sarcoplasmic reticulum in aged skeletal muscle. Acta Physiol Scand. 167: 331-8, 1999.

28. Mastrigt van R: Age dependence of urinary bladder contractility. Neurourol Urodyn. 11: 315-317, 1992.

29. Pagala MK, Tetsoti L, Nagpal D and Wise GJ: Aging effects on contractility of longitudinal and circular detrusor and trigone of rat bladder. J Urol. 166: 721-7, 2001.

30. Bosch JL, Kranse R, van Mastrigt R and Schroder FH: Dependence of male voiding efficiency on age, bladder contractility and urethral resistance: development of a voiding efficiency nomogram. J Urol. 154: 190-4, 1995.

31. Inui E, Ochiai A, Naya Y, Ukimura O and Kojima M: Comparative morphometric study of bladder detrusor between patients with benign prostatic hyperplasia and controls. J Urol. 161: 827-30, 1999.

32. Gosling JA: Modification of bladder structure in response to outflow obstruction and ageing. Eur Urol. 32 Suppl 1: 9-14, 1997. 
33. Guyton AC: Textbook of medical physiology. Philadelphia, W.B. Saunders Company, 1991.

34. Chun AL, Ruzich JV, Wein AJ and Levin RM: Functional and pharmacological effects of ureteral diversion. J Urol. 141: 403-7, 1989.

35. Lipski BA, Yoshino K, Yao LY, Carr MC and Mitchell ME: A unique new model to study the effects of urinary diversion in the developing rabbit bladder. J Urol. 160: 1454-8, 1998.

36. Machado MG, Yoo JJ and Atala A: Defunctionalized bladders: effects before and after refunctionalization in an animal model. J Urol. 164: 1002-7, 2000.

37. Madersbacher S, Pycha A, Klingler CH, Mian C, Djavan B, Stulnig $\mathrm{T}$ and Marberger $\mathrm{M}$ : Interrelationships of bladder compliance with age, detrusor instability, and obstruction in elderly men with lower urinary tract symptoms. Neurourol Urodyn. 18: 3-15, 1999.

38. Madersbacher S, Pycha A, Schatzl G, Mian C, Klingler CH and Marberger $M$ : The aging lower urinary tract: a comparative urodynamic study of men and women. Urology. 51: 206-12, 1998.

39. Eckhardt MD, van Venrooij GE and Boon TA: Symptoms, prostate volume, and urodynamic findings in elderly male volunteers without and with LUTS and in patients with LUTS suggestive of benign prostatic hyperplasia. Urology. 58: 966-71, 2001.

40. Eckhardt MD, van Venrooij GE and Boon TA: Symptoms and quality of life versus age, prostate volume, and urodynamic parameters in 565 strictly selected men with lower urinary tract symptoms suggestive of benign prostatic hyperplasia. Urology. 57: 695-700, 2001.

41. Abrams P, Cardozo L, Fall M, Griffiths D, Rosier P, Ulmsten U, van Kerrebroeck P, Victor A and Wein A: The standardisation of terminology of lower urinary tract function: report from the Standardisation Sub-committee of the International Continence Society. Neurourol Urodyn. 21: 167-78, 2002.

42. Bosch JL: The overactive bladder: current aetiological concepts. BJU Int. 83 Suppl 2: 7-9, 1999. 
43. Knutson T, Edlund $\mathrm{C}$, Fall $\mathrm{M}$ and Dahlstrand $\mathrm{C}$ : BPH with coexisting overactive bladder dysfunction--an everyday urological dilemma. Neurourol Urodyn. 20: 237-47, 2001.

44. Eckhardt $\mathrm{MD}$, van Venrooij $\mathrm{GE}$ and Boon TA: Interactions between prostate volume, filling cystometric estimated parameters, and data from pressure-flow studies in 565 men with lower urinary tract symptoms suggestive of benign prostatic hyperplasia. Neurourol Urodyn. 20: 579-90, 2001.

45. Greenland JE and Brading AF: The effect of bladder outflow obstruction on detrusor blood flow changes during the voiding cycle in conscious pigs. J Urol. 165: 245-8, 2001.

46. Uvelius B and Arner A: Changed metabolism of detrusor muscle cells from obstructed rat urinary bladder. Scand $\mathbf{J}$ Urol Nephrol Suppl. 184: 59-65, 1997.

47. Tammela TL, Longhurst PA, Wein AJ and Levin RM: The effect of furosemide-induced diuresis on rabbit micturition and bladder contractile function. J Urol. 150: 204-8, 1993.

48. Ohnishi N, Horan P, Levin SS and Levin RM: Sucrose diuresis protects rat bladder from outlet partial obstruction-induced contractile dysfunction. Urology. 54: 183-7, 1999. 


\section{Chapter 3}

\section{The short-term effects of increased urine output on male bladder function and lower urinary tract symptoms}

M.G. (Mark) Spigt ${ }^{1}$

J.A. (André) Knottnerus ${ }^{1}$

C. (Cees) van de Beek ${ }^{2}$

Ph.E. (Philip) van Kerrebroeck ${ }^{2}$

L.G.P.M. (Ludovic) van Amelsvoort ${ }^{3}$

C.P. (Onno) van Schayck ${ }^{1}$

Affiliations:

1. University of Maastricht, Research institute Caphri, Department of General Practice

2. University Hospital Maastricht, Department of Urology

3. University of Maastricht, Research institute Caphri, Department of Epidemiology

Spigt MG, Knottnerus JA, Van De Beek C, Van Kerrebroeck PE, Van Amelsvoort LG and Van Schayck CP: Short-term effects of increased urine output on male bladder function and lower urinary tract symptoms. Urology. 64: 499-503, 2004. 


\section{Abstract}

\section{Background}

Bladder dysfunction is considered to be an important factor in the development of lower urinary tract symptoms (LUTS). Animal studies have shown that bladder function can be improved by increasing the urine output. We studied whether the human bladder can also adapt to such an increased physiological load.

\section{Methods}

44 men between 55-75 years of age were asked to increase their daily fluid intake by 2 litres, for a period of two months. Objective outcome measures were maximum urinary flow rate (DaCapo homeflow meter), maximum voided volume (frequency-volume chart) and average voided volume (frequency-volume chart). The International Prostate Symptoms Score (IPSS) and global perceived benefit of the intervention were recorded to assess the subjective effects of the intervention.

\section{Results}

Maximum flow rate increased by $13 \%(2.3 \mathrm{ml} / \mathrm{s})$, maximum voided volume increased by $23 \%(93.8 \mathrm{ml})$, and average voided volume increased by $25 \%(60.1 \mathrm{ml})$. $56 \%$ of the participants reported an improvement of their lower urinary tract function, but the IPSS score increased statistically significant with 1.2 points.

\section{Conclusions}

The human bladder seems able to adapt to an increased load. Future randomised effectiveness studies with a longer follow-up period should determine the upper limit of objective bladder adaptation. In addition, future studies should address the long-term efficacy in the prevention of symptoms. 


\section{Introduction}

In males, the ability to store and void urine gradually diminishes with increasing age. Approximately $30 \%$ of men aged 50 or over experience Lower Urinary Tract Symptoms (LUTS). ${ }^{1}$ Traditionally, male voiding dysfunction has been thought to arise from Bladder Outlet Obstruction (BOO) caused by prostatic enlargement. However, because of its crucial role in urination, it is increasingly being accepted that the clinical manifestation of voiding dysfunction relies on the functional behaviour of the bladder.

The animal urinary bladder responds to experimentally induced stress with compensatory alterations in bladder mass, compliance, and contractility. In case of bladder outlet obstruction there is a marked increase of bladder mass, and a decrease of both compliance and contractility. ${ }^{2}$ These changes can be reversed by relieving the obstruction. ${ }^{3}$ In case of experimental diuresis, the animal bladder mass is also increased, but contrary to the obstructive situation, the compliance and contractility improve. ${ }^{4,5} \mathrm{~A}$ study of Tammela et al. ${ }^{4}$ showed that in rabbits, a diuretics-induced 3-fold increase in urine output caused, within two weeks, a $60 \%$ increase in bladder weight, a significant increase in contractile responses to both field and pharmacological stimulation, and a $190 \%$ increase in compliance of the bladder. Contrary to the alterations observed in pathologic situations such as BOO, increased urine output is therefore thought to provide a physiologic stimulus for animal bladder function improvement. ${ }^{2,4,5}$

If we can achieve a similar adaptive response in the human bladder, we might be able to influence a crucial factor in the development of LUTS. ${ }^{6}$ It is still unknown, however, whether the human bladder can also adapt to increased urine output.

Since humans can be asked to increase their fluid intake, no diuretics are needed to increase the urine output. In this paper we describe the results of a follow-up study in which we examined the shortterm effects of drinking additional water in order to increase the urine output on several measures of bladder function in humans. 


\section{Methods}

We recruited 55 to 75 year old male participants via a written invitation from two general practitioners and via an advertisement in a local newspaper. Both symptomatic and asymptomatic men could assign for the study. Exclusion criteria were: past surgery of the lower urinary tracts, a history of prostatic or bladder carcinoma, Parkinson's disease, the use of medication for LUTS, and the use of diuretics. A series of 62 men gave informed consent after the invitation of the general practitioner. We excluded 7 men. The other 55 men were invited for an informative meeting. After this meeting, 11 men withdrew. The reasons for withdrawal varied and included unavailability for the research period and expected inconvenience of the intervention. A total of 44 men started the intervention. During the intervention period 4 subjects dropped out due to interference of the intervention with their daily occupation $(n=2)$, or because of gastrointestinal complaints $(n=2)$.

The essence of the intervention was to substantially increase daily fluid intake for a period of 8 weeks. We requested the participants to drink 1 litre of additional water per day in the first week, 1.5 litre per day in the second week, and 2 litres per day in weeks 3 to 8 .

Maximum urinary flow rate (Qmax) was calculated by measuring the voided volume per unit of time $(\mathrm{ml} / \mathrm{s})$ with the DaCapo ${ }^{\mathrm{TM}}$ homeflow meter. ${ }^{7}$ We measured the maximum flow rate every other week on two consecutive days at the same time. We calculated the mean score of the two measurements if both recorded voidings on the two consecutive days were valid (i.e. $>150 \mathrm{ml}$ ).

To assess the subjective effects of an increased urine output, the International Prostate Symptom Score ${ }^{8,9}$ (IPSS; range: 0-35) with Quality of Life question (IPSS-QoL; range: 0-6) was measured at baseline, four weeks and eight weeks. Global perceived benefit of the intervention was measured using the question: "How did your lower urinary tract function change since treatment initiation? (7-point scale: 0 $=$ much worse to $6=$ much better). 
Participants kept a 3×24-hour diary in which they registered voided volumes and fluid intake at baseline, one month and two months. From these diaries total diurnal fluid intake, total diurnal and nocturnal urine volume, diurnal and nocturnal frequency, average voided volume, and maximum voided volume were calculated. If data was complete for all three days a mean score was calculated. If a subject kept the diary for less than three days, the mean of the remaining days (at least 24 -hour) ${ }^{10}$ was taken.

The differences between the measurements were tested for their statistical significance with paired-samples t-tests (SAS). Changes in Qmax scores were adjusted for voided volume using mixed model analysis for repeated measurements (SAS). This procedure uses the calculated correlation between Qmax and voided volume of all recorded assessments at the 5 subsequent time points to adjust each assessment of qmax for the voided volume. A two-tailed p-value $<0.05$ was considered statistically significant.

The ethical review committee of the University Hospital Maastricht/ University of Maastricht approved the research protocol. 


\section{Results}

\section{Baseline characteristics}

Table 1 shows the baseline characteristics for the total population and for mildly symptomatic participants and moderately/severely symptomatic participants separately. Mean age of the total population was 61 years. The participants were on average mildly symptomatic (IPSS: 7.9), had a maximum flow rate of $17.4 \mathrm{ml} / \mathrm{s}$, and were fairly satisfied with their urinary condition (IPSS-QoL: 1.9). Participants with moderate to severe symptoms reported a significantly worse IPSS-QoL (table 1), lower flow rates, increased diurnal and nocturnal frequency, and decreased average and maximum voided volumes.

\section{Table 1 Baseline characteristics.}

\begin{tabular}{|c|c|c|c|c|c|}
\hline & \multicolumn{2}{|c|}{$\begin{array}{l}\text { Total population } \\
\qquad \mathrm{n}=44\end{array}$} & \multirow{2}{*}{$\begin{array}{c}\text { Mild } \\
\text { symptoms } \\
\text { (IPSS } 0 \text { to } 7 \text { ) } \\
\mathrm{n}=25 \\
\text { Mean }\end{array}$} & \multicolumn{2}{|c|}{$\begin{array}{c}\text { Moderate/severe } \\
\text { symptoms } \\
\text { (IPSS }=\geq 8 \text { ) } \\
n=19\end{array}$} \\
\hline & Mean & (SD) & & Mean & p-value \\
\hline Age (years) & 61 & (4) & 60 & 62 & 0.151 \\
\hline $\operatorname{IPSS}(0-35)^{*}$ & 7.9 & $(5.9)$ & 3.4 & 13.9 & $<0.001$ \\
\hline IPSS-QoL $(0-6)^{*}$ & 1.9 & (1.3) & 1.1 & 2.8 & $<0.001$ \\
\hline Maximum flow rate $(\mathrm{ml} / \mathrm{s})$ & 17.4 & $(7.2)$ & 20.8 & 12.1 & $<0.001$ \\
\hline Diurnal fluid intake (ml) & 2145 & $(553)$ & 2055 & 2258 & 0.235 \\
\hline Diurnal urine volume & 1853 & $(634)$ & 1778 & 1948 & 0.391 \\
\hline Daytime frequency & 8.1 & $(2.4)$ & 6.9 & 9.5 & $<0.001$ \\
\hline Nocturnal urine volume & 583 & $(257)$ & 600 & 564 & 0.687 \\
\hline Night-time frequency & 0.9 & $(0.7)$ & 0.8 & 1.2 & 0.064 \\
\hline Average voided volume $(\mathrm{ml})$ & 238 & $(74)$ & 263 & 206 & 0.011 \\
\hline Maximum voided volume (ml) & 416 & $(128)$ & 447 & 376 & 0.071 \\
\hline
\end{tabular}




\section{Changes in fluid intake and urine output}

Total fluid intake during the day increased statistically significant by $1578 \mathrm{ml}$ at two months (p: <0.001) (data not shown in table). The mean increase in total diurnal urine volume was $1224 \mathrm{ml}(\mathrm{p}$ : <0.001) and at two months nocturnal urine volume increased by $252 \mathrm{ml}$ (p: $<0.001$ ). At the end of the intervention period, the participants had to void an average of 2.6 ( $\mathrm{p}:<0.001$ ) times more during the day, and nocturnal frequency increased by 0.3 (p: 0.006 ).

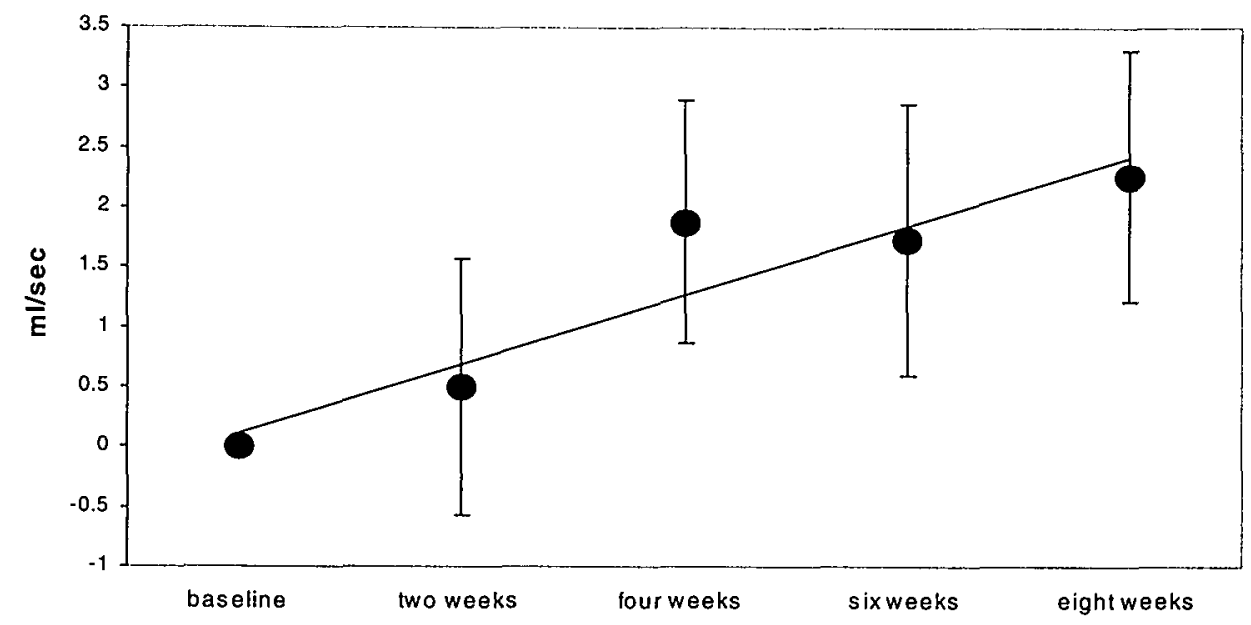

Figure 1 Mean improvement of maximum flow rate (Qmax).

The dots represent the mean change in Qmax from baseline to eight weeks. The vertical lines are 95\%-confidence intervals. The changes in Qmax were corrected for voided volumes, and a regression line was fitted through the means.

\section{Objective changes}

As shown in figure 1, maximum flow rate adjusted for voided volume increased gradually and statistically significant to a maximum increase of $13 \%(2.3 \mathrm{ml} / \mathrm{s})$ at two months. In addition, at two months, maximum and average voided volume (figure 2 ) increased statistically significant by $23 \%$ $(93.8 \mathrm{ml})$, respectively $25 \%(60.1 \mathrm{ml})$ when compared to baseline scores. Mildly symptomatic and moderately/severely symptomatic men did not 
respond significantly different on these objective measurements (change score at 2 months, mild symptoms vs. moderate/severe symptoms: Qmax 2.3 vs. 2.0 (p:0.4094); Average voided volume: 62 vs. 57 (p: 0.770); Maximum voided volume: 98 vs. 87 (p: 0.759).

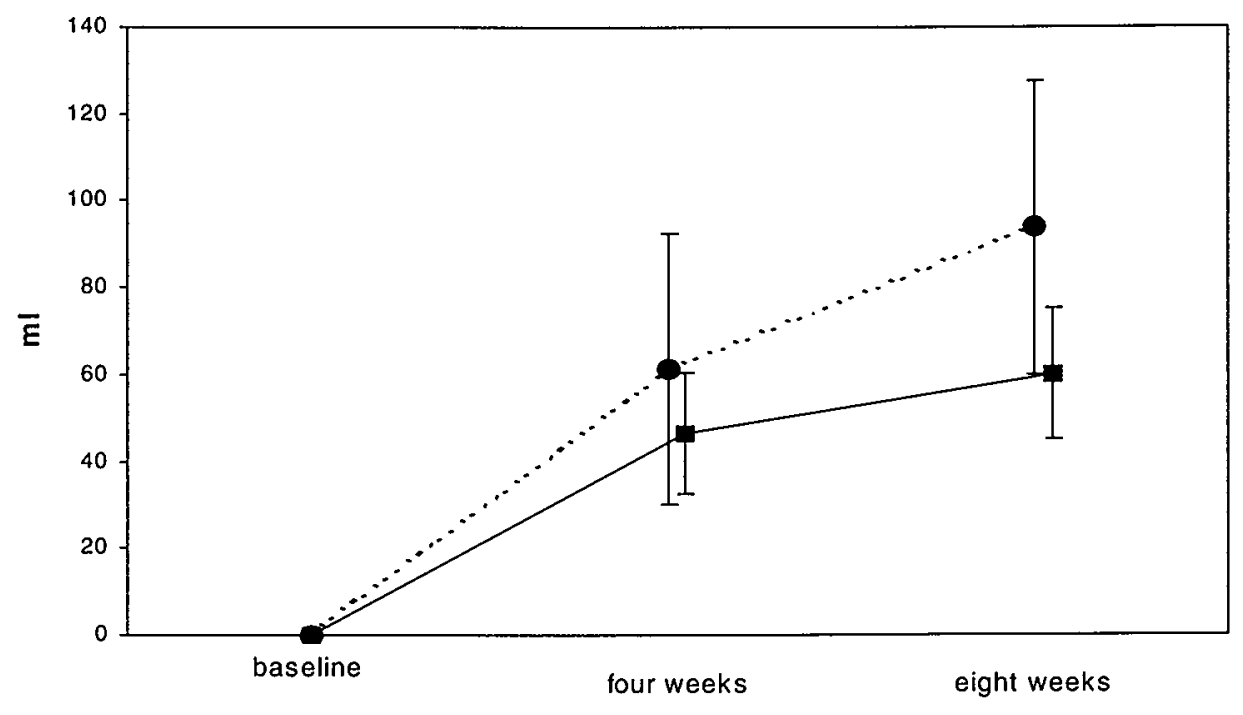

Figure 2 Mean improvement of maximum and average voided volume.

The dots represent the mean change in maximum voided volume from baseline to eight weeks. The squares represent the mean change in average voided volume. The vertical lines are $95 \%$-confidence intervals.

\section{Subjective changes}

The IPSS score increased statistically significant by 1.2 points at two months (table 2). There was no statistically significant change in mean IPSS-QoL. After two months $7.3 \%$ stated that their lower urinary tract function had worsened, $36.6 \%$ experienced no change, and $56.1 \%$ reported an improvement. There were no large differences in subjective change scores between mildly symptomatic and moderately/severely symptomatic men, at two months (change score at 2 months, mild symptoms v.s. moderate/severe symptoms: IPSS 1.8 v.s. 0.3 (p: 0.124 ); IPSS-QoL 0.0 v.s. -0.4 (p: 0.232)). 
Table 2 Changes on subjective measurements.

$\begin{array}{ccc}\text { Score } & \text { Change score } & \text { p-value } \\ \text { Mean (SD) } & \text { Mean }(\mathrm{CI}) & \end{array}$

IPSS $(0-35)^{*}$

$\begin{array}{llll}\text { Baseline score } & 7.9(5.9) & & \\ \text { One month } & 8.9(6.2) & 1.5(0.2 \text { to } 2.8) & 0.028 \\ \text { Two months } & 8.9(5.7) & 1.2(0.2 \text { to } 2.1) & 0.021\end{array}$

IPSS-QoL (0-6)*

Baseline score

One month

Two months

Perceived benefit of the intervention

worsened
no change
improved

$1.9(1.3)$

$1.8(1.4)$

$0.1(-0.2$ to 0.4$)$

0.401

$1.6(1.2)$

$-0.2(-0.5$ to 0.1$)$

0.295

One month Two months

* Bold score is the most favourable score.

$8.6 \% \quad 7.3 \%$

$48.6 \% \quad 36.6 \%$

$42.8 \% \quad 56.1 \%$ 


\section{Discussion}

The aim of this study was to gain insight into the ability of the human bladder to adapt to an increased physiologic load. Due to increased water intake, urine production increased significantly. Maximum urinary flow rate, and average and maximum voided volume increased gradually and significantly. Therefore, as was observed in animal studies, the human bladder seems able to improve its function in response to an increased physiologic load.

As a first topic of discussion we first want to address the fact that we did not include a control group at this preliminary stage of studying this new hypothesis. Consequently, several non-specific treatment effects, natural course of disease and regression to the mean, may have influenced the results to the positive. This should be considered when interpreting the results. Considering the global perceived benefit of the intervention for example, we feel that this parameter was subject to placebo-effects or answers of politeness. This may also partly explain the discrepancy between perceived benefit and the change in IPSS scores, which we feel is less susceptible to answers of politeness. Improvements on the objective effect parameters were not likely to be simply a result of natural course or regression to the mean, because subjects were not selected on the basis of poor scores on these effect parameters.

As a result of the advice to drink 2 litres of water additional to commonly consumed beverages, the self-recorded 24-hour urine output increased by approximately 1.5 litres. Estimates of fluid intake and urine output can be subject to registration bias. ${ }^{11,12}$ The coherent increases in fluid intake, average and maximum voided volumes, and total urine output, however suggests that the effect of registration bias is not large in this study. In future studies labelled water (deuterium) may be used to assess the changes in water turnover precisely. ${ }^{13}$ As regards maximum and average voided volumes, we showed that moderately/severely symptomatic men had lower voided volumes compared to mildly symptomatic men at baseline. A recent study of Blanker et al. confirms these findings. ${ }^{14}$ In addition, Blanker et al. observed a gradual decrease 
of maximum voided volumes and average voided volumes with increasing age. These findings seem to illustrate the significance of a reduction of the storage function of the bladder in the development of LUTS. In our study, mean maximum voided volume increased by $94 \mathrm{ml}$ and average voided volume incieased by $60 \mathrm{ml}$. As a consequence, participants with moderate to severe symptoms improved to a level that was comparable to the mildly symptomatic participants at baseline, and to the youngest group (50-54 years) in the study of Blanker et al. However, it should be noted that, although voided volumes seem clinically relevant, no definitive conclusions can be drawn regarding bladder capacity, since no urodynamic measurements were performed. It is therefore possible that the observed increased voided volumes were merely due to an intentional prolongation of the decision to void, rather than due to physiologic changes of the bladder.

Additionally, at baseline we observed a significantly decreased maximum flow rate in moderately/severely symptomatic participants when compared to participants with mild symptoms. This has also been observed in other recently published cross-sectional studies. ${ }^{15,}{ }^{16}$ Taking into consideration the profound increases of contractility observed in the animal studies, and compared to the observed improvement of voided volumes, we consider the improvement of maximum flow rate relatively small. On the other hand, the improvement is similar to the average increase in maximum flow rate after treatment with a blockers, ${ }^{17,18}$ and the gradual increase in maximum flow rate over the intervention period suggests that the maximum flow rate will continue to improve along with a longer intervention period.

Regarding the symptomatology in response to increased urine output the following should be taken into account. In this initial phase, we did not know whatsoever, whether the human bladder is able to adapt to an increased load. We therefore wanted to increase the urine output maximally so that the bladder was stressed to the maximum. However, some items of the IPSS (item 2, 4, and 7) seem highly dependent on urine output, without necessarily indicating bother. Future studies with a less extreme intervention, and a longer follow-up period should determine whether this intervention is clinically relevant, i.e. reduces symptoms in the long run. 
Several other aspects of feasibility should also be addressed more carefully in future research. Although no signs of renal or cardiac dysfunction were reported, blood pressure, blood sodium and creatin levels should be monitored in future studies.

\section{Conclusions}

The human bladder seems able to adapt to an increased load. Future randomised effectiveness studies with a longer follow-up period should determine the upper limit of objective bladder adaptation. In addition, future studies should address the long-term efficacy in the prevention of symptoms. 


\section{References:}

1. Wolfs GG, Knottnerus JA, Van der Horst FG, Visser AP and Janknegt RA: Determinants of doctor consultation for micturition problems in an elderly male population. Eur Urol. 33: 1-10, 1998.

2. Levin RM, Monson FC, Haugaard N, Buttyan R, Hudson A, Roelofs M, Sartore $S$ and Wein AJ: Genetic and cellular characteristics of bladder outlet obstruction. Urol Clin North Am. 22: 263-83, 1995.

3. Malmgren A, Uvelius B, Andersson KE and Andersson PO: On the reversibility of functional bladder changes induced by infravesical outflow obstruction in the rat. J Urol. 143: 1026-31, 1990.

4. Tammela TL, Longhurst PA, Wein AJ and Levin RM: The effect of furosemide-induced diuresis on rabbit micturition and bladder contractile function. J Urol. 150: 204-8, 1993.

5. Ohnishi N, Horan P, Levin SS and Levin RM: Sucrose diuresis protects rat bladder from outlet partial obstruction-induced contractile dysfunction. Urology. 54: 183-7, 1999.

6. Spigt $M G$, van Schayck $C$, van Kerrebroeck PE, van Mastrigt $R$ and Knottnerus JA: Pathophysiological aspects of bladder dysfunction: a new hypothesis for the prevention of 'prostatic' symptoms. Med Hypotheses. 62: 448-52, 2004.

7. Jorgensen JB, Jacobsen HL, Bagi P, Hvarnes $\mathrm{H}$ and Colstrup $\mathrm{H}$ : Home uroflowmetry by means of the $\mathrm{Da}$ Capo home uroflowmeter. Eur Urol. 33: 64-8, 1998.

8. Barry MJ, Fowler FJ, Jr., O'Leary MP, Bruskewitz RC, Holtgrewe HL, Mebust WK and Cockett AT: The American Urological Association symptom index for benign prostatic hyperplasia. The Measurement Committee of the American Urological Association. J Urol. 148: 1549-57, 1992.

9. Barry MJ, Fowler FJ, Jr., O'Leary MP, Bruskewitz RC, Holtgrewe HL and Mebust WK: Correlation of the American Urological Association symptom index with self-administered versions of the Madsen-Iversen, Boyarsky and Maine Medical Assessment 
Program symptom indexes. Measurement Committee of the American Urological Association. J Urol. 148: 1558-63, 1992.

10. Gisolf KW, van Venrooij GE, Eckhardt MD and Boon TA: Analysis and reliability of data from 24-hour frequency-volume charts in men with lower urinary tract symptoms due to benign prostatic hyperplasia. Eur Urol. 38: 45-52, 2000.

11. van Haarst EP, van Andel G, Heldeweg EA, Schlatmann TJ and van der Horst $\mathrm{HJ}$ : Evaluation of the diagnostic workup in young women referred for recurrent lower urinary tract infections. Urology. 57: 1068-72, 2001.

12. Hunt $J$ and Waller $G$ : The reliability of self-report of behaviours associated with recurrent urinary tract infection. Br J Urol. 74: 308-10, 1994.

13. Westerterp KR: Body composition, water turnover and energy turnover assessment with labelled water. Proc Nutr Soc. 58: 94551, 1999.

14. Blanker MH, Groeneveld FP, Bohnen AM, Bernsen RM, Prins A, Thomas S and Ruud Bosch JL: Voided volumes: normal values and relation to lower urinary tract symptoms in elderly men, a community-based study. Urology. 57: 1093-8 discussion 1098-9, 2001.

15. Venrooij van GE, Eckhardt MD, Gisolf $\mathrm{KW}$ and Boon TA: Data from frequency-volume charts versus symptom scores and quality of life score in men with lower urinary tract symptoms due to benign prostatic hyperplasia. Eur Urol. 39: 42-7, 2001.

16. Eckhardt MD, van Venrooij GE and Boon TA: Symptoms, prostate volume, and urodynamic findings in elderly male volunteers without and with LUTS and in patients with LUTS suggestive of benign prostatic hyperplasia. Urology. 58: 966-71, 2001.

17. Michel MC, Flannery MT and Narayan P: Worldwide experience with alfuzosin and tamsulosin. Urology. 58: 508-16, 2001.

18. Debruyne FM: Alpha blockers: are all created equal? Urology. 56: 20-2, 2000. 


\section{Chapter 4}

\section{A randomised trial on the effects of increased fluid intake/urine output on male lower urinary tract function}

Does the elderly male bladder function improve in response to an increased physiological load?
M.G. (Mark) Spigt ${ }^{1}$
Ph.E. (Philip) van Kerrebroeck ${ }^{3}$
C.P. (Onno) van Schayck ${ }^{1}$
J.J. (Johan) $\mathrm{Pel}^{4}$
P.G. (Paul) Knipschild ${ }^{1}$
K.R. (Klaas) Westerterp ${ }^{2}$
R. (Ron) van Mastrigt ${ }^{4}$
C. (Cees) van de Beek ${ }^{3}$
J.A. (André) Knottnerus ${ }^{1}$

\section{Affiliations:}

1. Maastricht University, Research institute Caphri, Department of General Practice

2. Maastricht University, Research institute Nutrim, Department of Human Biology

3. Maastricht University Hospital, Department of Urology

4. Erasmus Medical Centre, Department of Urology, Sector Furore

Submitted for publication 


\section{Abstract}

\section{Background}

The aim of our research was to find a preventive intervention for Lower Urinary Tract Symptoms (LUTS) in elderly men. We focussed on bladder performance since the bladder plays a crucial role in micturition. Several animal studies have shown that bladder performance can be improved by increasing the urine output. In humans this can be achieved by increasing the fluid intake, which could be an adequate preventive intervention.

\section{Methods}

In a randomised trial participants $(n=141,55-75$ years, moderate symptom severity) were assigned to either the advice to increase the daily fluid intake by 1.5 litres, or to placebo ( $8 \mathrm{ml}$ inactive syrup). After six months we measured several objective and subjective effect parameters. The actual change in water turnover was measured with deuterium.

\section{Results}

At six months, the effects on isovolumetric bladder pressure, bladder wall tension and average voided volume (24-h frequency volume chart) were statistically significant (respectively: $20 \mathrm{cmH}_{2} \mathrm{O} ; \mathrm{p}=0.007$, $\left.1.9 \mathrm{~N} / \mathrm{cm}^{2} ; \mathrm{p}=0.02,26 \mathrm{ml} ; \mathrm{p}=0.04\right)$. There were no statistically significant effects on maximum flow rate, bladder wall thickness, residual volume and maximum voided volume (respectively: $0.9 \mathrm{ml} / \mathrm{s}$; $\mathrm{p}=0.2,0.03 \mathrm{~mm} ; \mathrm{p}=0.6,-5 \mathrm{ml} ; \mathrm{p}=0.8,44 \mathrm{ml} ; \mathrm{p}=0.05$ ). Subjective effects parameters improved in both groups but there were no statistically significant differences between the two groups.

\section{Conclusions}

The elderly male bladder seems able to improve its functioning in response to increased urine output. However, it takes a lot of effort to increase the daily urine output in humans and the resultant positive effects are relatively small. It is therefore too early to advise elderly men to increase their daily fluid intake in order to prevent LUTS. 


\section{Introduction}

The aim of our research was to find a preventive intervention for Lower Urinary Tract Symptoms (LUTS) in elderly men. This disorder manifests itself as symptoms such as weak stream, incomplete emptying of the bladder, (urge) incontinence, and frequent voiding during the day and night. These so-called lower urinary tract symptoms (LUTS) are present in approximately $20-30 \%$ of the elderly men. ${ }^{1-3}$ A progressed state of the disorder often involves chronic and/or acute urinary retention, potentially leading to severe renal complications. ${ }^{4}$ Because of the high prevalence and the associated costs, prevention of these symptoms is of great importance from a health policy perspective. ${ }^{5,6}$ In our search for a preventive remedy we have focussed on bladder performance since the bladder plays a crucial role in micturition. If we would be able to improve the bladder function, we might be able to influence a crucial factor in the development of LUTS.

Several animal studies have shown that bladder performance can be improved by increasing the urine output. ${ }^{7,8}$ It is assumed that this is an adaptive response to an increased physiological load. This response is essentially different from the pathological adaptation observed in case of bladder outlet obstruction (BOO). ${ }^{9-13}$ In the latter there is a marked increase of bladder mass, and a decrease of both compliance (flexibility) and contractility. ${ }^{13}$ In case of diuresis, the animal bladder mass is also increased, but the compliance and contractility improve. ${ }^{7,8}$

The animal studies made us wonder whether it would also be possible to improve the functioning of the human urinary tract by increasing the urine output. ${ }^{14}$ In humans an increased urine output can be achieved by increasing the fluid intake. In a previously published patient series among symptomatic and asymptomatic elderly men, we observed a gradual and remarkable improvement of maximum urinary flow rate and maximum and average voided volumes after two months of increased fluid intake. ${ }^{15}$ These findings supported our hypothesis.

The next step was to study the long-term effects in a controlled setting. This paper reports on a randomised placebo controlled trial that 
we carried out to study the effects of increased fluid intake on elderly male lower urinary tract function and LUTS.

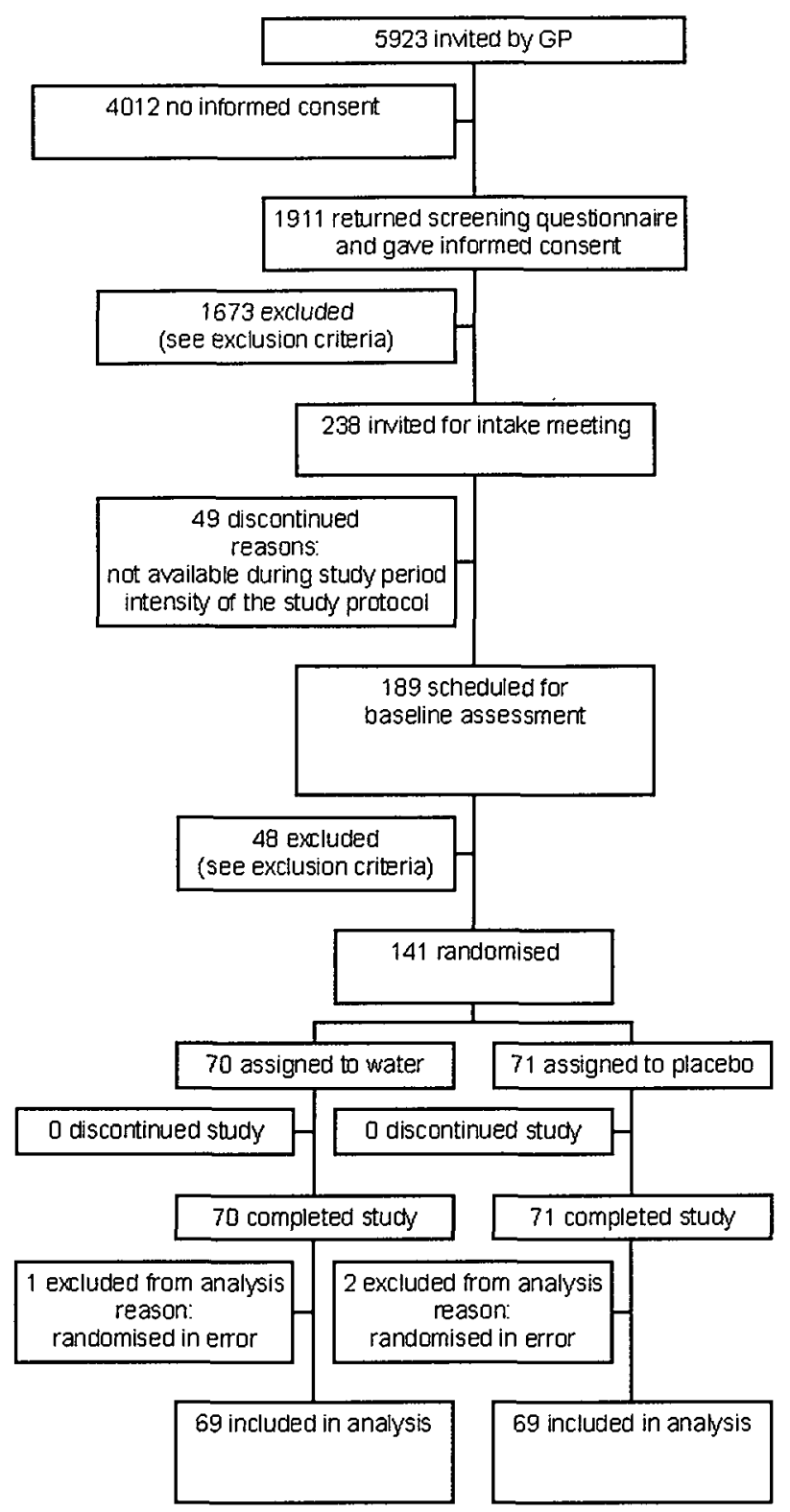

\section{Figure 1 Trial profile}




\section{Methods}

\section{Patients}

The study population was recruited via 21 general practices. Figure 1 shows the trial profile of this study. The GPs invited their total male population between 55 and 75 years of age to participate. A screening questionnaire, containing the International Prostate Symptom Score (IPSS; range 0-35), ${ }^{16,17}$ questions on co-morbidity, and a 24 -hours drink diary, together with the informed consent documents, were enclosed with the doctor's invitation. 1911 men gave informed consent and were screened for moderate LUTS (IPSS-score: 8-19). The main exclusion criteria were: the presence of mild (IPSS-score: 0-7) or severe (IPSSscore: 20-35) LUTS, and a self reported fluid intake above 2 litres per day. Other exclusion criteria were: the presence of diabetes; Parkinson's disease; renal diseases; past surgery of the lower urinary tract; a history of prostatic or bladder carcinoma; and the use of diuretics, medication for LUTS, or tricyclic antidepressive agents. We excluded 1673 men on the basis of these criteria. The remaining 238 men were invited for an intake visit and for a baseline assessment. At this point participants were excluded if no baseline assessment was possible (e.g., inability to urinate in the presence of the assessor), if prostate cancer was diagnosed (PSA > $4.0 \mu \mathrm{g} / \mathrm{l}$ followed by biopsy that confirmed the presence of a carcinoma), or if they had a serum sodium level below $130 \mathrm{mmol} / \mathrm{l}$. The final decision to enrol a person was made by the principal researcher (MS).

\section{Study protocol}

A person, who was otherwise not involved in the execution of the study, and had no access to the baseline data, generated the random allocation sequence with a computerised random-number generator, and randomly assigned the participants to two groups. People in the intervention group were advised to drink 1.5 litres of water per day, additionally to their normally consumed beverages, for a period of six months. They were advised to divide this amount into three portions of 0.5 litre spread over the day. To improve the adherence to the intervention they were supplied with 0.5 litre glasses. The control group received a placebo intervention in the form of syrup (one tablespoon 
(8ml) each day during dinner), also for a period of six months. A person who was not involved in the effect measurements told the participants which intervention they would receive, and kept contact with the participants during the study by telephone (at two, eight and twelve weeks) to maintain treatment adherence.

The participants were informed that we investigated whether it was possible to prevent urination disorders. We did not give any information on the specific goal of both interventions to accomplish blinding for the nature of the interventions and the hypothesis of this study. We mentioned that they would be allocated in a random fashion to one of the interventions, and that it was possible that they received an ineffective intervention for a period of 6 months. All participants were fully informed after study termination. The ethical review committee of the University Hospital Maastricht/ University of Maastricht approved the research protocol and the informed consent procedure.

\section{Parameters of effect}

A physiological adaptive response of the lower urinary tract should hypothetically result in increased bladder weight, contractility and compliance. Because of the preventive setting of this study and the corresponding non-clinical study population, we did not want to use invasive urodynamic tests. We derived the relevant parameters from noninvasive objective measurements and we used subjective measurements to assess the effects on symptoms. These parameters were recorded at baseline and at 6 months (immediately after termination of the intervention period).

\section{Measurement procedure of objective effect parameters}

The objective measurements were conducted at the Maastricht University Hospital, Department of Urology. Seven participants were scheduled for each session that lasted approximately 4-5 hours. They were requested to drink a lot of water during each session so that they would produce enough urine to void four times.

Maximum urinary flow rate $(\mathrm{Q} \max )$ was assessed two times by measuring the voided volume per unit of time $(\mathrm{ml} / \mathrm{s})$ with a Dantec flow meter. ${ }^{18-20}$ We calculated the mean of the measurements if both recorded 
voidings were valid (i.e. $>150 \mathrm{ml}$ ), otherwise only the valid measurement was included in the final analysis. Isovolumetric bladder pressure was assessed two times with the condom catheter method. ${ }^{21-25}$ With this procedure, the patient voids through a modified incontinence condom, which is connected, via a measurement unit, with three tubes. During voiding, the tubes are closed and the pressure inside the condom is measured. This pressure represents the isovolumetric bladder pressure. The maximum value attained in the two measurements was included in the analysis. Bladder wall thickness was assessed ultrasonically by measuring the thickness of the anterior bladder wall. ${ }^{26-30}$ The measurements were performed 2 times with a Hitachi EUB 6000 with a 3.5 $\mathrm{MHz}$ probe. The thickness of the anterior bladder wall was measured at three points. We calculated afterwards the mean of these three observations in each measurement and subsequently the mean of those two means.

In addition, we ultrasonically measured the filling volume of the bladder, prior to the measurement of isovolumetric bladder pressure, with the same ultrasound equipment. By combining the isovolumetric bladder pressure, the filling volume of the bladder, and the bladder wall thickness, the maximally generated bladder wall tension $/ \mathrm{cm}^{2}$ was calculated according to the method described by Bross et al. ${ }^{31}$ Residual volume was also assessed ultrasonically after each measurement of maximum urinary flow rate. A mean of the two measurements was calculated. In addition to these measurements performed in the hospital, we calculated the maximum and average voided volume per urination from a 24-hours frequency volume chart. ${ }^{32}$

\section{Measurements of subjective effect parameters}

Global perceived benefit of the intervention was measured with the question: "How did your urinary condition change since treatment initiation? (7-point scale: $0=$ much worse to $6=$ much better). The scores were recoded into a 3-point scale indicating worsening (score 0-2), no change (score 3 ) or improvement (score 4-6) of urinary tract function. To assess symptom severity we measured the International Prostate Symptom Score ${ }^{16,17}$ (IPSS; range: 0 -35) with Quality of Life question (IPSS-QoL; range: 0-6). 


\section{Assessments of co-variables/stratification}

We classified the subjects into obstructed and non-obstructed patients by combining the maximum flow rate with the isovolumetric bladder pressure with the following formula: Qmax < 4.5ml/s=obstructed; Qmax > 13.8ml/s=non-obstructed; Qmax between $4.5-13.8 \mathrm{ml} / \mathrm{s}$ : obstructed if measured bladder pressure $>36.4+$ $5.8^{*}$ Qmax. This method has been described by Pel et al. ${ }^{33}$ Obstruction was used as a stratification factor in the randomisation procedure. In addition, we measured prostate size with a $6.5 \mathrm{Mhz}$ rectal probe.

\section{Assessment of adherence}

Adherence to the experimental intervention was carefully monitored by using deuterium $\left({ }^{2} \mathrm{H}_{2} \mathrm{O}\right)$ labelled water. The deuterium method is considered to be the 'gold standard' for measuring water turnover in humans. ${ }^{34,35}$ After ingestion, deuterium mixes with the total body water and is eliminated depending on the rate of water turnover; the lower the deuterium concentration in urine over a certain period of time, the steeper the decrease in the deuterium concentration of the body water in time. Therefore, by plotting the deuterium concentration in urine against time, we were able to determine the total water turnover. The experimental as well as the control group followed the deuterium protocol 2 weeks prior to the baseline assessment in the hospital and in the final 2 weeks of the intervention period.

\section{Sample size}

With an assumed standard deviation (SD) of 5.2 (derived from: Ezz El Din et $a l .{ }^{36}$ ) we needed 68 patients per group to detect a clinically worthwhile effect of $2.5 \mathrm{ml} / \mathrm{s}$ on Qmax ( 0.9 power, $\mathrm{a}=0.05$, two-sided). With this sample size we were able to detect a difference of 1.5 points on the IPSS (assumed SD: $3.2^{36}$ ). To compensate for nonevaluable patients, we planned to enrol 80 patients per group. 141 participants were enrolled into the study (figure 1). Three subjects turned out later to be ineligible because they had a baseline IPSS-score above the maximum of 19 points (scores of 20,21 and 22 respectively). They were allocated in error and were therefore excluded from the final statistical analysis. 


\section{Statistical analysis}

For the estimation of the treatment effect, we performed multiple linear regression analyses (ANCOVA) in which the follow-up measurement was used as outcome variable, the intervention type as a predictive variable, and baseline score of that outcome variable, prostate size and age as covariates. ${ }^{37,38}$ The randomisation code was revealed to the researchers after the first main statistical analyses were performed. The analysis was by "intention to treat" and was performed in SPSS. As a per protocol analysis, the analysis was subsequently carried out without the subjects in the experimental intervention group who had not increased their water turnover above the median (intervention group) level. In addition, we studied the linear relationship between the effect measures and actual increase in water turnover (linear regression). We determined $95 \%$ confidence intervals (CI) and a two-tailed p-value smaller than 0.05 was considered statistically significant. 


\begin{tabular}{|c|c|c|}
\hline Control & Water & Effect of water* \\
\hline $\begin{array}{c}\text { Mean SD } \\
(n=69)\end{array}$ & $\begin{array}{c}\text { Mean SD } \\
(n=69)\end{array}$ & $(95 \% \mathrm{CI})$ \\
\hline
\end{tabular}

Objective effect parameters

Maximum urine flow rate $(\mathrm{ml} / \mathrm{s})$

Baseline

$17.5(6.8) \quad 15.8(5.6)$

Six months

$16.3(6.5) \quad 15.8(5.4) \quad 0.9(-0.4$ to 2.2$) \quad 0.2$

Isovolumetric bladder pressure $\left(\mathrm{cmH}_{2} \mathrm{O}\right)$

Baseline

$124(45) \quad 128(53)$

Six months

$110(40) \quad 131(58)$

20 (6 to 34$)$

Bladder wall thickness (mm)

Baseline

$1.9(0.3) \quad 1.9(0.3)$

Six months

$2.1(0.3)$

$2.1(0.3)$

$0.03(-0.1$ to 0.1$)$

0.6

Bladder wall tension $\left(\mathrm{N} / \mathrm{cm}^{2}\right)$

Baseline

$13.8(5.5) \quad 13.4(5.8)$

Six months

$11.5(4.7)$

$12.9(5.7) \quad 1.9(0.3$ to 3.5$)$

0.02

Postvoid residual volume $(\mathrm{ml})$

Baseline

168 (113) $134(107)$

Six months

$169(123) \quad 143(117)$

$-5(-39$ to 29$) \quad 0.8$

Maximum voided volume per urination $(\mathrm{ml})$

Baseline
Six months

$351(117) \quad 345(132)$

$337(135) \quad 381(138) \quad 44(-1$ to 90$) \quad 0.05$

Average voided volume per urination $(\mathrm{ml})$

Baseline

$218(78) \quad 205(75)$

Six months

$206(87) \quad 226(65)$

26 (1 to 51 )

0.04

Subjective effect parameters

Symptoms (IPSS) (0-35)**

Baseline

$13.4(3.1) \quad 12.2(3.3)$

Six months

$11.2(4.3) \quad 11.1(4.2)$

$0.5(-0.9$ to 2.0$)$

0.5

Quality of Life (IPSS-QoL) (0-6)**

Baseline
Six months

$2.9(1.0) \quad 2.6(1.0)$

$2.5(1.2) \quad 2.3(0.9)$

$0.1(-0.2$ to 0.4$) \quad 0.6$

* Note: The estimated effect (effect size) was determined with regression analysis, in which we adjusted for differences in baseline score, prostate size and age.

** Note: Bold score is most favourable score. 


\section{Results}

\section{Objective effect changes}

The effects of the experimental intervention on the bladder are shown in table 1. At six months, it showed that there was no statistically significant effect of increased water intake on maximum flow rate when compared to placebo. There was a statistically significant effect on bladder pressure and bladder wall tension. There was no statistically significant effect on bladder wall thickness and postvoid residual volume. The experimental group had higher maximum as well as average voided volumes per urination at six months; the effect on average voided volume was statistically significant.

\section{Subjective changes}

At six months, 7 men (10\%) in the experimental group reported a worsening and 42 men $(61 \%)$ reported an improvement of their urinary function, against $5(7 \%)$ and $34(49 \%)$ in the control group (chi-square: p-value: 0.2 ; data not shown in table). As regards symptoms, both groups had a lower IPSS-score and IPSS-QoL-score at six months, but there was no statistically significant effect when the intervention was compared to the placebo.

\section{Treatment adherence}

The 24-hour water turnover in the experimental group increased by $1030 \pm$ sd: $586 \mathrm{ml}$ from $3034 \pm 631 \mathrm{ml}$ at baseline (data not shown). The water turnover in the control group was $2950 \pm 498 \mathrm{ml}$ at baseline and was $672 \pm 443 \mathrm{ml}$ higher at six months. The effect of the experimental intervention compared to the placebo was calculated at $359 \mathrm{ml}(95 \% \mathrm{CI}$ : 171 to 548$)$.

\section{Per protocol analysis}

Excluding the participants from the experimental group that scored below the median score of $955 \mathrm{ml}$, did not increase the effects (effect of water: Qmax: $0.7 \pm \mathrm{se}: 0.9 \mathrm{ml} / \mathrm{s}$; bladder pressure: $15 \pm 9 \mathrm{cmH}_{2} \mathrm{O}$; IPSS: $0.8 \pm 0.9$ ). In addition it showed that changes in maximum urinary flow 
rate, isovolumetric bladder pressure and IPSS-score could not be predicted by changes in water turnover (coefficients for 1 litre increase in water turnover: qmax: $1.0 \pm \mathrm{se}: 0.7 \mathrm{ml} / \mathrm{s}$, bladder pressure: $-1.4 \pm 7.6$ $\mathrm{cmH}_{2} \mathrm{O}$, IPSS-score: $-0.09 \pm 0.7$ ).

\section{Analysis of effect modification by age and obstruction}

The interaction terms for obstruction and age added to the regression analysis, were not statistically significant for all outcome measures, indicating that the effect of the experimental intervention was not statistically different for obstructed vs. non-obstructed participants, and for the older versus the younger participants (data not shown). In addition, no clinically relevant differences between the age and obstruction subgroups were observed in the stratified analyses for the effects on maximum urinary flow rate, bladder pressure and IPSS-score (data not shown). 


\section{Discussion}

The results of animal studies formed the basis of our hypothesis and there were no reasons to assume that a similar effect would not be possible in humans. In addition to these animal studies, the results of an uncontrolled study among 44 elderly men showed remarkably positive effects and therefore seemed to confirm our ideas. In this trial, six months after we gave the advice to increase the daily fluid intake by 1.5 litres, we found some statistically significant but modest effects on the bladder function. There were no important effects on subjective effect parameters.

The two questions to be answered now are: 1 . Does the elderly male bladder function improve in response to increased urine output? 2. Should we advise elderly men to increase their fluid intake?

In order to answer the first question, the achieved contrast in urine output must be taken into account. In the animal studies, using diuretics, a 200-300\% increase in urine output was achieved. In our study we accomplished a contrast of approximately $10 \%$ at the end of the study. This contrast might have been somewhat larger if the Dutch summer of 2003 had not been the second warmest summer in the last 100 years. The mean ambient temperature during the follow up measurements was $21^{\circ} \mathrm{C}$ (range 17 to $25{ }^{\circ} \mathrm{C}$ ), while $18{ }^{\circ} \mathrm{C}$ is normal for that period. The hot summer increased the water turnover in the control group, which may have reduced the contrast with regard to urine output. Considering the physiological nature of the intervention, the large effects in the pilot study and the observed effects in the trial, despite relatively poor contrast, we are inclined to consider that, just as the animal bladder, the human bladder is able to adapt favourably to an increased physiological load. Only the amount of extra water intake/urine output must probably be very large to have animal-like effects.

But should we advise elderly men to increase their daily fluid intake? Achieving a large increase in urine output for a longer period of time takes quite some effort. Against this effort the potential benefits seem rather small. On the other hand, drinking water had no negative effects on lower urinary tract functioning, and the small increase in 
bladder pressure might just be enough to prevent, for example, a potential case of acute urinary retention. Hence, it can be argued that there might be some advantages without disadvantages. Still, we have a preference of finding the effects not really worth the effort.

Future studies on the adaptive capability of the bladder must put much effort in achieving a more profound increase in urine output. An additional approach that may be considered, is to improve the bladder blood flow. The reduced vascularisation and innervation of the elderly bladder $^{12,39-41}$ probably impairs the adaptive capacity. There is some evidence that suggests that alpha-blockers ${ }^{42}$ and aspirin ${ }^{43}$ improve the bladder blood flow. These agents might therefore be used in combination with increased urine output.

\section{Conclusion}

The elderly male bladder seems able to improve its functioning in response to increased physiological loading. However, the positive effects are relatively small considering the effort it takes to increase the daily urine output. It is therefore too early to advise elderly men to increase their daily fluid intake in order to prevent LUTS. 


\section{References:}

1. Bosch JL, Hop WC, Kirkels WJ and Schröder FH: The International Prostate Symptom Score in a community-based sample of men between 55 and 74 years of age: prevalence and correlation of symptoms with age, prostate volume, flow rate and residual urine volume. Br J Urol. 75: 622-30, 1995.

2. Berges RR, Pientka L, Hofner K, Senge T and Jonas U: Male lower urinary tract symptoms and related health care seeking in Germany. Eur Urol. 39: 682-7, 2001.

3. Wolfs GG, Knottnerus JA, Van der Horst FG, Visser AP and Janknegt RA: Determinants of doctor consultation for micturition problems in an elderly male population. Eur Urol. 33: 1-10, 1998.

4. Sutaria PM and Staskin DR: Hydronephrosis and renal deterioration in the elderly due to abnormalities of the lower urinary tract and ureterovesical junction. Int Urol Nephrol. 32: 119-26, 2000.

5. Kortt MA and Bootman JL: The economics of benign prostatic hyperplasia treatment: a literature review. Clin Ther. 18: 1227-41, 1996.

6. Roehrborn CG: Acute relief or future prevention: is Urology ready for preventive health care? Urology. 56: 12-9, 2000.

7. Tammela TL, Longhurst PA, Wein AJ and Levin RM: The effect of furosemide-induced diuresis on rabbit micturition and bladder contractile function. J Urol. 150: 204-8, 1993.

8. Ohnishi N, Horan P, Levin SS and Levin RM: Sucrose diuresis protects rat bladder from outlet partial obstruction-induced contractile dysfunction. Urology. 54: 183-7, 1999.

9. Buttyan R, Chen MW and Levin RM: Animal models of bladder outlet obstruction and molecular insights into the basis for the development of bladder dysfunction. Eur Urol. 32 Suppl 1: 32-9, 1997.

10. Levin RM, Levin SS, Zhao Y and Buttyan R: Cellular and molecular aspects of bladder hypertrophy. Eur Urol. 32 Suppl 1: 15-21, 1997. 
11. Mauroy B: Bladder consequences of prostatic obstruction. Eur Urol. 32 Suppl 1: 3-8, 1997.

12. Gosling JA: Modification of bladder structure in response to outflow obstruction and ageing. Eur Urol. 32 Suppl 1: 9-14, 1997.

13. Levin RM, Monson FC, Haugaard N, Buttyan R, Hudson A, Roelofs M, Sartore S and Wein AJ: Genetic and cellular characteristics of bladder outlet obstruction. Urol Clin North Am. 22: 263-83, 1995.

14. Spigt MG, van Schayck CP, van Kerrebroeck PE, van Mastrigt $R$ and Knottnerus JA: Pathophysiological aspects of bladder dysfunction: a new hypothesis for the prevention of 'prostatic' symptoms. Med Hypotheses. 62: 448-52, 2004.

15. Spigt MG, Knottnerus JA, Beek Cvd, Kerrebroeck van PE, Amelsvoort LGM and Schayck van CP: The short-term effects of increased urine output on male bladder function and lower urinary tract symptoms. Urology. 64: 499-503, 2004.

16. Barry MJ, Fowler FJ, Jr., O'Leary MP, Bruskewitz RC, Holtgrewe HL, Mebust WK and Cockett AT: The American Urological Association symptom index for benign prostatic hyperplasia. The Measurement Committee of the American Urological Association. J Urol. 148: 1549-57, 1992.

17. Barry MJ, Fowler FJ, Jr., O'Leary MP, Bruskewitz RC, Holtgrewe $\mathrm{HL}$ and Mebust WK: Correlation of the American Urological Association symptom index with self-administered versions of the Madsen-Iversen, Boyarsky and Maine Medical Assessment Program symptom indexes. Measurement Committee of the American Urological Association. J Urol. 148: 1558-63, 1992.

18. Beek van de C, Stoevelaar HJ, McDonnell J, Nijs HG, Casparie AF and Janknegt RA: Interpretation of uroflowmetry curves by urologists. J Urol. 157: 164-8, 1997.

19. Ather $\mathrm{MH}$ and Memon A: Uroflowmetry and evaluation of voiding disorders. Tech Urol. 4: 111-7, 1998.

20. Jensen KM: Uroflowmetry in elderly men. World J Urol. 13: 213, 1995.

21. Mastrigt van $\mathrm{R}$ and Pel JJ: Towards a noninvasive urodynamic diagnosis of infravesical obstruction. BJU Int. 84: 195-203, 1999. 
22. Rikken B, Pel JJ and van Mastrigt R: Repeat noninvasive bladder pressure measurements with an external catheter. J Urol. 162: 4749, 1999.

23. Pel JJ and van Mastrigt R: Non-invasive measurement of bladder pressure using an external catheter. Neurourol Urodyn. 18: 45569, 1999.

24. Pel JJ and van Mastrigt $\mathrm{R}$ : The variable outflow resistance catheter: a new method to measure bladder pressure noninvasively. J Urol. 165: 647-52, 2001.

25. Huang Foen Chung JW, Bohnen AM, Pel JJ, Bosch JL, Niesing R and van Mastrigt R: Applicability and reproducibility of condom catheter method for measuring isovolumetric bladder pressure. Urology. 63: 56-60, 2004.

26. Manieri C, Carter SS, Romano G, Trucchi A, Valenti M and Tubaro A: The diagnosis of bladder outlet obstruction in men by ultrasound measurement of bladder wall thickness. J Urol. 159: 761-5, 1998.

27. Kojima $M$, Inui E, Ochiai A, Naya $Y$, Ukimura $O$ and Watanabe $H$ : Noninvasive quantitative estimation of infravesical obstruction using ultrasonic measurement of bladder weight. J Urol. 157: 4769, 1997.

28. Kojima M, Inui E, Ochiai A, Naya Y, Kamoi K, Ukimura O and Watanabe H: Reversible change of bladder hypertrophy due to benign prostatic hyperplasia after surgical relief of obstruction. J Urol. 158: 89-93, 1997.

29. Kojima M, Inui E, Ochiai A, Naya Y, Ukimura O and Watanabe H: Ultrasonic estimation of bladder weight as a measure of bladder hypertrophy in men with infravesical obstruction: a preliminary report. Urology. 47: 942-7, 1996.

30. Ochiai A and Kojima M: Correlation of ultrasound-estimated bladder weight with ultrasound appearance of the prostate and postvoid residual urine in men with lower urinary tract symptoms. Urology. 51: 722-9, 1998.

31. Bross S, Schumacher S, Scheepe JR, Braun PM, Alken P and Juenemann KP: Combined evaluation of detrusor pressure and bladder wall thickness as a parameter for the assessment of 
detrusor function: an experimental in vivo study. J Urol. 166: 1130-5, 2001.

32. Gisolf KW, van Venrooij GE, Eckhardt MD and Boon TA: Analysis and reliability of data from 24-hour frequency-volume charts in men with lower urinary tract symptoms due to benign prostatic hyperplasia. Eur Urol. 38: 45-52, 2000.

33. Pel JJ, Bosch JL, Blom JH, Lycklama a Nijeholt AA and van Mastrigt R: Development of a non-invasive strategy to classify bladder outlet obstruction in male patients with LUTS. Neurourol Urodyn. 21: 117-25, 2002.

34. Westerterp KR, Wouters $L$ and van Marken Lichtenbelt WD: The Maastricht protocol for the measurement of body composition and energy expenditure with labeled water. Obes Res. 3 Suppl 1: 49$57,1995$.

35. Westerterp KR: Body composition, water turnover and energy turnover assessment with labelled water. Proc Nutr Soc. 58: 945$51,1999$.

36. el Din KE, Kiemeney LA, de Wildt MJ, Debruyne FM and de la Rosette JJ: Correlation between uroflowmetry, prostate volume, postvoid residue, and lower urinary tract symptoms as measured by the International Prostate Symptom Score. Urology. 48: 393-7, 1996.

37. Vickers AJ and Altman DG: Statistics notes: Analysing controlled trials with baseline and follow up measurements. BMJ. 323: 11234, 2001.

38. Twisk $\mathrm{J}$ and Proper K: Evaluation of the results of a randomized controlled trial: how to define changes between baseline and follow-up. J Clin Epidemiol. 57: 223-8, 2004.

39. Elbadawi A: Voiding dysfunction in benign prostatic hyperplasia: trends, controversies and recent revelations. II. Pathology and pathophysiology. Urology. 51: 73-82, 1998.

40. Saito M, Ohmura $M$ and Kondo A: Effect of ageing on blood flow to the bladder and bladder function. Urol Int. 62: 93-8, 1999.

41. Tarcan T, Azadzoi KM, Siroky MB, Goldstein I and Krane RJ: Age-related erectile and voiding dysfunction: the role of arterial insufficiency. Br J Urol. 82 Suppl 1: 26-33, 1998. 
42. Das AK, Leggett RE, Whitbeck C, Eagen G and Levin RM: Effect of doxazosin on rat urinary bladder function after partial outlet obstruction. Neurourol Urodyn. 21: 160-6, 2002.

43. Schröder A, Levin RM, Kogan BA and Longhurst PA: Aspirin treatment improves bladder function after outlet obstruction in rabbits. Urology. 58: 608-13, 2001. 



\section{Chapter 5}

\section{The validity and ethics of giving placebo in a randomised non-pharmacological trial}

M.G. (Mark) Spigt,

P.G. (Paul) Knipschild,

C.P. (Onno) van Schayck,

J.A. (André) Knottnerus,

Affiliation:

University of Maastricht, Research institute Caphri, Department of General Practice

Accepted for publication in: Journal Of Clinical Epidemiology 


\section{Abstract}

\section{Background}

When we study the effects of a non-pharmacological intervention, the choice of a control group is often difficult. In a study on the effectiveness of increased water intake on voiding dysfunction in elderly men we used an unusual design. This paper addresses the internal validity and ethics of this design.

\section{Methods}

The randomised trial we evaluated had a six months follow-up period and was carried out among 141 elderly men with moderate lower urinary tract symptoms. The experimental group was given the instruction to drink more water, the control group received placebo-medication. The participants were not informed that there was a 50\% change of receiving placebo. We measured whether the prior expectations and preferences were comparable for the two study groups, whether blinding was preserved throughout the study period, and whether the participants considered this design ethical.

\section{Results}

Prior to randomisation, patients had higher expectations for the experimental intervention, but there was no statistically significant difference in their preference. During the study period two out of 71 patients in the control group unmasked the placebo. In general, both groups fully agreed with the informed consent procedure.

\section{Conclusions}

This design can be considered when the effects of a nonpharmacological intervention are studied. 


\section{Introduction}

In 2001 we started a study on the effectiveness of increased water intake on bladder function and lower urinary tract symptoms in elderly men. We wanted to study if it was possible to train the human elderly bladder by increasing the urine output. We hypothesised that by training the bladder, frequently reported urinary symptoms such as weak stream and incomplete emptying might be prevented. ${ }^{\prime}$ In that study we used an unusual design. In a randomised trial we gave the experimental group the instruction to drink more water, while the control group was given a placebo (one spoon of (inactive) syrup per day during dinner). The participants were not informed that there was a $50 \%$ chance of getting a placebo. In this paper we do not report on the effectiveness of drinking water on bladder function, but we describe the methodological considerations that made us use this design, and we subsequently describe the evaluation of this design as regards internal validity and ethics.

\section{Background}

A placebo control group is often the best option and is still the standard, although it is increasingly considered unethical to use placebos when alternative effective interventions are available. ${ }^{2,3}$ In pharmacological trials the fabrication of a placebo drug is relatively easy. However, in many other cases such as psychotherapy and physical therapy, the experimental therapy is less easily transformed into a placebo or sham treatment. ${ }^{4-9}$ The substitute design that is often used is a design in which the control group receives no intervention or usual care. Occasionally, some ingenious control intervention is used such as sham traction ${ }^{10}$. or sham spinal manipulation ${ }^{11}$ for low back pain, placebo acupuncture, ${ }^{12}$ or placebo Transcutaneous Electical Nerve Stimulation (TENS). ${ }^{9}$

Finding a proper control group is particularly difficult when one wants to study the effects of a lifestyle advice. ${ }^{5}$ Giving advice is an. important aspect of medical care and it may have placebo effects that the researcher may want to control for. However, an advice is impossible to copy into a placebo, and unless the lifestyle advice is changed into a complex intervention such as a complex exercise program, living by such 
an advice is possible for everyone. A potential control group, hearing of a promising new advice, could easily implement the experimental advice into daily life resulting in contamination bias.

\section{Evaluation of different designs}

The idea to use a placebo in the control group occurred to us after we explored several conventional designs. Table 1 shows the different designs that we initially considered for our water study. For each design we considered the pros and cons as regards internal validity. Although this table may also be applicable to other studies and gives insight into the strengths and weaknesses of different designs, one must realise that the scoring is arbitrary and that practical aspects often determine the final decision. From our analysis we concluded that a no-treatment control group with a conventional randomisation procedure, appeared to be the least desirable design in that, for example, only the experimental group would feel treated, and the disappointed control group might want to seek treatment outside the study. As is shown in table 1, finding a comparably attractive alternative intervention and using prerandomisation would be a much more promising approach. ${ }^{13,14}$ In our case however, there was no standard urologic preventive lifestyle advice that we could use as an alternative intervention. The next option we considered was to use a sham advice. For our study, we considered to advice wearing thermal undersocks or to advice the avoidance of eating some specific products (e.g. organ meat, or shell-fish). However, we could not be really sure that such an advice would be inactive. What's more, the advice to wear thermal undersocks might seem a bit ridiculous in summertime. Using a 'real' placebo such as a tablet without active elements was not considered from the beginning and is therefore not presented in table 1. We figured that participants who are informed that there is a placebo involved, would probably reason that, since a tablet can easily be turned into a placebo, the advice would be the real intervention. So it appeared that we were stuck on the no-treatment possibility.

However, since the critical aspect of not being able to use a placebo was in the information given to the patient, we wondered whether it would be possible to partially inform the participants. Randomised trials in which the participants are not informed on the specific goal of the 


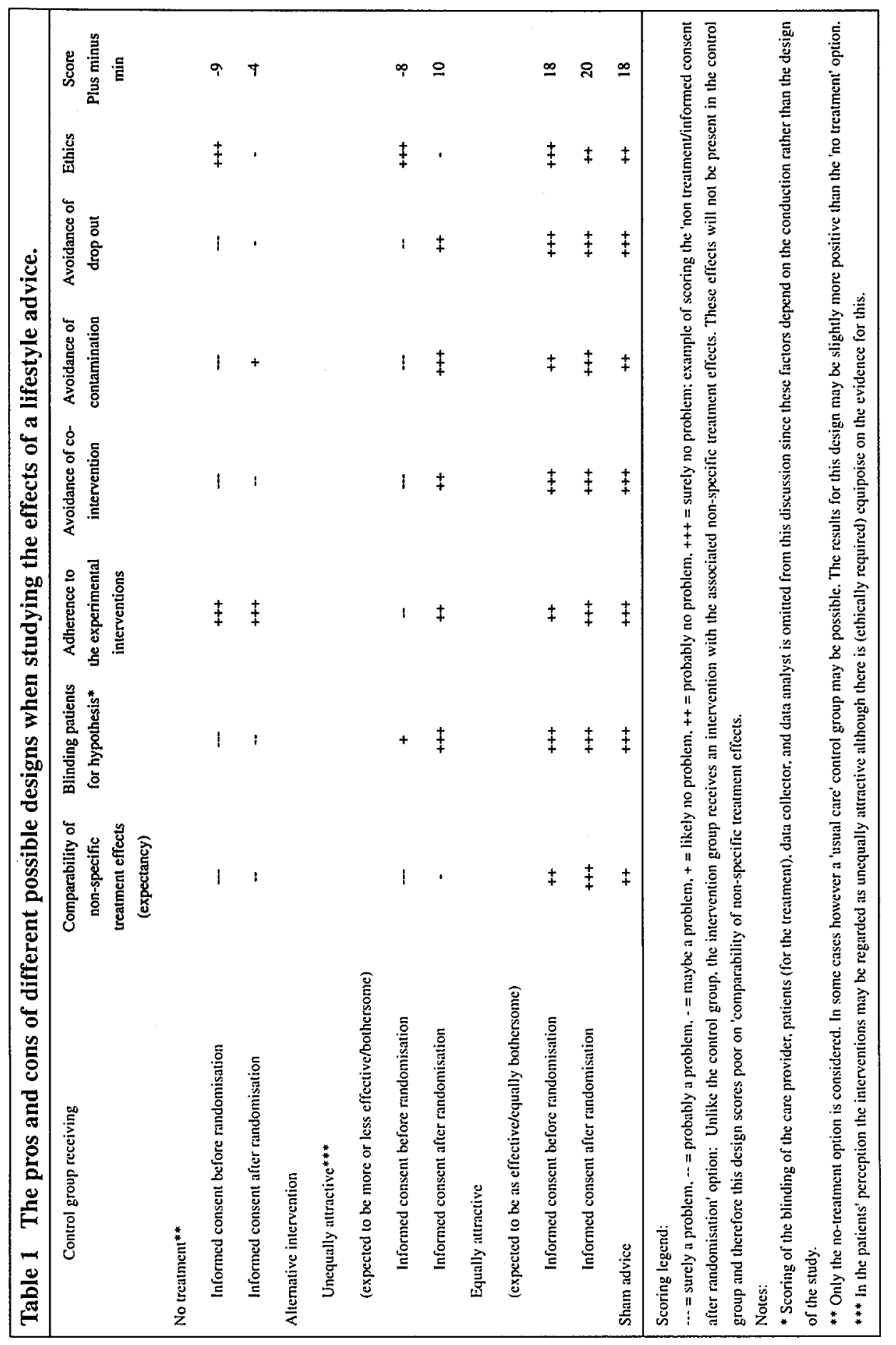


study beforehand, have been performed in the past. Several examples of such studies are presented in a review by Di Blasi et al. ${ }^{15}$ Di Blasi reviewed several trials on the manipulation of "context effects" such as giving positive ("you will be better soon") versus negative ("I do not know what is the matter with you") diagnoses to patients presenting with similar symptoms. In such cases it is impossible to fully inform the participants on the actual aim of the study, and the interventions to be studied.

If we would withhold the information on the rationale behind the interventions, we figured that it might be possible to give the control group a 'real' placebo. Without knowing that there would be a placebo involved, the participants could probably be blinded for our ideas. It would thus be possible to investigate the effects of increased water intake and meet most aspects of internal validity.

\section{Brief description of the study}

Before we continue with the evaluation of this design we will first describe the study in which we evaluated the design briefly. Figure 1 shows the study profile of the study on the effects of increased water intake on bladder function and urinary symptoms. The study population was recruited via 21 general practices. The general practitioners of these practices invited their male population between 55 and 75 years of age to participate in the study. A screening questionnaire and the informed consent documents were enclosed with the doctor's invitation. Using the screening questionnaire and a baseline assessment we excluded 1721 men on the basis of symptom severity and relevant co-morbidity (e.g., renal pathology, prostatic carcinoma) and 49 participants withdrew after a first intake meeting. A total of 141 participants were enrolled into the study.

Subjects in the intervention group were advised to additionally drink 1.5 litres of water per day for a period of six months. They were advised to divide this amount in three portions of 0.5 litre spread over the day. To improve the adherence to the intervention they obtained a 0.5 litre glass. The control group received a placebo intervention in the form of syrup (one spoon each day during dinner), also for a period of six months. We chose to use inactive syrup because of the preventive setting 


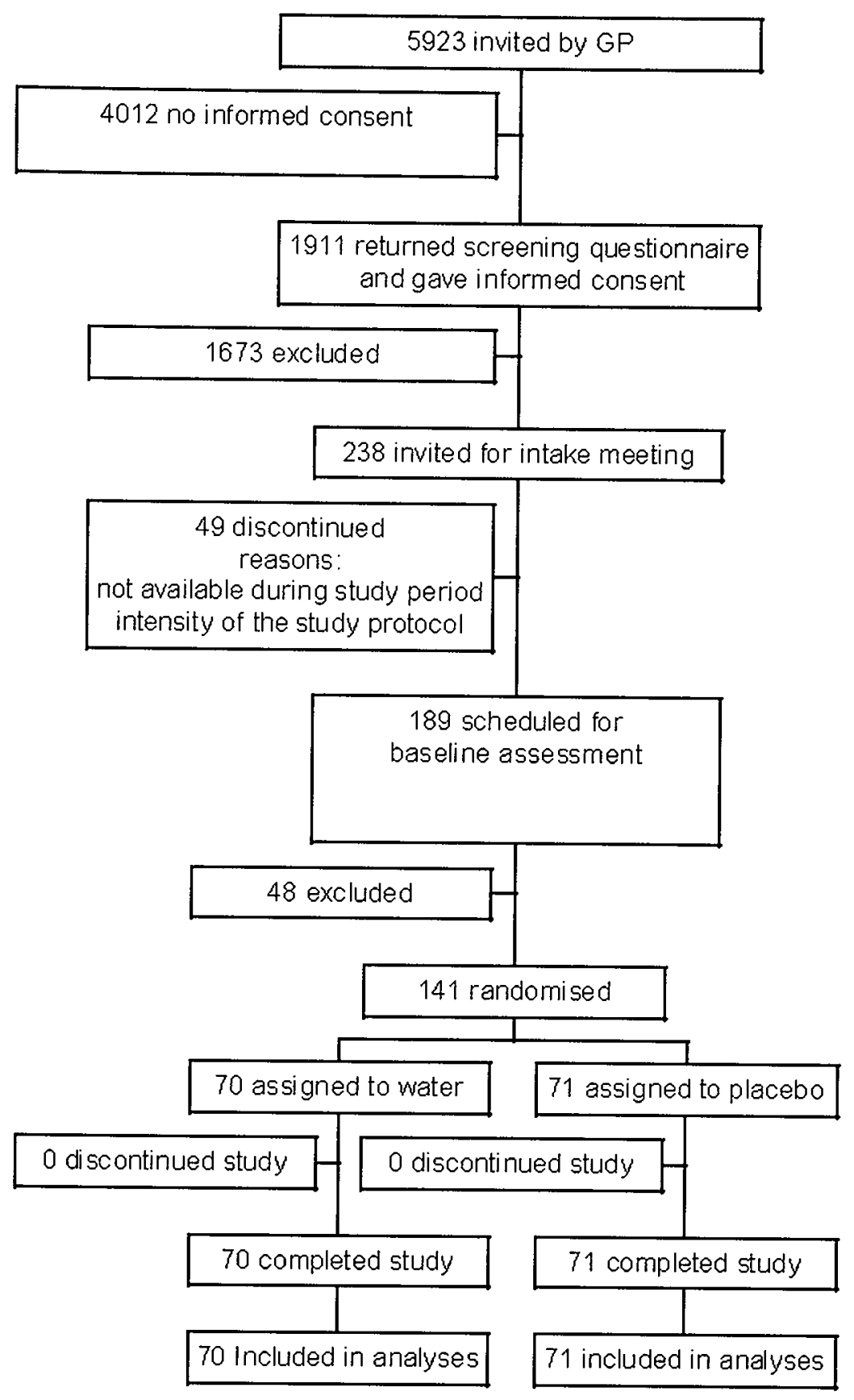

\section{Figure 1 Trial profile}


of the study; we did not want to give non-patients a strong suggestion of medication. A person, who was otherwise not involved in the execution of the study, and had no access to the baseline data, generated the random allocation sequence, and randomly assigned the participants to the two groups. A person, who was not involved in the effect measurements, told the participants which intervention they would receive, and kept contact with the participants during the study by telephone (at two, eight and twelve weeks) to maintain treatment adherence. The primary outcome parameters were bladder function and symptom severity measured at six months. 


\section{Evaluation of internal validity}

We evaluated several aspects of internal validity. Each section of this evaluation starts with a short discussion or review of the literature, in which we explain why the particular aspect was assessed.

\section{Comparability of non-specific treatment effects}

Several non-specific effects such as natural course of the disease and regression to the mean constitute a large proportion of the perceived treatment effect. ${ }^{16,17}$ The psychological component of an intervention is specific to the intervention and may therefore vary among different interventions. ${ }^{18-21}$ A treatment that is new, convincing, and is presented with enthusiasm is likely to result in higher expectations from the patient, which in turn could lead to a more positive treatment outcome, especially when this outcome is sensitive to psychological factors. ${ }^{21-23}$ In regular placebo controlled studies this expectation component is equal for the experimental and the placebo group, because the two interventions can not be distinguished. In our study however, the appearance of both interventions was essentially different. We therefore evaluated whether there were significant differences in expectancy between water and syrup.

Table 2 shows the differences in expected effect. We assessed this by asking the participants to rate their expected effect for both interventions on an 11 point-scale ranging from 0 to $10(0=$ no improvement, $10=$ much improvement). Participants could also indicate that they had no idea what to expect.

Because, prior to randomisation, the majority of participants had no idea what to expect of the interventions, the non-specific treatment effects seemed comparable for the most part. Those who were assigned to the control group however, reported more often to have no idea and they expected much improvement less often. This suggests that the syrup was expected less effective than increased water intake.

Another way to get an impression of the psychological strength of the intervention is to register the patient's preference. On the basis of the reported expectancy we figured that the participants would prefer water more often than syrup. However, it showed that the participants who had 
a preference (again a minority) did not seem to prefer water above the syrup (table 2).

Table 2 Comparability of expectancy and preference.

\begin{tabular}{|c|c|c|c|}
\hline & $\begin{array}{l}\text { Intervention } \\
\text { (Water) }\end{array}$ & $\begin{array}{l}\text { Control } \\
\text { (Syrup) }\end{array}$ & $\mathrm{p}$-value** \\
\hline \multicolumn{4}{|c|}{ Expected effect prior to randomisation* } \\
\hline No idea & $36(51 \%)$ & $48(68 \%)$ & \\
\hline No/little improvement & $15(21 \%)$ & $17(24 \%)$ & \\
\hline Much improvement & $19(27 \%)$ & $6(9 \%)$ & 0.03 \\
\hline \multicolumn{4}{|c|}{ Preferred intervention prior to randomisation } \\
\hline Water & $13(19 \%)$ & $8(11 \%)$ & \\
\hline Syrup (control) & $13(19 \%)$ & $16(23 \%)$ & \\
\hline No preference & $44(63 \%)$ & $47(66 \%)$ & 0.45 \\
\hline
\end{tabular}

\section{Blinding patients for our hypothesis}

With this design the chance of unmasking the placebo intervention and the actual hypothesis of the study is considerable. Through the media, colleagues, experience of participants from previous studies, or through a slip of the tongue of the research team, participants may find out whether they actually receive an inactive intervention, and as a consequence blinding may be lost.

Since we did not want to introduce the suggestion that a placebo was involved in this study, we could not ask the participants directly whether they thought that their intervention was a placebo. Instead, we recorded their perceived benefit of the intervention at 3 and 6 months, with the request to give a reason for (non)benefit. This request for a reason also accompanied the expectancy question prior to randomisation. 


\section{Table 3 Comparability of the perceived effects of the interventions at 3 and 6 months.}

\begin{tabular}{|c|c|c|c|c|}
\hline & & $\begin{array}{l}\text { Intervention } \\
\text { (Water) }\end{array}$ & $\begin{array}{l}\text { Control } \\
\text { Syrup) }\end{array}$ & p-value* \\
\hline \multicolumn{2}{|c|}{ Perceived benefit of the intervention $(0-10)$} & Mean (sd) & Mean (sd) & \\
\hline \multicolumn{2}{|c|}{3 months } & $3.73(2.9)$ & $2.84(2.8)$ & 0.07 \\
\hline \multicolumn{2}{|c|}{6 months } & $4.17(3.0)$ & $3.35(3.4)$ & 0.11 \\
\hline \multicolumn{5}{|c|}{ The effect of my intervention is: } \\
\hline \multirow[t]{4}{*}{3 months } & No idea & $58(84 \%)$ & $63(90 \%)$ & \\
\hline & Worse & $0(0 \%)$ & $0(0 \%)$ & \\
\hline & Not different & $6(9 \%)$ & $3(4 \%)$ & \\
\hline & Better & $6(9 \%)$ & $4(6 \%)$ & 0.45 \\
\hline \multicolumn{5}{|c|}{ The effect of my intervention is: } \\
\hline \multirow[t]{4}{*}{6 months } & No idea & $62(89 \%)$ & $53(75 \%)$ & \\
\hline & Worse & $1(1 \%)$ & $5(7 \%)$ & \\
\hline & Not different & $2(3 \%)$ & $5(7 \%)$ & \\
\hline & Better & $5(7 \%)$ & $8(11 \%)$ & 0.15 \\
\hline
\end{tabular}

* We used t-tests (perceived benefit) and chi-square (effect my intervention) statistical tests.

In this way, the participants could mention the possibility of a placebo while we did not mention it.

It showed that, prior to randomisation, neither the syrup nor the water group reported 'placebo' as a reason for expected non-benefit (data not shown in table). At three and six months, the intervention group seemed slightly more enthusiastic about their intervention (table 3). However, this may have been a reflection of real treatment effects (although not statistically significant) since (at six months) only two out of 70 men in the syrup group thought that they had received a placebo. Accordingly, they reported no improvement on perceived benefit, and thought that their intervention was worse than the other (table 3). In addition to these two, three other men in the control group felt that their intervention was worse than the other, against one man in the intervention group. 


\section{Treatment adherence and avoidance of contamination}

As the control group knew that drinking additional water was one of the interventions they could decide to drink more water. Besides, the experimental group could not be told why they should drink such an amount of water. This might reduce the willingness to adhere to the intervention and reduce the contrast between the two groups. Adherence to the experimental intervention was carefully monitored by using deuterium $\left({ }^{2} \mathrm{H}_{2} \mathrm{O}\right)$ labelled water. The deuterium method is regarded to be the 'gold standard' for measuring water turnover in humans. ${ }^{24,25}$ The experimental as well as the control group followed the deuterium protocol two weeks prior to the baseline assessment in the hospital, and the final two weeks of the intervention period.

At six months follow-up, the 24-hour water turnover in the water group had increased by $1030( \pm 586) \mathrm{ml}$ from $3034( \pm 631) \mathrm{ml}$ at baseline. The water turnover in the control group was $673( \pm 443) \mathrm{ml}$ higher than the $2950( \pm 498) \mathrm{ml}$ at baseline (data not shown in table). The difference between the two groups, calculated with linear regression analysis in which we adjusted for differences in age and baseline scores, was 359 (95\% CI: 171 to 548 ) $\mathrm{ml}$.

Considering the fact that only the water group was advised to increase their water intake (by 1.5 litres), this was considered a relatively small contrast. However, we assume that the extremely high ambient temperatures of the Dutch summer of 2003 may have disturbed our evaluation of adherence and contamination to some extent. It was the second warmest summer in the last 100 years, and the mean ambient temperature during the final measurements was $20.8^{\circ} \mathrm{C}$ while $17.6^{\circ} \mathrm{C}$ is normal for that period. There was a significant relationship between the temperature and the water turnover in the control group (pearson correlation: $0.4 ; \mathrm{p}=<0.001$ ), which suggests that temperature was an important determinant of the increase in water turnover in the control group. In addition, the high temperatures probably also attenuated the contrast between the groups (at lower temperatures the contrast between the groups was larger). Nevertheless, if we look at the water group, the increase should have been larger than $1030 \mathrm{ml}$.

So if we go back to our evaluation of internal validity, it seems that, although we do not have experience with this intervention in other 
designs, achieving a good adherence is a potential weakness of this design. As regards contamination, we assume that the high temperature is the main reason for the increased water intake in the control group.

\section{Avoidance of co-interventions and drop out}

Studies using a no-treatment or usual care control group have the disadvantage that they often suffer from differences in co-interventions and drop out rates. ${ }^{14}$ During our study we asked the participants whether they had received any other treatment for their urinary symptoms elsewhere. It showed that such co-interventions were not reported by the intervention group, nor by the control group. As regards drop out, as is shown in figure 1, every subject who was randomised visited the followup assessments. 


\section{Evaluation of ethical acceptability}

To the Ethical Review Committee of the Maastricht University Hospital/University of Maastricht we proposed we would inform the participants as follows:

"In this study we will compare two groups, one group will receive the advice to increase the water intake for a period of six months and the other group will receive a syrup, also for a period of six months. For scientific reasons we will not inform you on the specific goals of these two interventions. Full information on the specific goals of the interventions will be given at the end of the study".

In the intake visit we explicitly informed the potential participants again that we would not give any information on the specific goals of both interventions. We mentioned that they would have been excluded if they had a high risk of side-effects. We also told them that they would be allocated in a random fashion to one of the interventions by an independent person, that it was possible that they received an ineffective intervention for a period of six months, that they should not talk about the intervention and its effectiveness with other participants, and that they should not tell the assessors who performed the effect measurements which intervention they had been allocated to. The ethical review committee approved the informed consent procedure and the study protocol.

We found one other study that used a similar design. This study was performed in 1975 by Cox et al. ${ }^{26}$ They conducted a trial of 27 patients with tension-type headache. One intervention group received biofeedback on muscle tension, and another group received verbal relaxation instructions. The control group received a green and white glucose capsule that was administered during weekly individual sessions. The control group was told that the medication was a peripherally-acting time-release muscle relaxant known to be effective. The investigators do not describe the ethical implications of the design.

Cox et al. chose to increase the credibility of the placebointervention in order to make the interventions equally credible. Our 
approach was different from that of Cox et al. in that we did not try to increase the credibility of the placebo by providing a fictive rationale. Instead, we did not state anything regarding the targets or objectives of both interventions. With regard to the ethical aspects of this design, we believe that this is an essential aspect. It would not feel just to make up some story, and the participants could feel betrayed afterwards.

Nevertheless, we were curious how our participants perceived the ethics of our design and the informed consent procedure. Therefore, we asked them whether they found the informed consent procedure acceptable (11 point -scale: $0=$ unacceptable to $10=$ totally acceptable). This was done at the end of the study, after we had fully informed them, so that they knew that the syrup was a placebo. Table 4 shows the reported ethical support. The high mean scores (9.03 in the water group and 9.09 in the syrup group) indicate that, in general, the participants fully agreed with the informed consent procedure. Two participants, both in the syrup group, gave a report mark below 6 indicating that they did not agree with the procedure.

\begin{tabular}{|c|c|c|c|}
\hline & $\begin{array}{c}\text { Intervention } \\
\text { (Water) } \\
\text { Mean (sd) Min-max }\end{array}$ & $\begin{array}{c}\text { Control } \\
\text { (Syrup) } \\
\text { Mean (sd) Min-max }\end{array}$ & p-value* \\
\hline $\begin{array}{l}\text { How acceptable do you find this } \\
\text { procedure }(0-10)\end{array}$ & $9.03(1.1) \quad 6-10$ & $9.09(1.3) \quad 4-10$ & 0.40 \\
\hline
\end{tabular}

Another ethical element to consider is the potential withholding of treatment. In our case, participants were screened on urinary symptoms, and did not seek nor required immediate medical help. In addition, preventive interventions for urinary symptoms are currently not available, so that there were no other alternative interventions with proven effectiveness that we would withhold from them. We also asked the participants whether they had experienced any disadvantageous effects of the procedure (e.g., delay of treatment). One of the participants stated that such was the case. He reported that his urination problem had not improved during the study period. 


\section{Discussion}

With this design we were able to blind most of the participants for our hypothesis. We were also able to achieve relatively good comparability of non-specific treatment effects. In addition, our study was not hampered by high drop out rates and co-interventions. The local ethical review committee and the participants generally accepted the ethical aspects of this design.

This design might be employed in studies on the effectiveness of non-pharmacological interventions. For ethical reasons, the experimental intervention should have a minimal chance of side-effects and the target illness should not demand urgent medical attention. For example, an improvement on headache, urine incontinence, chronic back pain, arthritis, obesity, and early stage deterioration of cognitive, cardiovascular, kidney or liver function, can be monitored over time and may improve by nonpharmacological interventions. Nutritional (e.g., drink more water, avoid organic foods, eat more vegetables) and behavioural (e.g., try to postpone voiding, stay active, take some rest) instructions are imaginable for these illnesses/conditions, and may therefore be studied in a randomised trial using a placebo-medication control group.

With this design one should bear in mind several aspects. First, depending on the appearance and presentation of the experimental intervention and the placebo, there will probably be a difference in expectation. Therefore, the patient's expectancies and preferences should be taken into account. ${ }^{21-23}$

Second, if the placebo is unmasked, a no-treatment group remains. As a consequence, it is not possible to control for placebo-effects, participants in the control group may want to discontinue the study, and they may try to seek therapy outside the study. However, not all will be lost because studies using a no-treatment control group are often successfully performed, and the effects of placebo over no-treatment appear to be relatively small. ${ }^{27}$ However, the situation where the placebo is unfortunately disclosed, possibly raises more problems due to the created breach of trust. 
Third, the adherence to the intervention should be carefully monitored and one should try to facilitate the adherence without revealing the hypothesis. If this is not possible, and if poor adherence is expected to threat the study, for example, if the intervention is unattractive and/or requires a fair amount of effort from the patient, it may be better to use a no-treatment or usual care control group and use prerandomisation. It will then be possible to explain why the intervention may have beneficial effects, so that the patients become enthusiastic about it.

Finally, when one considers this design the ethical aspects should be carefully dealt with. In our opinion, as is always the case in placebo controlled trials, the availability of an alternative intervention should largely determine the decision about application of this design. Apart from that, researchers should pay attention to what they tell the participants in the informed consent procedure. Recently, Linde and Dincer ${ }^{28}$ published a review on the information given to patients in acupuncture trials. They showed that researchers in acupuncture trials often do not tell the subjects explicitly that there is a sham intervention involved, because subjects would probably be able to distinguish the real from the sham acupuncture. Apparently, there is some room for interpretation of the World Medical Association Declaration of Helsinki (www.wma.net) stating that the design of the study must be publicly available and that each potential subject must be adequately informed on the aims and methods of the study. In our case, the research team, the ethical review board and the participants, deemed the informed consent procedure acceptable.

A further discussion on whether or not partial informed consent is acceptable in cases where blinding is otherwise impossible, will be facilitated if researchers give detailed information on how they informed the potential subjects. In that way, the readers can judge themselves whether they find the procedure acceptable. Giving detailed information will also help other researchers who plan to use a similar design. 


\section{References:}

1. Spigt MG, van Schayck CP, van Kerrebroeck PE, van Mastrigt $R$ and Knottnerus JA: Pathophysiological aspects of bladder dysfunction: a new hypothesis for the prevention of 'prostatic' symptoms. Med Hypotheses. 62: 448-52, 2004.

2. Macklin R: The ethical problems with sham surgery in clinical research. N Engl J Med. 341: 992-6, 1999.

3. Pocock SJ: The pros and cons of noninferiority trials. Fundam Clin Pharmacol. 17: 483-90, 2003.

4. Whitehead WE: Control groups appropriate for behavioral interventions. Gastroenterology. 126: S159-63, 2004.

5. Knottnerus JA: Gezondheidszorgonderzoek in extramurale settings: Ethiek en recht in de gezondheidszorg. Deventer, Kluwer, 1997 aanv. 21, pp 151-194.

6. Horvath P: Placebos and common factors in two decades of psychotherapy research. Psychol Bull. 104: 214-25, 1988.

7. Parloff MB: Placebo controls in psychotherapy research: a sine qua non or a placebo for research problems? J Consult Clin Psychol. 54: 79-87, 1986.

8. Laporte JR and Figueras A: Placebo effects in psychiatry. Lancet. 344: 1206-9, 1994.

9. Deyo RA, Walsh NE, Schoenfeld LS and Ramamurthy S: Can trials ${ }^{\circ}$ of physical treatments be blinded? The example of transcutaneous electrical nerve stimulation for chronic pain. Am J Phys Med Rehabil. 69: 6-10, 1990.

10. Beurskens AJ, van der Heijden GJ, de Vet HC, Koke AJ, Lindeman E, Regtop W and Knipschild PG: The efficacy of traction for lumbar back pain: design of a randomized clinical trial. J Manipulative Physiol Ther. 18: 141-7, 1995.

11. Ernst $E$ and Harkness E: Spinal manipulation: a systematic review of sham-controlled, double-blind, randomized clinical trials. J Pain Symptom Manage. 22: 879-89, 2001.

12. Streitberger $\mathrm{K}$ and Kleinhenz $\mathrm{J}$ : Introducing a placebo needle into acupuncture research. Lancet. 352: 364-5, 1998. 
13. Zelen M: A new design for randomized clinical trials. N Engl J Med. 300: 1242-5, 1979.

14. Schellings R, Kessels AG, ter Riet $G$ and Sturmans F: The Zelen design may be the best choice for a heroin-provision experiment. $\mathbf{J}$ Clin Epidemiol. 52: 503-7, 1999.

15. Di Blasi Z, Harkness E, Ernst E, Georgiou A and Kleijnen J: Influence of context effects on health outcomes: a systematic review. Lancet. 357: 757-62, 2001.

16. Sech SM, Montoya JD, Bernier PA, Barnboym E, Brown S, Gregory A and Roehrborn CG: The so-called "placebo effect" in benign prostatic hyperplasia treatment trials represents partially a conditional regression to the mean induced by censoring.Urology. 51: 242-50, 1998.

17. Ernst $\mathrm{E}$ and Resch KL: Concept of true and perceived placebo effects. BMJ. 311: 551-3, 1995.

18. Vickers AJ and de Craen AJ: Why use placebos in clinical trials? A narrative review of the methodological literature. J Clin Epidemiol. 53: 157-61, 2000.

19. Kaptchuk TJ, Goldman P, Stone DA and Stason WB: Do medical devices have enhanced placebo effects? J Clin Epidemiol. 53: 786-92, 2000.

20. Crow R, Gage H, Hampson S, Hart J, Kimber A and Thomas H: The role of expectancies in the placebo effect and their use in the delivery of health care: a systematic review. Health Technol Assess. 3: 1-96, 1999.

21. Halpern SD: Evaluating preference effects in partially unblinded, randomized clinical trials. J Clin Epidemiol. 56: 109-15, 2003.

22. McPherson $\mathrm{K}$ and Chalmers I: Incorporating patient preferences into clinical trials. Information about patients' preference must be obtained first. BMJ. 317: 78, 1998.

23. Silverman WA and Altman DG: Patients' preferences and randomised trials. Lancet. 347: 171-4, 1996.

24. Marken Lichtenbelt van WD, Westerterp KR and Wouters L: Deuterium dilution as a method for determining total body water: effect of test protocol and sampling time. Br J Nutr. 72: 491-7, 1994. 
25. Westerterp KR: Body composition, water turnover and energy turnover assessment with labelled water. Proc Nutr Soc. 58: 94551, 1999.

26. Cox DJ, Freundlich A and Meyer RG: Differential effectiveness of electromyograph feedback, verbal relaxation instructions, and medication placebo with tension headaches. J Consult Clin Psychol. 43: 892-8, 1975.

27. Hrobjartsson A and Gotzsche PC: Is the placebo powerless? An analysis of clinical trials comparing placebo with no treatment. N Engl J Med. 344: 1594-602, 2001.

28. Linde $\mathrm{K}$ and Dincer $\mathrm{F}$ : How informed is consent in shamcontrolled trials of acupuncture? J Altern Complement Med. 10: 379-85, 2004. 


\section{Chapter 6}

The effects of long-term increased water intake on blood sodium, glomerular filtration rate, blood pressure and quality of life in an elderly male population (55-75 years)

M.G. (Mark) Spigt ${ }^{1}$

J.A. (André) Knottnerus ${ }^{1}$

K.R. (Klaas) Westerterp ${ }^{2}$

M.G.M. (Marcel) Olde Rikkert ${ }^{3}$

C.P. (Onno) van Schayck ${ }^{1}$

Affiliations:

1. Maastricht University, Research institute Caphri, Department of General Practice

2. Maastricht University, Research institute Nutrim, Department of Human Biology

3. University Medical Centre Nijmegen, Department of Geriatrics

Submitted for publication 


\section{Abstract}

\section{Background}

Dehydration is common in the elderly and it is assumed to be associated with noteworthy co-morbidity. On the other hand, the aged are susceptible to overhydration. Long-term longitudinal data on the positive and/or negative health effects of increased fluid intake in the general elderly population is lacking.

\section{Methods}

The data were derived from a randomised trial, in which we studied the effects of increased fluid intake on Lower Urinary Tract Symptoms (LUTS). We included 141 healthy participants (55-75 year). One group was given the advice to increase their daily fluid intake by 1.5 litres of water, the other group was given placebo-medication $(8 \mathrm{ml}$ inactive syrup per day). At six months we measured blood sodium, glomerular filtration rate (GFR), blood pressure and quality of life (QOL). The changes in water turnover were measured with deuterium.

\section{Results}

Blood pressure, sodium level, GFR, and QOL remained constant in both groups during the intervention period. In addition, the cases reporting a worsening on the effect measures were equally distributed over the two study groups. In men with a GFR lower than $80 \mathrm{ml} / \mathrm{min}$ there was a statistically significant longitudinal effect of drinking water on diastolic (-5.6 $\mathrm{mm} \mathrm{Hg}$; 95\% CI: -9.1 to -2.1$)$ and systolic $(-8.6 \mathrm{~mm} \mathrm{Hg}$; $95 \% \mathrm{CI}:-16.3$ to -0.9$)$ blood pressure.

\section{Conclusions}

The advice to increase the fluid intake by 1.5 litres had no negative long term effects in reasonably healthy $55-75$ year-old men. The effects on blood pressure in patients with decreased GFR should be studied more carefully. 


\section{Introduction}

Dehydration is a common condition affecting the elderly ${ }^{1}$ and it is assumed to be associated with co-morbidity such as decubitus ulcer, ${ }^{2}$ constipation, ${ }^{3,4}$ urolithiasis, ${ }^{5}$ headache, ${ }^{6}$ and even bladder, ${ }^{7}$ colorectal ${ }^{8}$ and breast cancer. ${ }^{9}$ The chance of dehydration is increased in the elderly by a reduced intracellular, extracellular and total-body water, ${ }^{10,11} \mathrm{a}$ diminished sensation of thirst in response to a period of fluid restriction and a reduction of the maximal water conservation capacity of the kidney. ${ }^{12-14}$

On the other hand, the elderly seem susceptible to overhydration. It is well documented that on average renal function declines with age due to glomerular sclerosis, which results in a decrease in cortical mass. ${ }^{15}$ As a consequence, the mean glomerular filtration rate (GFR) declines. Additionally, there is less efficient sodium-conserving capacity and a reduced ability to excrete a surplus water load due to decline in the renal responsiveness to changes in concentration of antidiuretic hormone, natriuretic peptide and aldosterone..$^{12,15-17}$ It is assumed that these factors make the elderly prone to overhydration potentially leading to hyponatremia, which may be fatal in severe cases.

In 2001 a study was started on the effects of increased urine output on bladder function and Lower Urinary Tract Symptoms (LUTS) in elderly males (55-75 years). The hypothesis behind this intervention is described elsewhere. ${ }^{22}$ In short, it was hypothesised that increasing the urine output could trigger a physiological adaptive response of the bladder, leading to function improvement of the bladder muscle. This might prevent frequently reported symptoms such as weak stream and incomplete emptying.

Since the increased urine output was achieved by increasing the fluid intake by 1.5 litres, there was considerable debate whether this could do harm in such an elderly population. Searching the literature, it appeared that no long-term longitudinal data existed on the general health effects of increased fluid intake in the elderly.

It is not sound to base the reluctance to hydration in the elderly on theory and case reports, particularly if hydration potentially has positive 
health effects. On the other hand, it may well be that the decreased renal and haemodynamic functioning make the elderly prone to overhydration, so that indeed one should be careful to give hydration advises in this population. ${ }^{23}$ To investigate whether increasing the fluid intake has a relevant negative effect in the elderly, general health effects were monitored during this randomised trial. The effects on bladder function and LUTS are not part of this paper. 


\section{Methods}

The analysis of the general health effects of increased fluid intake in the elderly were part of a randomised trial in which we investigated the effects of increased fluid intake on bladder function and LUTS. In this trial, participants were randomised to the advice to increase their daily fluid intake by 1.5 litres of water, or to placebo-medication. Both groups were followed for a period of six months

\section{Description of the trial}

The study population was recruited via 21 general practices. The general practitioners invited their total male population between 55 and 75 years of age to participate in the study. A screening questionnaire, containing the International Prostate Symptom Score (IPSS; range 0$35),{ }^{24,25}$ questions on co-morbidity, a drink diary and informed consent documents, were enclosed with the doctor's invitation. 1911 men gave informed consent and they were screened for moderate LUTS (IPSSscore: 8-19). On the base of the screening questionnaire 1673 men were excluded. Exclusion criteria were: mild or severe (LUTS) (IPSS $<8$ or $>$ 19); diabetes; Parkinson; past surgery of the lower urinary tracts; a history of prostatic or bladder carcinoma; the use of medication for LUTS or tricyclic antidepressive agents. In addition, potential participants were excluded who reported to have a fluid intake of more than 2.0 litres per day; who had a renal disease; used diuretics; in whom prostate cancer was diagnosed (PSA $>4.0$ and biopsy confirmed carcinoma); or who had a blood sodium level below $130 \mathrm{mmol} / \mathrm{l}$. A total of 141 participants were enrolled into the study.

A person, who was otherwise not involved in the execution of the study, and had no access to the baseline data, generated a random allocation sequence with a computerised random-number generator, and randomly assigned the participants to the two groups. People in the intervention group were advised to additionally drink three portions of 0.5 litres of water spread over the day. To improve the adherence to the intervention they were supplied with 0.5 litre glasses. People in the control group received placebo-medication ( $8 \mathrm{ml}$ inactive syrup per day). 
A person, who was not involved in the effect measurements, told the participants which intervention they would receive, and kept contact with the participants during the study by telephone (at two, eight and twelve weeks) to maintain treatment adherence.

The participants were informed that we would investigate whether it was possible to prevent LUTS. No information was given on the specific goal of both interventions to accomplish blinding for the nature of the interventions and the hypothesis of this study. They were mentioned that they would be allocated in a random fashion to one of the interventions, and that it was possible that they received an ineffective intervention for a period of 6 months. All participants were fully informed after study termination. The ethical review board of the University Hospital Maastricht/ University of Maastricht approved the research protocol and the informed consent procedure.

\section{Measurements}

Assessment of total body water and water turnover

To measure the hydration status of the participants prior and during the study period, and to measure the actual change in water turnover, the deuterium $\left({ }^{2} \mathrm{H}_{2} \mathrm{O}\right)$ labelled water method was used. This is regarded to be the 'gold standard' for measuring total body water (TBW) and water turnover in humans. ${ }^{26,27}$ After equilibration of a known mass of deuterium in the body water compartment, TBW can be calculated by measuring deuterium concentration in urine. Subsequently, deuterium is eliminated depending on the rate of water turnover; the higher the water turnover, the lower the deuterium concentration in urine after a certain period of time. Accordingly, the urine samples from both groups, taken at different time points within two weeks (days: $0 ; 1 ; 7 ; 14$ ), were analysed. This was done prior to the baseline assessment in the hospital, and in the final 2 weeks of the intervention period.

\section{Assessment of (adverse) effects}

If a hydration regime has negative effects on the general health in the elderly, it is primarily expected to result in changes in blood sodium levels, renal functioning, haemodynamic functioning and (global) quality of life. The effects of the intervention were assessed at baseline and 
directly at the end of the intervention period (at six months). From blood samples we determined sodium and creatinine levels. From the creatinine levels the Glomerular Filtration Rate (GFR) was estimated with the Cockroft and Gault formula. ${ }^{28}$ Diastolic and systolic blood pressure were measured two times at each assessment, with the oscillometric device Omron $705 \mathrm{CP} .{ }^{29}$ The mean of the two measurements was calculated. The SF36 was used to monitor (global) quality of life (QOL). ${ }^{30,}{ }^{31} \mathrm{We}$ included the mean score of the different SF36-subscales into the analysis.

\section{Statistical analysis}

Three subjects turned out later to have a baseline IPSS-score above the maximum of 19 points (scores of 20,21 and 22 respectively). They were allocated in error, but because this criterion was not essential for the research question in this paper, they were not excluded from the statistical analysis.

We analysed the baseline differences between the two age subgroups (55-65 and 66-75 year) with independent samples t-test. The linear relationship between age and baseline characteristics were analysed with linear regression. For the estimation of the treatment effect, we performed multiple linear regression analyses (ANCOVA) in which the follow-up measurement was used as outcome variable, the intervention type as a predictive variable, and the baseline score of that outcome variable and age as covariates. ${ }^{32}$ As a per protocol analysis, the analysis was subsequently carried out without the subjects in the experimental intervention group, who had not increased their water turnover above the median (intervention group) level. In addition, we studied the linear relationship between the effect measures and actual increase in water turnover (linear regression). We further investigated the possible harmful effects of increased water intake by selecting the worst $20 \%$ of cases on each effect parameter, after which we analysed the distribution of these cases between the water and control group. As an explorative analysis we analysed possible effect modification of age and GFR by performing a stratified analyses of treatment effect for these subgroups. The analysis was performed in SPSS. We determined 95\% confidence intervals $(\mathrm{CI})$ and a two-tailed p-value smaller than 0.05 was considered statistically significant. 


\section{Results}

\section{Baseline characteristics}

At baseline the elderly subgroup (66-75 year) had a statistically significant lower 24-h water turnover as compared to the younger subgroup (55-65 year) (table 1). GFR and blood sodium level were also statistically significant lower in the older subjects. Age was statistically significantly related to a decrease in TBW, 24-h water turnover and GFR. Systolic blood pressure increased statistically significant with increasing age.

\begin{tabular}{|c|c|c|c|c|}
\hline $\begin{array}{l}\text { Baseline characteristics for } \\
\text { and the estimated effect of }\end{array}$ & ifferent age $g$ & oups, the diff & rences betwe & these groups \\
\hline & $\begin{array}{c}55-65 \text { years } \\
(n=89) \\
\text { Mean }(\mathrm{sd})\end{array}$ & $\begin{array}{l}66-75 \text { years } \\
\quad(n=52) \\
\text { Mean (sd) }\end{array}$ & $\begin{array}{c}\text { Difference } \\
\text { between } \\
\text { means (se) }\end{array}$ & $\begin{array}{c}\text { Estimated effect* } \\
\text { of one year } \\
\text { increase in } \\
\text { age (se) }\end{array}$ \\
\hline 24-h water turnover $(\mathrm{ml})$ & $3075(592)$ & $2858(509)$ & $-217(103)^{* *}$ & $-30(9)^{* *}$ \\
\hline Total body water (l) & $43(5)$ & $42(5)$ & $-1.5(0.8)$ & $-0.3(0.1)^{* *}$ \\
\hline Diastolic blood pressure $(\mathrm{mm} \mathrm{Hg})$ & $93(11)$ & $91(12)$ & $-1(2)$ & $0.04(0.2)$ \\
\hline Systolic blood pressure (mm Hg) & $158(22)$ & $169(22)$ & $5(4)$ & $1.0(0.4)^{* *}$ \\
\hline Glomerular filtration rate $(\mathrm{GFR})(\mathrm{ml} / \mathrm{min})$ & $87(16)$ & $77(14)$ & $-10(3)^{* *}$ & $-1.3(0.3)^{* *}$ \\
\hline Blood sodium $(\mathrm{mmol} / \mathrm{l})$ & $138(3)$ & $137(3)$ & $-1.1(0.5)^{* *}$ & $-0.09(0.05)$ \\
\hline Quality of life (QOL) (SF36) & $73(16)$ & $77(12)$ & $5(3)$ & $0.4(0.3)$ \\
\hline
\end{tabular}

\section{Effects of increased fluid intake}

At six months follow-up, the 24-h water turnover in the water group was $359 \mathrm{ml}$ higher than the control group (table 2). TBW, Blood pressure, blood sodium level, GFR, and QOL remained constant in both groups during the intervention period. Excluding the non-adherence participants (24-h water turnover increase below median score $955 \mathrm{ml}$ ) from the analysis did not influence the results relevantly (data not shown). 
In addition, there was no statistically significant relationship between changes in water turnover and changes in effect (coefficients for 1 litre increase in water turnover: diastolic BP: $0.8 \pm \mathrm{se}: 1.4 \mathrm{~mm} \mathrm{Hg}$, systolic BP: $5 \pm 3 \mathrm{~mm} \mathrm{Hg}$, GFR: $-1.7 \pm 1.6 \mathrm{ml} / \mathrm{min}$, sodium $-0.7 \pm 0.4$ $\mathrm{mmol} / \mathrm{l}, \mathrm{SF} 36: 3 \pm 2$ ).

\section{Table 2 The effects of increased water intake.}

\begin{tabular}{|c|c|c|c|}
\hline & $\begin{array}{l}\text { Water }(n=70) \\
\text { Mean }(s d)\end{array}$ & $\begin{array}{l}\text { Control }(n=71) \\
\text { Mean (sd) }\end{array}$ & $\begin{array}{c}\text { Estimated effect of } \\
\text { water* }(95 \% \mathrm{CI})\end{array}$ \\
\hline \multicolumn{4}{|l|}{ 24-h water turnover $(\mathrm{ml})$} \\
\hline Baseline & $3034(631)$ & $2950(498)$ & \\
\hline Six months & $4036(988)$ & $3628(764)$ & $359(171 \text { to } 548)^{* *}$ \\
\hline \multicolumn{4}{|l|}{ Total body water (l) } \\
\hline Baseline & $42(4)$ & $43(5)$ & \\
\hline Six months & $42(4)$ & $43(5)$ & $0.2(-0.4$ to 0.8$)$ \\
\hline \multicolumn{4}{|l|}{ Diastolic blood pressure (mm Hg) } \\
\hline Baseline & $92(11)$ & $92(11)$ & \\
\hline Six months & $89(12)$ & $90(11)$ & $-0.9(-3.7$ to 2.0$)$ \\
\hline \multicolumn{4}{|l|}{ Systolic blood pressure (mm Hg) } \\
\hline Baseline & $166(22)$ & $165(23)$ & \\
\hline Six months & $159(25)$ & $161(24)$ & $-2.4(-8.0$ to 3.2$)$ \\
\hline \multicolumn{4}{|l|}{ Glomerular filtration rate $(\mathrm{GFR})(\mathrm{ml} / \mathrm{min})$} \\
\hline Baseline & $82(16)$ & $85(16)$ & \\
\hline Six months & $81(16)$ & $85(19)$ & $-0.1(-3.2$ to 2.9$)$ \\
\hline \multicolumn{4}{|l|}{ Blood sodium ( $\mathrm{mmol} / \mathrm{l})$} \\
\hline Baseline & $137(3)$ & $138(3)$ & \\
\hline Six months & $138(3)$ & $138(3)$ & $-0.2(-1.1$ to 0.6$)$ \\
\hline \multicolumn{4}{|l|}{ Quality of life (QOL) (SF36) } \\
\hline Baseline & $74(14)$ & $74(15)$ & \\
\hline Six months & $74(14)$ & $73(15)$ & $1.1(-2.4$ to 4.8$)$ \\
\hline \multicolumn{4}{|c|}{$\begin{array}{l}* \text { The estimated effect was determined with regression analysis, in which we adjusted for differences } \\
\text { in baseline score, and age. } \\
* *=\text { statistically significant with } p<0.05\end{array}$} \\
\hline
\end{tabular}




\section{Distribution of worst cases}

The cases reporting a relatively large worsening on the effect measures were equally distributed over the two study groups (table 3 ), and a blood sodium level below $130 \mathrm{mmol} / \mathrm{l}$ did not occur during the study period.

\section{Table 3 Distribution of selected adverse effects between the two study groups.}

\begin{tabular}{|c|c|c|}
\hline & $\begin{array}{c}\text { Water }(\mathrm{n}=70) \\
\mathrm{N}(\%)\end{array}$ & $\begin{array}{c}\text { Control }(\mathrm{n}=71) \\
N(\%)\end{array}$ \\
\hline \multicolumn{3}{|l|}{ Diastolic blood pressure ( $\mathrm{mm} \mathrm{Hg}$ ) } \\
\hline Worst $20 \%$ (>5 mm Hg increase) & $14(21 \%)$ & $15(22 \%)$ \\
\hline \multicolumn{3}{|l|}{ Systolic blood pressure } \\
\hline Worst $20 \%$ (>6.5 $\mathrm{mm} \mathrm{Hg}$ increase) & $15(23 \%)$ & $14(21 \%)$ \\
\hline \multicolumn{3}{|l|}{ Glomerular filtration rate (GFR) (ml/min) } \\
\hline Worst $20 \%(<=-6.00 \mathrm{ml} / \mathrm{min}$ decrease $)$ & $13(21 \%)$ & $12(18 \%)$ \\
\hline \multicolumn{3}{|l|}{ Quality of life (QOL) (SF36) } \\
\hline Worst $20 \%(<=-7.79$ decrease $)$ & $9(15 \%)$ & $15(23 \%)$ \\
\hline
\end{tabular}

\section{Effect modification by age and GFR}

The stratified analyses for age revealed that the effects of increased water intake were not different for the elderly subgroup (66-75 years) when compared to the younger subgroup (55-65 years) (data not shown). Stratification on GFR ( $<$ or $>80 \mathrm{ml} / \mathrm{min}$ ) did appear to modify the effect of increased water intake, but only on blood pressure, where increased water intake had a statistically significant effect on diastolic as well as systolic blood pressure. In men with a GFR lower than $80 \mathrm{ml} / \mathrm{min}$ there was a statistically significant longitudinal effect of drinking water on diastolic $(-5.6 \mathrm{~mm} \mathrm{Hg} ; \mathrm{p}=0.002$; CI: -9.1 to -2.1$)$ and systolic $(-8.6 \mathrm{~mm}$ $\mathrm{Hg}, \mathrm{p}=0.03$; $\mathrm{CI}:-16.3$ to -0.9$)$ blood pressure. 


\section{Discussion}

Both negative and positive effects of hydration are often presumed, but surprisingly little scientific evidence exists on the long-term effects of hydration, especially in the "average" elderly individual. This study provided a unique opportunity to study the general health effects and potential adverse effects of hydration in the elderly.

At baseline there was a statistically significant negative relation between age and TBW and between age and 24-h water turnover. The observed decrease in total body water with increasing age, has been reported by others and is assumed to be largely determined by a decrease in fat free mass. ${ }^{33}$ A decrease in water turnover with increasing age matches with the findings of a study of Raman et al. ${ }^{33}$ Several factors such as a reduced physical activity level ${ }^{34,35}$ and reduced beverage intake, ${ }^{14,33}$ might explain the lower water turnover in the aged. Whether a reduced water turnover has any causal relationship with other age related negative changes of the human body is unknown. It is also unknown whether influencing these factors by increasing the fluid intake has a positive effect.

The advice to increase the fluid intake by 1.5 litres had no negative effects in our study. Neither were there differences in the distribution of adverse events between the control and experimental group. In addition, in the long term, the elderly subgroup (65-75 years) showed to be as well able to cope with the increased water intake as the younger individuals (55-65 years). We therefore conclude that the advice to increase the fluid intake by 1.5 litres can safely be given to reasonably healthy elderly men between 55-75 years of age. Safety is not guaranteed in patients with known renal disorders, with a blood sodium level below $130 \mathrm{mmol} / \mathrm{l}$, with a high (self reported) prior fluid intake, or with evident cardiac decompensation, since they were not included into this study. In such a population, extra precautionary measures should be taken to monitor possible overhydration. In addition, too large increases of water intake (for example 5-10 litres per day) will probably be harmful, especially in an elderly population and in cases of malnutrition. 
We observed beneficial effects of increased fluid intake on diastolic and systolic blood pressure in a subgroup of persons with a decreased GFR. Some research has been performed on the short-term effects of increased fluid intake and blood pressure showing a temporary increase in blood pressure. ${ }^{36-39}$ In addition, the relationship between decreased renal function and high blood pressure is known. ${ }^{40}$ However, as far as we know, a possible positive effect of long-term increased fluid intake on hypertension has not been addressed before. Some caution is required since our observation is based on subgroup analyses, but the data appeared consistent as in a subgroup with high (baseline) blood pressure and decreased GFR, the size of the effect increased, and the effect remained statistically significant even in this small subgroup (DiasBP: $-7 \mathrm{~mm} \mathrm{Hg}$ ( $\mathrm{p}=0.03 \mathrm{Cl}$ : -13 to -1 ); SystBP $-18 \mathrm{~mm} \mathrm{Hg}, \mathrm{p}=0.005$ CI: -30 to -6$)$. We hypothesize that the decline in blood pressure in subjects with decreased renal function is mediated by a different physiological adaptation to overhydration subsequently leading to decreased peripheral resistance. Future studies in clinically relevant populations (i.e. patients with hypertension and low GFR) are needed to verify these results and to investigate the underlying physiological mechanism.

Finally, it must be noted that increasing the fluid intake and achieving a large contrast between study groups is difficult. In this study we achieved a mean contrast of approximately $350 \mathrm{ml}$ per $24-\mathrm{h}$, which was essentially lower as was requested. The fact that the Dutch summer of 2003 was the second warmest summer in the last 100 years may partly explain this. The mean ambient temperature during the follow up measurements was $20.9{ }^{\circ} \mathrm{C}$ (range: 17.3 to $24.6^{\circ} \mathrm{C}$ ), while $17.6^{\circ} \mathrm{C}$ is normal for that period. Consequently, the control group had a much higher fluid intake compared to baseline reducing the contrast between the two groups. For a clear evaluation of increased fluid intake, future research should preferably be carried out outside of the summer months. Motivating the participants, and providing feedback on the actual increase of fluid intake, is, in our opinion, the key to a better adherence to the advice to increase the fluid intake. We do not think that other methods (e.g. to supply a 1.5 litre bottle) will be more feasible, but this might be a topic for future research. 


\section{Conclusion}

The advice to increase the fluid intake by 1.5 litres had no negative long term effects on haemodynamic outcome measures nor on quality of life in reasonably healthy 55-75 year-old men. Future studies should further investigate the relationship between age, age related physiologic changes, and decreased water turnover. In addition, potential positive effects, on for example blood pressure in patients with decreased GFR, should be studied more carefully. 


\section{References:}

1. Weinberg $\mathrm{AD}$ and Minaker KL: Dehydration. Evaluation and management in older adults. Council on Scientific Affairs, American Medical Association. JAMA. 274: 1552-6, 1995.

2. Casimiro C, Garcia de Lorenzo A and Usan L: Prevalence of decubitus ulcer and associated risk factors in an institutionalized Spanish elderly population. Nutrition. 18: 408-14, 2002.

3. Arnaud MJ: Mild dehydration: a risk factor of constipation? Eur J Clin Nutr. 57 Suppl 2: S88-95, 2003.

4. Wilson JA: Constipation in the elderly. Clin Geriatr Med. 15: 499-510, 1999.

5. Borghi L, Meschi T, Amato F, Briganti A, Novarini A and Giannini A: Urinary volume, water and recurrences in idiopathic calcium nephrolithiasis: a 5-year randomized prospective study. J Urol. 155: 839-43, 1996.

6. Blau JN, Kell CA and Sperling JM: Water-deprivation headache: a new headache with two variants. Headache. 44: 79-83, 2004.

7. Michaud DS, Spiegelman D, Clinton SK, Rimm EB, Curhan GC, Willett WC and Giovannucci EL: Fluid intake and the risk of bladder cancer in men. N Engl J Med. 340: 1390-7, 1999.

8. Tang R, Wang JY, Lo SK and Hsieh LL: Physical activity, water intake and risk of colorectal cancer in Taiwan: a hospital-based case-control study. Int J Cancer. 82: 484-9, 1999.

9. Bar David Y, Gesundheit B, Urkin J and Kapelushnik J: Water intake and cancer prevention. J Clin Oncol. 22: 383-5, 2004.

10. Ritz P: Chronic cellular dehydration in the aged patient. $\mathbf{J}$ Gerontol A Biol Sci Med Sci. 56: M349-52, 2001.

11. Olde Rikkert MG, Deurenberg P, Jansen RW, van't Hof MA and Hoefnagels WH: Validation of multifrequency bioelectrical impedance analysis in monitoring fluid balance in healthy elderly subjects. J Gerontol A Biol Sci Med Sci. 52: M137-41, 1997.

12. Phillips PA, Johnston CI and Gray L: Disturbed fluid and electrolyte homoeostasis following dehydration in elderly people. Age Ageing. 22: S26-33, 1993. 
13. Stachenfeld NS, DiPietro L, Nadel ER and Mack GW: Mechanism of attenuated thirst in aging: role of central volume receptors. Am J Physiol. 272: R148-57, 1997.

14. Kenney WL and Chiu P: Influence of age on thirst and fluid intake. Med Sci Sports Exerc. 33: 1524-32, 2001.

15. Epstein M: Aging and the kidney. J Am Soc Nephrol. 7: 1106-22, 1996.

16. Rolls BJ and Phillips PA: Aging and disturbances of thirst and fluid balance. Nutr Rev. 48: 137-44, 1990.

17. Beck LH: The aging kidney. Defending a delicate balance of fluid and electrolytes. Geriatrics. 55: 26-8, 31-2, 2000.

18. Burke MP and Opeskin K: Sudden death from hyponatremia and hypokalemia in a woman with Gardner syndrome. Am J Forensic Med Pathol. 22: 84-7, 2001.

19. Garigan TP and Ristedt DE: Death from hyponatremia as a result of acute water intoxication in an Army basic trainee. Mil Med. 164: 234-8, 1999.

20. Goldman MB: Moderate hyponatremia and death in a polydipsic schizophrenic on lithium. Biol Psychiatry. 36: 485-6, 1994.

21. Fox BD: Crash diet potomania. Lancet. 359: 942, 2002.

22. Spigt $M G$, van Schayck $C P$, van Kerrebroeck PE, van Mastrigt $R$ and Knottnerus JA: Pathophysiological aspects of bladder dysfunction: a new hypothesis for the prevention of 'prostatic' symptoms. Med Hypotheses. 62: 448-52, 2004.

23. Lindeman RD, Romero LJ, Liang HC, Baumgartner RN, Koehler KM and Garry PJ: Do elderly persons need to be encouraged to drink more fluids? J Gerontol A Biol Sci Med Sci. 55: M361-5, 2000.

24. Barry MJ, Fowler FJ, Jr., O'Leary MP, Bruskewitz RC, Holtgrewe HL, Mebust WK and Cockett AT: The American Urological Association symptom index for benign prostatic hyperplasia. The Measurement Committee of the American Urological Association. J Urol. 148: 1549-57, 1992.

25. Barry MJ, Fowler FJ, Jr., O'Leary MP, Bruskewitz RC, Holtgrewe HL and Mebust WK: Correlation of the American Urological Association symptom index with self-administered versions of the 
Madsen-Iversen, Boyarsky and Maine Medical Assessment Program symptom indexes. Measurement Committee of the American Urological Association. J Urol. 148: 1558-63, 1992.

26. Westerterp KR, Wouters $L$ and van Marken Lichtenbelt WD: The Maastricht protocol for the measurement of body composition and energy expenditure with labeled water. Obes Res. 3 Suppl 1: 4957, 1995.

27. Westerterp KR: Body composition, water turnover and energy turnover assessment with labelled water. Proc Nutr Soc. 58: 94551, 1999.

28. Cockcroft DW and Gault MH: Prediction of creatinine clearance from serum creatinine. Nephron. 16: 31-41, 1976.

29. O'Brien E, Atkins N, Mee F, Coyle D and Syed S: A new audiovisual technique for recording blood pressure in research: the Sphygmocorder. J Hypertens. 13: 1734-7, 1995.

30. Aaronson NK, Muller M, Cohen PD, Essink Bot ML, Fekkes M, Sanderman R, Sprangers MA, te Velde A and Verrips E: Translation, validation, and norming of the Dutch language version of the SF-36 Health Survey in community and chronic disease populations. J Clin Epidemiol. 51: 1055-68, 1998.

31. Razavi D and Gandek B: Testing Dutch and French translations of the SF-36 Health Survey among Belgian angina patients. J Clin Epidemiol. 51: 975-81, 1998.

32. Twisk $\mathrm{J}$ and Proper K: Evaluation of the results of a randomized controlled trial: how to define changes between baseline and follow-up. J Clin Epidemiol. 57: 223-8, 2004.

33. Raman A, Schoeller DA, Subar AF, Troiano RP, Schatzkin A, Harris T, Bauer D, Bingham SA, Everhart JE, Newman AB et al:: Water turnover in 458 American adults 40-79 yr of age. Am J Physiol Renal Physiol. 286: F394-401, 2004.

34. Shimamoto $\mathrm{H}$ and Komiya $\mathrm{S}$ : Comparison of body water turnover in endurance runners and age-matched sedentary men. J Physiol Anthropol Appl Human Sci. 22: 311-5, 2003.

35. Leiper JB, Carnie A and Maughan RJ: Water turnover rates in sedentary and exercising middle aged men. Br J Sports Med. 30: 24-6, 1996. 
Madsen-Iversen, Boyarsky and Maine Medical Assessment Program symptom indexes. Measurement Committee of the American Urological Association. J Urol. 148: 1558-63, 1992.

26. Westerterp KR, Wouters L and van Marken Lichtenbelt WD: The Maastricht protocol for the measurement of body composition and energy expenditure with labeled water. Obes Res. 3 Suppl 1: 4957, 1995.

27. Westerterp KR: Body composition, water turnover and energy turnover assessment with labelled water. Proc Nutr Soc. 58: 94551, 1999.

28. Cockcroft DW and Gault MH: Prediction of creatinine clearance from serum creatinine. Nephron. 16: 31-41, 1976.

29. O'Brien E, Atkins N, Mee F, Coyle D and Syed S: A new audiovisual technique for recording blood pressure in research: the Sphygmocorder. J Hypertens. 13: 1734-7, 1995.

30. Aaronson NK, Muller M, Cohen PD, Essink Bot ML, Fekkes M, Sanderman R, Sprangers MA, te Velde A and Verrips E: Translation, validation, and norming of the Dutch language version of the SF-36 Health Survey in community and chronic disease populations. J Clin Epidemiol. 51: 1055-68, 1998.

31. Razavi D and Gandek B: Testing Dutch and French translations of the SF-36 Health Survey among Belgian angina patients. J Clin Epidemiol. 51: 975-81, 1998.

32. Twisk $\mathrm{J}$ and Proper K: Evaluation of the results of a randomized controlled trial: how to define changes between baseline and follow-up. J Clin Epidemiol. 57: 223-8, 2004.

33. Raman A, Schoeller DA, Subar AF, Troiano RP, Schatzkin A, Harris T, Bauer D, Bingham SA, Everhart JE, Newman AB et al.: Water turnover in 458 American adults $40-79 \mathrm{yr}$ of age. Am J Physiol Renal Physiol. 286: F394-401, 2004.

34. Shimamoto $\mathrm{H}$ and Komiya S: Comparison of body water turnover in endurance runners and age-matched sedentary men. J Physiol Anthropol Appl Human Sci. 22: 311-5, 2003.

35. Leiper JB, Carnie A and Maughan RJ: Water turnover rates in sedentary and exercising middle aged men. Br J.Sports Med. 30: 24-6, 1996. 
36. Lu CC, Diedrich A, Tung CS, Paranjape SY, Harris PA, Byrne DW, Jordan J and Robertson D: Water ingestion as prophylaxis against syncope. Circulation. 108: 2660-5, 2003.

37. Shannon JR, Diedrich A, Biaggioni I, Tank J, Robertson RM, Robertson D and Jordan J: Water drinking as a treatment for orthostatic syndromes. Am J Med. 112: 355-60, 2002.

38. Jordan J: Acute effect of water on blood pressure. What do we know? Clin Auton Res. 12: 250-5, 2002.

39. Jordan J, Shannon JR, Black BK, Ali Y, Farley M, Costa F, Diedrich A, Robertson RM, Biaggioni I and Robertson D: The pressor response to water drinking in humans : a sympathetic reflex? Circulation. 101: 504-9, 2000.

40. Culleton BF, Larson MG, Wilson PW, Evans JC, Parfrey PS and Levy D: Cardiovascular disease and mortality in a communitybased cohort with mild renal insufficiency. Kidney Int. 56: 22149, 1999. 
36. Lu CC, Diedrich A, Tung CS, Paranjape SY, Harris PA, Byrne DW, Jordan $J$ and Robertson D: Water ingestion as prophylaxis against syncope. Circulation. 108: 2660-5, 2003.

37. Shannon JR, Diedrich A, Biaggioni I, Tank J, Robertson RM, Robertson D and Jordan J: Water drinking as a treatment for orthostatic syndromes. Am J Med. 112: 355-60, 2002.

38. Jordan J: Acute effect of water on blood pressure. What do we know? Clin Auton Res. 12: 250-5, 2002.

39. Jordan J, Shannon JR, Black BK, Ali Y, Farley M, Costa F, Diedrich A, Robertson RM, Biaggioni I and Robertson D: The pressor response to water drinking in humans : a sympathetic reflex? Circulation. 101: 504-9, 2000.

40. Culleton BF, Larson MG, Wilson PW, Evans JC, Parfrey PS and Levy D: Cardiovascular disease and mortality in a communitybased cohort with mild renal insufficiency. Kidney Int. 56: 22149, 1999. 


\title{
Chapter 7
}

Increasing the daily water intake for the prophylactic treatment of headache; A pilot trial

\author{
M.G. (Mark) Spigt ${ }^{1}$ \\ E.C. (Els) Kuijper ${ }^{1}$ \\ C.P. (Onno) van Schayck ${ }^{1}$ \\ J. (Jaap) Troost ${ }^{2}$ \\ P.G. (Paul) Knipschild 1 \\ V.M. (Vinca) Linssen ${ }^{1}$ \\ J.A. (André) Knottnerus ${ }^{1}$
}

Affiliations:

1. University of Maastricht, Research Institute Caphri, Department of General Practice

2. University Hospital Maastricht, Department of Neurology

Accepted for publication in: European Journal of Neurology 


\section{Abstract}

\section{Background}

Dehydration is commonly believed to result in headache, but the effectiveness of increasing the water intake in patients who frequently suffer from headaches has not been studied thus far. In a pilot study we examined the possible effects and feasibility of increased water intake in headache patients.

\section{Methods}

18 headache patients (all had migraine, 2 also had tension-type headache) were randomly allocated to placebo medication, or the advice to additionally drink 1.5 litres of water per day, for a period of 12 weeks. Effect measurements consisted of a two weeks headache diary and the Migraine Specific Quality of Life (MSQOL) questionnaire.

\section{Results}

The advice to increase the daily fluid intake by 1.5 litres increased the fluid intake in the intervention group by approximately 1 litre. This reduced the total hours of headache in two weeks by 21 hours (95\%CI: 48 to 5). Mean headache intensity decreased by $13 \mathrm{~mm}(95 \% \mathrm{CI}:-32$ to 5 ) on a visual analogue scale (VAS). The effects on MSQOL, number of headache episodes, and medication seemed to be small.

\section{Conclusions}

The data of the present study suggest a reduction in the total number of hours and intensity of headache episodes after increased water intake. Our results seem to justify larger scaled research on the effectiveness of increased water intake in headache patients. 


\section{Introduction}

A 56-year-old man suffered from migraine (without an aura) that occurred approximately twice a month during weekends. The headache aggravated on movement and was usually accompanied by nausea and photophobia. Each episode lasted approximately 24-hours. He participated in a study of our group on the effects of increased water intake on voiding dysfunction. While preventing voiding dysfunction was our aim in that study, this man spontaneously reported a reduced intensity and frequency of his headache after one month of increased water intake. The headaches came back again after he returned to a lower level of fluid intake. Now he drinks 1.5 litres of water additionally per day and he has only mild headaches occasionally.

A similar report has recently been published by Blau et al. ${ }^{1}$ They described two case reports of two medical students who developed headache after a period of water deprivation. Blau et al. declare that pure water-deprivation headache is well recognised by the public (e.g. the Internet), but not by the medical profession.

Although many precipitating factors have been suggested and studied for their ability to trigger migraine attacks, ${ }^{2-5}$ fluid intake is rarely considered in etiologic studies. A further search of the literature revealed that headache has been reported in cases of alcohol hangover, ${ }^{6}$ Ramadan fasting, ${ }^{7}$ altitude sickness, ${ }^{8}$ and heat illness, ${ }^{9}$ suggesting a possible relationship between body fluid homeostasis and headache.

To collect more information on this topic and to see if there is any sense in studying this topic any further, we carried out a randomised pilot study. The aims of this study were first to explore whether there could be a positive effect of increased water intake in headache patients, and second to get insight into the feasibility of this intervention. 


\section{Methods}

\section{Patients}

We recruited participants by an advertisement in a local newspaper. Participants responding to this advertisement were sent the study information, the informed consent documentation, and a screening questionnaire with the in- and exclusion criteria. We included participants who frequently (once a week or more) suffered from migraine or tension-type headache according to the diagnostic criteria of the International Headache Society (IHS) criteria, ${ }^{10}$ for at least the past six months. Patients whose headache could not be classified as migraine or tension-type headache were excluded, as well as patients with a headache that was secondary to other pathology. Also excluded were patients who would not be available during the research period, who used antidepressants and/or anxiolytica, and patients with gastrointestinal, hepatic, cardiovascular or renal disorders.

\section{Study design and interventions}

Patients were randomly allocated to two groups. Patients in the intervention group were advised to drink 1.5 litres of water per day, additionally to their normally consumed beverages, for a period of 12 weeks. They were advised to divide this amount into three portions of 0.5 litre spread over the day. The control group received a placebo intervention in the form of a tablet (one tablet each day during dinner), also for a period of 12 weeks.

To ensure blinding of the participants for the hypothesis of this study, the participants were informed that we would not give any information on the specific goal of both interventions during the study period, but that they would be fully informed after study termination. Hence, the participants did not know the nature of both interventions when they were included into the study. We mentioned that they would be allocated in a random fashion to one of the interventions and that it was possible that they received an ineffective intervention for a period of 3 months. The medical ethical committee of the University Hospital Maastricht/ University of Maastricht approved the research protocol and 
the informed consent procedure.

\section{Assessments}

Although participants were not informed on the actual goal of each intervention, we assessed their expected effect for both interventions prior to randomisation, in order to gain insight into the comparability of placebo effects in both groups. We asked the participants to rate their expected effect on a Visual Analogue Scale (VAS: $0=$ no effect, $100=$ much effect). In the final analyses only the rating of their 'own' intervention was included.

Baseline assessment of headache severity consisted of a 2-weeks headache diary and the 20 items Migraine Specific Quality Of Life questionnaire (MSQOL). ${ }^{11}$ Beside these effect measures, the participants kept a 3-days drink diary. The 2-weeks headache diary, MSQOL and 3days drink diary were assessed again at the end of the intervention period.

From the headache diary, we extracted the total number of hours of headache during 2 weeks, its mean intensity (VAS: $0=$ no headache, 100 = severe headache), the total number of headache episodes, and the use of pain medication (number of tablets). The MSQOL resulted in a sum score ranging from 20 (worst quality of life) to 80 (best quality of life). The drink diary, in which the participants measured and recorded all consumed beverages, served as a measure of intervention contrast between the two groups.

\section{Data analysis}

The analysis was performed without the two dropouts for whom follow-up measurements were not available. Also excluded from the analysis was one person in the intervention group of whom we had incomplete follow-up data. For the estimation of the treatment effect, we performed multiple linear regression analyses (ANCOVA) in which the follow-up measurement was used as outcome variable, the intervention type as a predictive variable and baseline score of that outcome variable as covariate. ${ }^{12,13}$ 


\section{Results}

\section{Patients}

Out of the 97 people who responded to the advertisement, 14 females and 4 males were included in the study. All 18 subjects (mean age: 44) had migraine (6 patients with an aura), two patients also met the criteria for tension-type headache. Two subjects withdrew after randomisation. One subject stopped his placebo medication after an aggravation of his headache and the other, also in the placebo group, left the study (and the country) for unknown reasons.

\section{Blinding of patients for the hypothesis}

Blinding the patients for the actual goal of our study seemed successful. The participants in the water group scored $50 \pm 29 \mathrm{~mm}$ on the VAS for expected effect of their intervention. The mean score in the placebo group was $67 \pm 15 \mathrm{~mm}$ (difference: $-17 \mathrm{~mm}, \mathrm{CI}:-43$ to 9) (data not shown in table), suggesting that the patients had more confidence in taking the (placebo) medication than in increasing their water intake.

\section{Effects of increased water intake}

The advice to increase the daily water intake by 1.5 litres resulted in a mean difference between the two groups of more than 1 litre (table I). Water seemed to have a considerable effect on total number of hours of headache and headache intensity, although the effects were not statistically significant. There appeared to be little to no effect on number of headache episodes, medication use and MSQOL. 
Table 1 Differences between the intervention and control group from baseline to 12 weeks.

Fluid intake (ml)

baseline

$2252(1062)$

Control

Water

Mean SD

Mean SD

$(n=8)$

$(\mathrm{n}=7)$

Estimated effect

12 weeks

3226 (1083)

$1775(671)$

1872 (285) 1020 (389 to 1650$)$

Hours of headache in two weeks

baseline

12 weeks

Mean headache intensity

(Visual Analogue Sçale; range 0-100 mm)

baseline

12 weeks

$45(17)$

39 (16)

$39(12)$

50 (16)

$-13(-32$ to 5$)$

Number of headache episodes

Baseline

12 weeks

$7.9(3.2)$

$6.1(3.6)$

$7.3(6.2)$

$7.1(7.3)$

12 weeks

Migraine Specific Quality Of Life

(range 20 (worst) - 80 (best))

$$
\begin{aligned}
& \text { baseline } \\
& 12 \text { weeks }
\end{aligned}
$$

$57(41)$

$58(46)$

$-21(-48$ to 5$)$
Medication use (number of tablets)

baseline
12 weeks
(worst) - 80 (best))

$51(13)$

$63(7)$

$55(15)$

$7.9(4.4)$

$7.1(3.6)$

$-1 \cdot(-4$ to 2$)$

$7.4(8.0)$

$8.1(5.7)$

$-1(-6$ to 4$)$

* Note: The estimated effect (effect size) was determined using regression analysis, in which we adjusted for differences in baseline score. 


\section{Discussion}

\section{Effects of increased water intake on headache}

From this pilot study it appears that drinking more water might have an effect on the total number of hours and intensity of headache episodes. Increased water intake seems to have little effect on total number of headache episodes and medication use. There seems to be no effect on migraine specific quality of life. The difference in total hours of headache during two weeks between the intervention group and the control group was 21 hours. The observed difference in mean improvement in headache intensity was $13 \mathrm{~mm}$ on a VAS in favour of the water group. Although imprecise due to the small sample size, these estimates seem relevant, and we suggest that more research should be done on this topic.

\section{Limitations of this study}

Obviously, there is limited value of statistical analysis with such a small sample size, and it is therefore impossible to draw firm conclusions from this data. However, studying such a new intervention directly in a large randomised trial, with only case reports as background, was considered a too large step in this phase.

Another limiting factor is the broad selection of the research population. However, the current state of knowledge on this topic is limited, and it is therefore uncertain which type of headache could benefit the most, or should be excluded from, drinking more water. In this preliminary phase we did not want to be too restrictive in our exclusion criteria. It turned out that all eligible patients had migraine, which improved the homogeneity of the study population. In future research on this topic the different types of headache should be studied separately.

\section{Feasibility}

Giving the advice to increase the daily water intake by 1.5 litres resulted in an average increase in daily fluid intake of almost 1 litre. Hence, although the requested amount of 1.5 litres additionally was not 
achieved, our data suggests that our approach (i.e. taking 0.5 litres three times a day) is an effective method to increase the daily water intake considerably. However, other approaches, like giving the advice to empty a 1.5 litres bottle during the day, could be as effective. No adverse effects of drinking water were reported in this study.

\section{The role of (de)hydration in the pathophysiology of headache}

Blau et al. ${ }^{1}$ suggest that dehydration might affect the meninges and the brain resulting in headache. Although dehydration is commonly believed to result in headache, and although some observational studies support this idea, at the moment, dehydration (or less optimal hydration) has not received much attention from the medical profession. Not much is known about the effects of mild dehydration on for example the brainstem nuclei involved in migraine. ${ }^{14,15}$ The fact that dehydration impairs cognitive performance ${ }^{16,17}$ supports the idea that dehydration can impair neurologic functioning. This hypothesis implies that headache may often be merely a symptom of a suboptimal internal (neuro)physiology instead of being a sign of evident pathology. Another pathophysiological hypothesis that might be considered in future research would be an increased clearance of circulating headache-inducing substances resulting from increased renal perfusion.

If increasing the water intake proves effective in reducing the severity and total number of hours of headache episodes, it could be a first-line approach in order to reduce headache to a lower level. That level may either be acceptable to the patient, or be more susceptible to the currently available pharmacological options.

\section{Conclusion}

The data of the present study suggest a reduction in the total number of hours and intensity of headache episodes after increased water intake. However, before definitive conclusions can be drawn, and before firm clinical recommendations can be given, this intervention must first prove its effectiveness in larger scaled effectiveness studies. 


\section{References:}

1. Blau JN, Kell CA and Sperling JM: Water-deprivation headache: a new headache with two variants. Headache. 44: 79-83, 2004.

2. Zivadinov R, Willheim K, Sepic Grahovac D, Jurjevic A, Bucuk M, Brnabic Razmilic O, Relja $G$ and Zorzon M: Migraine and tension-type headache in Croatia: a population-based survey of precipitating factors. Cephalalgia. 23: 336-43, 2003.

3. Spierings EL, Ranke $\mathrm{AH}$ and Honkoop PC: Precipitating and aggravating factors of migraine versus tension-type headache. Headache. 41: 554-8, 2001.

4. Chabriat H, Danchot J, Michel P, Joire JE and Henry P: Precipitating factors of headache. A prospective study in a national control-matched survey in migraineurs and nonmigraineurs. Headache. 39: 335-8, 1999.

5. Robbins L: Precipitating factors in migraine: a retrospective review of 494 patients. Headache. 34: 214-6, 1994.

6. Wiese JG, Shlipak MG and Browner WS: The alcohol hangover. Ann Intern Med. 132: 897-902, 2000.

7. Awada A and al Jumah M: The first-of-Ramadan headache. Headache. 39: 490-3, 1999.

8. Coote JH: Medicine and mechanisms in altitude sickness. Recommendations. Sports Med. 20: 148-59, 1995.

9. Eichner ER: Treatment of suspected heat illness. Int J Sports Med. 19 Suppl 2: S150-3, 1998.

10. IHS: Classification and diagnostic criteria for headache disorders, cranial neuralgias and facial pain. Headache Classification Committee of the International Headache Society. Cephalalgia. 8 Suppl 7: 1-96, 1988.

11. Passchier J, Mourik JC, McKenna SP, van den Berg M and Erdman RA: Evaluation of the Dutch version of the migraine quality of life instrument (MSQOL) and its application in headache coping. Cephalalgia. 21: 823-9, 2001. 
12. Twisk $\mathrm{J}$ and Proper $\mathrm{K}$ : Evaluation of the results of a randomized controlled trial: how to define changes between baseline and follow-up. J Clin Epidemiol. 57: 223-8, 2004.

13. Vickers AJ and Altman DG: Statistics notes: Analysing controlled trials with baseline and follow up measurements. BMJ. 323: 11234, 2001.

14. Spierings EL: Pathogenesis of the migraine attack. Clin J Pain. 19: 255-62, 2003.

15. Goadsby PJ, Lipton RB and Ferrari MD: Migraine - current understanding and treatment. N Engl J Med. 346: 257-70, 2002.

16. Cian C, Barraud PA, Melin B and Raphel C: Effects of fluid ingestion on cognitive function after heat stress or exerciseinduced dehydration. Int J Psychophysiol. 42: 243-51, 2001.

17. Armstrong LE and Epstein Y: Fluid-electrolyte balance during labor and exercise: concepts and misconceptions. Int J Sport Nutr. 9: 1-12, 1999. 


\section{Chapter 8}

\section{General Discussion}




\section{General discussion}

Our knowledge of the human body, how it functions and why it sometimes dysfunctions, has reached a high level. Our knowledge on genetics, for example, has developed to a point that we actually discuss whether it is ethical to proceed with some aspects of this research. We almost seem to know too much, but is that really the case? Some examples of unanswered research questions suggest the opposite. For instance, we do not know whether the human bladder muscle can be trained by increasing the physiological loading on it. We do not know whether headache patients may benefit from increased water intake. We do not know whether fluid intake plays a role in the long-term regulation of blood pressure. In fact, we do not know how much fluid a human being requires each day for optimal functioning.

The primary aim of the research in this $\mathrm{PhD}$-thesis was to find a preventive intervention for Lower Urinary Tract Symptoms (LUTS) in elderly men. We left the prostate hypothesis behind us and focussed our research on bladder function. The bladder hypothesis led to two studies in which we investigated whether the human bladder can be trained by increasing the urine output. The intervention to achieve this was to urge elderly men with a beginning bladder dysfunction and a low intake of fluid to drink more water. This is how we became acquainted with hydration research and the many questions that are still unanswered in that area. In this chapter the conclusions, limitations, meanings and implications of our research will be discussed.

\section{Can the human bladder adapt to an increased physiological load?}

In animals, a diuretics-induced 3-fold increase in urine output causes, within two weeks, a $60 \%$ increase in bladder weight, a significant increase in contractility and a $190 \%$ increase in bladder compliance (elasticity). ${ }^{1}$ In addition, diuresis protects the rat bladder from the morphologic defects that usually follow obstruction. ${ }^{2}$ Since these changes in bladder function are based on a basic physiological principle - exercise leads to muscle cell adaptation ${ }^{3}$ - there appear to be no reasons to believe that this phenomenon would not apply to the human bladder. 
We carried out two studies in which we investigated the effects of increased water intake/urine output in a human population.

In a cases series of 44 men between 55-75 years of age, we investigated whether the advice to increase the daily fluid intake by two litres of water, led to changes in bladder function and symptoms. Within two months, the maximum flow rate increased by $13 \%$, the maximum voided volume increased by $23 \%$ and the average voided volume increased by $25 \%$. The major limitation of this pilot study was that we did not include a control group. As a result, regression to the mean, natural course of the disease, and non-specific and other co-interventions effects (e.g. placebo effects) could have influenced the results to the positive. However, the bladder function seemed to improve to such an extent that we wanted to continue this line of research.

In a randomised trial we studied 141 participants for a period of six months. We randomly assigned them to the advice to increase the daily fluid intake by 1.5 litres, or to placebo. We observed some effects on bladder function when we compared the intervention to the control group. However, the effects were much smaller than those observed in the pilot study. For instance, there were no effects on maximum flow rate in the trial, while we observed a gradual and statistically significant increase in Qmax in the pilot study. In addition, the maximum and average voided volumes increased by approximately $10 \%$ in the trial compared to more then $20 \%$ in the pilot study.

There were some important differences between the trial and the pilot study that might have reduced the impact of the intervention, which in turn could explain the differences in treatment effect. Firstly, in the pilot study the requested increase in water intake was 2.0 litres where in the trial this was 1.5 litres. The reason that we chose to lower the requested intake was that the pilot study seemed to indicate that the treatment effect was not maximal at two months. The pilot study also indicated that drinking two litres of water additionally was quite a task for the participants. Especially the fourth half litre was difficult to implement in daily life. Therefore, we decided to lengthen the intervention period to have a larger treatment effect, but we decreased the requested extra fluid intake per day a bit.

A second aspect that was different in the trial and that may have 
reduced the impact of the intervention, was the inclusion of a (placebo) control group. Because we wanted to blind the participants for our hypothesis, we could not inform them on the actual purpose of drinking 1.5 litres of water. This might have reduced their motivation to adhere to the advice. This was essentially different from the pilot study where we informed the potential participants extensively on the ideas behind the intervention.

We did our trial in the hot Dutch summer of 2003. This increased the water intake in the control group, which probably reduced the contrast between the two groups with regard to urine output.

These aspects reduced the actual training effect on the bladder to an approximate $10 \%$ increase in urine output. This contrasts with the 200 to $300 \%$ that was achieved in the animal studies. This should be taken into account when drawing conclusions on whether the human bladder can be trained or not. Considering the physiological nature of the intervention, the large effects in the pilot study and the observed effects in the trial, despite relatively poor contrast, we are inclined to consider that, just as the animal bladder, the human bladder is able to adapt favourably to an increased physiological load. Only the amount of extra water intake/urine output must probably be very large to have animallike effects.

\section{Feasibility of the intervention in relation to its effectiveness}

In our research, we did not only want to answer the question whether the bladder can be trained. We also intended to develop an intervention that could be implemented as a preventive intervention. Therefore, the effectiveness of the intervention must be seen in relation to its feasibility.

Achieving a large increase in urine output for a longer period of time takes quite some effort. Not only does the patient has to force himself to drink the required amount of water, he must also be able to expel it. Understandably, this inconvenience is larger for elderly men with LUTS, since they may tend to drink less rather than more, in order to avoid a too large social interference of their LUTS., ${ }^{4}$ Some may argue that this would be a reason to disqualify the intervention beforehand, because the potential positive effects are accompanied with 
increased bother from LUTS. However, we hypothesised that, if increasing the urine output could improve the contractility and compliance of the bladder, the long-term advantages of these changes might outweigh the short-term disadvantages. When we started the study in 2002, it was unknown how well the human bladder could adapt to increased loading. The observed improvements in the animal studies were very large and occurred very fast. Considering this large physiological effect, we figured that, even if the adaptability of the human bladder is only a fraction of that of the animal, it might be enough to be effective and feasible.

We now know more about the (alleged) effectiveness of this intervention, but still it is a matter of weighing and considering the advantages against the disadvantages. The aspects that plead in favour of the intervention are: (1) Drinking more water had no negative effects; (2) the small improvement in bladder function might just be enough to prevent, for example, a potential case of acute urinary retention; (3) for the moment, there are no other effective preventive approaches available for LUTS; and (4) this intervention will be cost-effective even with a small effect size.

In our opinion there is one aspect that pleads against the intervention. This is the fact that the effects that we observed in the trial are small, despite the fact that we put much effort into achieving a maximum increase in urine output. At this moment, this argument weighs heavily on the consideration of implementation. We consider the amount of effort, that must be put into increasing the fluid intake/urine output, too large in relation to its effectiveness. Therefore, we have a preference of finding the effects too small to justify implementation.

\section{Future research on bladder function}

The physiological rationale behind the hypothesis and the results from our studies might inspire other researchers to proceed with this line of research. We suggest that two courses should be followed. Firstly, more research is needed on the bladder training hypothesis. Secondly, other approaches to improve bladder function should be investigated. These must be based on a careful consideration of the pathophysiology of bladder dysfunction. 


\section{Future studies on bladder training}

If one wants to study the adaptive capacity of the human bladder in future research, much effort should be put into achieving sufficient power. This might be achieved either by increasing the impact of the intervention or by increasing the size of the study population.

In order to increase the impact of the intervention the use of diuretics might be considered. That way a much larger increase in urine output can be achieved. In a healthy population such a study might answer the remaining questions on the adaptive capability of the human bladder. We do not exclude the possibility beforehand that diuretics might subsequently be considered for the prevention of LUTS. This will largely depend on the effect size in relation to the intervention period. For example, if only a few months of diuretics induced diuresis is sufficient to achieve a large improvement in bladder function, diuretics might be considered as a preventive approach against LUTS.

Another approach is to study the potential benefits of drinking water in a larger study population, with a longer follow-up period and with more pragmatic effect parameters. The idea behind this is that, although the short-term effects on bladder function may be small, in the long-term the improvement may just be enough to reduce the chance of acute urinary retention or the necessity of a more intrusive intervention. For example, the advice to increase the daily fluid intake by 1.5 litres might be presented in an educational folder. Two large groups, one in which the folder is handed out and one in which this is not, can subsequently be studied for a longer period of time to monitor differences in the progression of LUTS.

\section{Other approaches to improve the bladder function}

Much of our knowledge of bladder (dys)function comes from animal studies. Most of these studies have been performed on the effects of experimentally induced bladder outlet obstruction. It has been shown that bladder outlet obstruction results in bladder hypertrophy, decreased compliance, loss of innervation, and loss of contractility. ${ }^{6-8}$ Hence, it seems possible to reproduce the dimensions of the bladder dysfunction that might be relevant in relation to LUTS. The question, however, is: "What triggers these disadvantageous changes in the bladder?". One of the factors 
that is assumed to play an important role, is the detrusor blood flow.

In a healthy bladder there is a decreased blood flow and a rise in energy expenditure during contraction of the detrusor. The decreased blood flow causes a short state of anoxia in the bladder, and the increased energy expenditure during contraction reduces the local supply of metabolic substrate. ${ }^{9} \mathrm{~A}$ higher and longer increase of intravesical pressure is required in case of urethral obstruction. This is achieved by a more powerful and sustained contraction of the detrusor. As a consequence, there is a longer period of anoxia and a larger depletion of metabolic supplies. ${ }^{10-15}$ It is assumed that a long-lasting state of anoxia and substrate depletion is deleterious for the smooth muscles and neurons in the bladder. It is therefore assumed that this is an important factor in the development of bladder dysfunction. This hypothesis is confirmed by the finding that experimental bladder ischemia without an obstruction leads to changes similar to what is seen in case of obstruction. ${ }^{16-20}$

A reduced blood flow in the bladder is probably, besides a result of obstruction, also age-related. Vascular disease is common in the elderly, and it is, for example, assumed to be important in the development of erectile dysfunction. $^{21}$ There is no firm evidence for a reduced vascularisation of the bladder in the elderly, but this might be the case. Some research, for example, suggests that LUTS is associated with a history of cardiovascular disease. ${ }^{22}$ In addition, elderly women also experience LUTS, ${ }^{23-25}$ and show a reduced peak urinary flow rate and bladder capacity with increasing age. ${ }^{26}$

Several agents could be used to improve the blood flow of the detrusor muscle. It has been suggested, for example, that $\alpha$-adrenergic antagonists $^{27}$ and extracts from Pygeum africanum ${ }^{28}$ accomplish their beneficial effects on the bladder through an improvement of the detrusor blood flow. Another example of the beneficial effects of an improved blood flow has been provided by Schröder et al. ${ }^{12}$ They showed that lowdose aspirin (corresponding to a daily dose of $100 \mathrm{mg}$ in a human adult) protected the rabbit bladder against the contractile dysfunction that usually follows obstruction. Since bleeding time (measured by an incision into the ear) was increased after the low-dose aspirin treatment, they hypothesised that the positive effect of aspirin on the bladder 
function was possibly achieved by a decreased blood viscosity, resulting in an improvement of bladder tissue oxygenation.

Aspirin might also accomplish its positive effect on bladder function via inhibition of the prostaglandin synthesis. In 1976 Bultitude et al. $^{29}$ reported that prostaglandines are naturally produced by the bladder. They act to increase the tone, contractility and spontaneous activity of the detrusor by direct effects on the smooth muscle or via indirect effects on neurotransmission. ${ }^{30,31}$ Recently, Park et al. ${ }^{32,33}$ showed that stretching of the bladder wall by bladder outlet obstruction stimulated COX-2 expression, resulting in an increased prostaglandin synthesis. They suggested that the observed hyperactivity in response to obstruction is triggered by an increased prostaglandin synthesis. They also showed that COX-2 was highly expressed during the period of active cell proliferation. Hence, they suggested that prostaglandins are important in the development of pathological bladder hypertrophy. Cardozo et al.$^{34,35}$ provide clinical data for a possible positive effect of prostaglandin synthetase inhibitors on bladder function. ${ }^{34}$ They studied the effects of $100 \mathrm{mg}$ indomethacin twice daily on bladder overactivity, in a before-after comparison in patients with bladder overactivity. They found a reduction in diurnal and nocturnal frequency compared to baseline. Later, the same group studied the effects of flurbiprofen $50 \mathrm{mg}$ three times daily against placebo. ${ }^{35}$ Although only 30 patients were included in this cross-over trial, the effects of flurbiprofen on symptoms and bladder capacity were significantly better than placebo.

We doubt whether an increased prostaglandin synthesis is a causal factor in the development of bladder dysfunction. We rather see it as a consequence of increased stress by, for example, reduced blood flow. However, the potential effects of prostaglandin synthetase inhibitors on bladder overactivity plead for their use in combination with the advice to increase the daily fluid intake. A reduced bladder overactivity may have a positive influence on the functional capacity of the bladder, which in turn may reduce the discomforts of the intervention. Agents that improve the detrusor blood flow, might also be used in combination with increased fluid intake/urine output. The improved blood flow might improve the 'trainability' of the bladder due to the improved metabolic condition of the bladder. 


\section{Future research on the general health effects of increased fluid}

intake

Our research on the general health effects of increased fluid intake is preliminary and far from conclusive. Very few researchers are involved in hydration research, and as a consequence, surprisingly little is known about the effects of fluid intake on health; fluid intake and fluid homeostasis seem forgotten aspects in medicine. ${ }^{36,37}$ For example, many etiologic studies on LUTS and headache have studied all sorts of risk factors including exotic food ingredients, but we have not found one etiologic study in this area that assessed the etiologic value of total fluid intake. ${ }^{38-52}$ Grandjean et al. ${ }^{53}$ recently published a review paper in which they presented some remaining questions in hydration research. These questions include: How much fluid do healthy adults require daily?; How does one measure hydration status?; How do age, environment, physical activity, and other factors affect fluid needs?; Is there an optimal fluid intake beyond that needed for water balance?; Do foods and beverages differ in their contribution to water balance?. The fact that we do not know the answers to these vital questions, illustrates the huge lack of scientific knowledge when it comes to water.

We carried out a pilot study on the effects of increased water intake on headache, and we monitored several general health effects of longterm increased water intake in the elderly population of the trial. The results form the pilot study on water and headache suggest that more research should be done on the positive effects of increased fluid intake on headache. The observed differences between the control and intervention group were large, but the small sample size does not justify more firm conclusions. A similar report on the possible positive effects of water on headache has recently been published by Blau et al. ${ }^{54}$ They describe the case reports of two medical students who developed headache after a period of water deprivation. They suggest that dehydration affects the meninges and the brain, resulting in headache. Not much is known about the effects of mild dehydration on, for example, the brain-stem nuclei that are involved in migraine. ${ }^{55,56}$ The fact that dehydration impairs cognitive performance ${ }^{57,58}$ supports the idea that dehydration can impair neurologic functioning. This hypothesis implies that headache may often be merely a symptom of a suboptimal 
internal (neuro)physiology instead of being a sign of evident pathology. Another pathophysiological hypothesis that might be considered in future research would be an increased clearance of circulating headacheinducing substances resulting from increased renal perfusion. Future studies must determine whether dehydration or decreased renal perfusion are important factors in the development of headache, and whether drinking more water can effectively reduce headache.

Our analysis of the long-term general health effects of increased water intake in the elderly, showed that elderly individuals can safely increase their fluid intake for a longer period of time. This analysis was carried out because it is supposed that the elderly has an increased chance of getting dehydrated, as well as overhydrated. However, from the literature it appears that no long-term longitudinal data exist on the general health effects of increased fluid intake in the elderly.

Our data do not provide evidence for a possible beneficial effect of drinking extra water. However, this might still be the case. For instance, a cross-sectional analysis of the baseline data showed that water turnover and total body water correlated negatively with age. Whether a reduced water turnover has any causal relationship with other age related negative changes of the human body is unknown. It is also unknown whether increasing the fluid intake has a positive effect on the physiological processes that are involved in ageing.

In addition, we observed beneficial effects of increased fluid intake on diastolic and systolic blood pressure in a subgroup of persons with a decreased renal function. Some research has been performed on the short-term effects of increased fluid intake on blood pressure showing a temporary increase in blood pressure. ${ }^{59-62}$ In addition, the relationship between decreased renal function and high blood pressure is known. ${ }^{63}$ However, as far as we know, a possible positive effect of long-term increased fluid intake on hypertension has not been addressed before. We hypothesize that the decline in blood pressure in subjects with decreased renal function is mediated by a different physiological adaptation to overhydration subsequently leading to decreased peripheral resistance. Water may be a potent anti-hypertensivum, but caution is required since our observation is based on small numbers. Future studies in clinically relevant populations (i.e. patients with hypertension and low GFR) are 
needed to verify these results and to investigate the underlying physiological mechanism.

\section{Funding for everyday diseases}

The research questions that we investigated during our research may seem rather basic and it may seem surprising that questions such as whether the human bladder can be trained, whether increased fluid intake may reduce headache, and whether increased fluid intake has any positive or negative effects on general health, have not been addressed before. How is it possible that we know so much already about, for example, human genetics while we do not even know whether the human bladder can be trained, or how much fluid we require daily.

I think that there are two main reasons for the development and maintenance of these gaps in our knowledge. Firstly, there is the nature of the intervention. The hypothesis behind drinking more water was based on basic physiology. Applying physiological rules - such as: 'exercise leads to muscle function improvement' - is possible and without costs for almost everyone. As a consequence, there are very few parties that have a financial interest in such an intervention. The fact that it is consequently not being studied seems illustrative for the influence of the profit sector on the research agenda.

A second reason might be that LUTS and headache are not lifethreatening diseases. Our knowledge in the fields of cardiology and oncology for example, seems to become exhaustive down to the smallest detail. This is presumably strongly related to the research funding put into these topics. The research budget for the Dutch Heart Society in 2003 was 10,5 million Euro, ${ }^{64}$ the Dutch Cancer Society had a budget of 55 million Euro for $2003 .{ }^{65}$ This contrasts sharply with the governmental funding for research on typical everyday (general practice) disorders. This fund consisted of only 3.4 million Euro spread over a five years period.

At the moment, the life expectancy of a new-born Dutch person is approximately 80 years. ${ }^{66}$ So it seems that we are able to extend our lives tremendously. However, a general practitioner also sees many patients with non-lethal but very bothersome diseases that affect the patient every day. Many of these diseases may be dealt with by simple and cheap 
solutions, but there is very little money available to investigate them and their potential remedies. As a consequence, in the 21 st century they will continue to affect the quality of life of many people. Even stronger, if we are able to extend the life expectancy further, these diseases will bother people even more than 80 years. Until more research funding is available to study everyday non-lethal diseases, every now and then we will be amazed by the simplicity of a new solution to deal with a highly prevalent disease. Fortunately, this keeps research exciting for the few that are involved in this kind of research. 


\section{References:}

1. Tammela TL, Longhurst PA, Wein AJ and Levin RM: The effect of furosemide-induced diuresis on rabbit micturition and bladder contractile function. J Urol. 150: 204-8, 1993.

2. Ohnishi N, Horan P, Levin SS and Levin RM: Sucrose diuresis protects rat bladder from outlet partial obstruction-induced contractile dysfunction.Urology. 54: 183-7, 1999.

3. Guyton AC: Textbook of medical physiology. Philadelphia, W.B. Saunders Company, 1991.

4. Garraway WM, Russell EB, Lee RJ, Collins GN, McKelvie GB, Hehir M, Rogers AC and Simpson RJ: Impact of previously unrecognized benign prostatic hyperplasia on the daily activities of middle-aged and elderly men. Br J Gen Pract. 43: 318-21, 1993.

5. Wolfs GG, Knottnerus JA, Van der Horst FG, Visser AP and Janknegt RA: Determinants of doctor consultation for micturition problems in an elderly male population. Eur Urol. 33: 1-10, 1998.

6. Buttyan R, Chen MW and Levin RM: Animal models of bladder outlet obstruction and molecular insights into the basis for the development of bladder dysfunction. Eur Urol. 32 Suppl 1: 32-9, 1997.

7. Levin RM, Wein AJ, Buttyan R, Monson FC and Longhurst PA: Update on bladder smooth-muscle physiology. World J Urol. 12: 226-32, 1994.

8. Mauroy B: Bladder consequences of prostatic obstruction. Eur Urol. 32 Suppl 1: 3-8, 1997.

9. Brading AF: Alterations in the physiological properties of urinary bladder smooth muscle caused by bladder emptying against an obstruction. Scand J Urol Nephrol Suppl. 184: 51-8, 1997.

10. Levin RM, Levin SS, Zhao Y and Buttyan R: Cellular and molecular aspects of bladder hypertrophy. Eur Urol. 32 Suppl 1: 15-21, 1997.

11. Azadzoi KM, Tarcan T, Kozlowski R, Krane RJ and Siroky MB: Overactivity and structural changes in the chronically ischemic bladder. J Urol. 162: 1768-78, 1999. 
12. Schröder A, Levin RM, Kogan BA and Longhurst PA: Aspirin treatment improves bladder function after outlet obstruction in rabbits.Urology. 58: 608-13, 2001.

13. Greenland JE and Brading AF: The effect of bladder outflow obstruction on detrusor blood flow changes during the voiding cycle in conscious pigs. J Urol. 165: 245-8, 2001.

14. Uvelius B and Arner A: Changed metabolism of detrusor muscle cells from obstructed rat urinary bladder. Scand J Urol Nephrol Suppl. 184: 59-65, 1997.

15. Greenland JE, Hvistendahl JJ, Andersen H, Jorgensen TM, McMurray G, Cortina Borja M, Brading AF and Frokiaer J: The effect of bladder outlet obstruction on tissue oxygen tension and blood flow in the pig bladder. BJU Int. 85: 1109-14, 2000.

16. Azadzoi KM, Shinde VM, Tarcan T, Kozlowski R and Siroky MB: Increased leukotriene and prostaglandin release, and overactivity in the chronically ischemic bladder. J Urol. 169: 1885-91, 2003.

17. Azadzoi KM, Tarcan T, Siroky MB and Krane RJ: Atherosclerosisinduced chronic ischemia causes bladder fibrosis and noncompliance in the rabbit. J Urol. 161: 1626-35, 1999.

18. Azadzoi KM, Tarcan T, Kozlowski R, Krane RJ and Siroky MB: Overactivity and structural changes in the chronically ischemic bladder. J Urol. 162: 1768-78, 1999.

19. Chen MW, Buttyan R and Levin RM: Genetic and cellular response to unilateral ischemia of the rabbit urinary bladder. $\mathbf{J}$ Urol. 155: 732-7, 1996.

20. Gill HS, Monson FC, Wein AJ, Ruggieri MR and Levin RM: The effects of short-term in-vivo ischemia on the contractile function of the rabbit urinary bladder. J Urol. 139: 1350-4, 1988.

21. Milbank AJ and Goldfarb DA: Urological manifestations of vascular disease. Urol Clin North Am. 30: 13-26, 2003.

22. Klein BE, Klein R, Lee KE and Bruskewitz RC: Correlates of urinary symptom scores in men. Am J Public Health. 89: 1745-8, 1999.

23. Lepor $\mathrm{H}$ and Machi G: Comparison of AUA symptom index in unselected males and females between fifty-five and seventy-nine years of age.Urology. 42: 36-40, 1993. 
24. Chai TC, Belville WD, McGuire EJ and Nyquist L: Specificity of the American Urological Association voiding symptom index: comparison of unselected and selected samples of both sexes. $\mathbf{J}$ Urol. 150: 1710-3, 1993.

25. Chancellor MB and Rivas DA: American Urological Association symptom index for women with voiding symptoms: lack of index specificity for benign prostate hyperplasia. J Urol. 150: 1706-8, 1993.

26. Madersbacher S, Pycha A, Schatzl G, Mian C, Klingler CH and Marberger $M$ : The aging lower urinary tract: a comparative urodynamic study of men and women. Urology. 51: 206-12, 1998.

27. Das AK, Leggett RE, Whitbeck C, Eagen G and Levin RM: Effect of doxazosin on rat urinary bladder function after partial outlet obstruction. Neurourol Urodyn. 21: 160-6, 2002.

28. Levin RM, Hass MA, Bellamy F, Horan P, Whitbeck K, Chow PH, Kung LS and Gosling J: Effect of oral Tadenan treatment on rabbit bladder structure and function after partial outlet obstruction. J Urol. 167: 2253-9, 2002.

29. Bultitude MI, Hills NH and Shuttleworth KE: Clinical and experimental studies on the action of prostaglandins and their synthesis inhibitors on detrusor muscle in vitro and in vivo. $\mathbf{B r}$ J Urol. 48: 631-7, 1976.

30. Palea S, Toson G, Pietra C, Trist DG, Artibani W, Romano O and Corsi M: Pharmacological characterization of thromboxane and prostanoid receptors in human isolated urinary bladder. $\mathbf{B r} \mathbf{J}$ Pharmacol. 124: 865-72, 1998.

31. Maggi CA: Prostanoids as local modulators of reflex micturition. Pharmacol Res. 25: 13-20, 1992.

32. Park JM, Yang T, Arend LJ, Smart AM, Schnermann JB and Briggs JP: Cyclooxygenase- 2 is expressed in bladder during fetal development and stimulated by outlet obstruction. Am J Physiol. 273: F538-44, 1997.

33. Park JM, Yang T, Arend LJ, Schnermann JB, Peters CA, Freeman MR and Briggs JP: Obstruction stimulates COX-2 expression in bladder smooth muscle cells via increased mechanical stretch. Am J Physiol. 276: F129-36, 1999. 
34. Cardozo LD and Stanton SL: A comparison between bromocriptine and indomethacin in the treatment of detrusor instability. J Urol. 123: 399-401, 1980.

35. Cardozo LD, Stanton SL, Robinson H and Hole D: Evaluation of flurbiprofen in detrusor instability. Br Med J. 280: 281-2, 1980.

36. Kleiner SM: Water: an essential but overlooked nutrient. J Am Diet Assoc. 99: 200-6, 1999.

37. Stookey JD: Another look at: fuel + $\mathrm{O} 2-\rightarrow \mathrm{CO} 2+\mathrm{H} 2 \mathrm{O}$. Developing a water-oriented perspective. Med Hypotheses. 52: 285-90, 1999.

38. Chyou PH, Nomura AM, Stemmermann GN and Hankin JH: A prospective study of alcohol, diet, and other lifestyle factors in relation to obstructive uropathy. Prostate. 22: 253-64, 1993.

39. Ekman P: BPH epidemiology and risk factors. Prostate Suppl. 2: 23-31, 1989.

40. Glynn RJ, Campion EW, Bouchard GR and Silbert JE: The development of benign prostatic hyperplasia among volunteers in the Normative Aging Study. Am J Epidemiol. 121: 78-90, 1985.

41. Haidinger G, Temml C, Schatzl G, Brossner C, Roehlich M, Schmidbauer CP and Madersbacher S: Risk factors for lower urinary tract symptoms in elderly men. For the Prostate Study Group of the Austrian Society of Urology. Eur Urol. 37: 413-20, 2000.

42. Lagiou P, Wuu J, Trichopoulou A, Hsieh CC, Adami HO and Trichopoulos D: Diet and benign prostatic hyperplasia: a study in Greece. Urology. 54: 284-90, 1999.

43. Lee E, Park MS, Shin C, Lee H, Yoo K, Kim Y, Shin Y, Paik HY and Lee C: A high-risk group for prostatism: a population-based epidemiological study in Korea. Br J Urol. 79: 736-41, 1997.

44. Platz EA, Kawachi I, Rimm EB, Colditz GA, Stampfer MJ, Willett WC and Giovannucci E: Physical activity and benign prostatic hyperplasia. Arch Intern Med. 158: 2349-56, 1998.

45. Platz EA, Rimm EB, Kawachi I, Colditz GA, Stampfer MJ, Willett WC and Giovannucci E: Alcohol consumption, cigarette smoking, and risk of benign prostatic hyperplasia. Am J Epidemiol. 149: 106-15, 1999. 
46. Seitter WR and Barrett Connor E: Cigarette smoking, obesity, and benign prostatic hypertrophy: a prospective population-based study. Am J Epidemiol. 135: 500-3, 1992.

47. Sidney S, Quesenberry C, Jr., Sadler MC, Lydick EG, Guess HA and Cattolica EV: Risk factors for surgically treated benign prostatic hyperplasia in a prepaid health care plan. Urology. 38 : 13-9, 1991.

48. Thomas JA: Diet, micronutrients, and the prostate gland. Nutr Rev. 57: 95-103, 1999.

49. Zivadinov R, Willheim K, Sepic Grahovac D, Jurjevic A, Bucuk M, Brnabic Razmilic O, Relja G and Zorzon M: Migraine and tension-type headache in Croatia: a population-based survey of precipitating factors. Cephalalgia. 23: 336-43, 2003.

50. Spierings EL, Ranke AH and Honkoop PC: Precipitating and aggravating factors of migraine versus tension-type headache. Headache. 41: 554-8, 2001.

51. Chabriat H, Danchot J, Michel P, Joire JE and Henry P: Precipitating factors of headache. A prospective study in a national control-matched survey in migraineurs and nonmigraineurs. Headache. 39: 335-8, 1999.

52. Robbins L: Precipitating factors in migraine: a retrospective review of 494 patients. Headache. 34: 214-6, 1994.

53. Grandjean AC, Reimers KJ and Buyckx ME: Hydration: issues for the 21st century. Nutr Rev. 61: 261-71, 2003.

54. Blau JN, Kell CA and Sperling JM: Water-deprivation headache: a new headache with two variants. Headache. 44: 79-83, 2004.

55. Spierings EL: Pathogenesis of the migraine attack. Clin J Pain. 19: 255-62, 2003.

56. Goadsby PJ, Lipton RB and Ferrari MD: Migraine - current understanding and treatment. N Engl J Med. 346: 257-70, 2002.

57. Cian C, Barraud PA, Melin B and Raphel C: Effects of fluid ingestion on cognitive function after heat stress or exerciseinduced dehydration. Int J Psychophysiol. 42: 243-51, 2001.

58. Armstrong LE and Epstein Y: Fluid-electrolyte balance during labor and exercise: concepts and misconceptions. Int J Sport Nutr. 9: 1-12, 1999. 
59. Lu CC, Diedrich A, Tung CS, Paranjape SY, Harris PA, Byrne DW, Jordan $\mathrm{J}$ and Robertson D: Water ingestion as prophylaxis against syncope. Circulation. 108: 2660-5, 2003.

60. Shannon JR, Diedrich A, Biaggioni I, Tank J, Robertson RM, Robertson $\mathrm{D}$ and Jordan J: Water drinking as a treatment for orthostatic syndromes. Am J Med. 112: 355-60, 2002.

61. Jordan J: Acute effect of water on blood pressure. What do we know? Clin Auton Res. 12: 250-5, 2002.

62. Jordan J, Shannon JR, Black BK, Ali Y, Farley M, Costa F, Diedrich A, Robertson RM, Biaggioni I and Robertson D: The pressor response to water drinking in humans : a sympathetic reflex? Circulation. 101: 504-9, 2000.

63. Culleton BF, Larson MG, Wilson PW, Evans JC, Parfrey PS and Levy D: Cardiovascular disease and mortality in a communitybased cohort with mild renal insufficiency. Kidney Int. 56: 22149, 1999.

64. Hartverslag 2003 Nederlandse Hartstichting. www.hartstichting.nl, Nederlandse Hartstichting, 2003.

65. Kankerbestrijding Onze Manier voor 2003. www.kwfkankerbestrijding.nl, Nederlandse Kankerbestrijding Koningin Wilhelmina Fonds, 2003.

66. Statistisch jaarboek 2004. Voorburg/Heerlen, CBS, 2004. 


\section{Summary}




\section{Summary}

\section{Introduction (chapter 1)}

The key topic of this thesis is the evaluation of a potential preventive intervention - drinking more water - for lower urinary tract symptoms (LUTS) in elderly men. A diminished functioning of the lower urinary tract manifests itself as symptoms such as weak stream, incomplete emptying of the bladder, (urge) incontinence, and frequent voiding during the day and night. LUTS are seldom life-threatening, but nevertheless, many elderly men are significantly bothered by these symptoms. Moreover, a progressed state of the disorder, often involves chronic urinary retention, which can potentially lead to renal complications.

\section{Hypothesis (chapter 2)}

Traditionally, male LUTS have been though to arise from bladder outlet obstruction (BOO) due to prostatic enlargement. Numerous crosssectional studies correlating prostate size, urinary flow and symptom severity have been performed during the past decades. However, the results of these studies have confirmed the prostate hypothesis insufficiently.

Given that lower urinary tract function involves the storage and voiding of urine, proper functioning of this system largely depends on bladder performance. Therefore, it is reasonable to assume that bladder function is also an important factor in the development of LUTS. The fact that many men with BOO do not complain of having symptoms, and the fact that many women also have similar LUTS as men, plead for this hypothesis.

Several aspects such as urethral obstruction, ageing and bladder inactivity may impair the contractility and compliance - and thus the functionality - of the bladder. On the other hand, it seems possible to improve the bladder function. Animal studies have shown that the bladder is able to adapt to increased load. In this respect the bladder behaves very much like skeletal muscle. The similarities between the bladder and skeletal muscle in terms of muscle adaptation suggest that 
regular exercise is also crucial for bladder function and that an increased workload should lead to functional improvement. In humans, increased physiological loading of the bladder can be achieved by increasing the fluid intake, resulting in increased urine output. Therefore, we hypothesise that drinking more water could lead to bladder muscle function improvement. This improved functionality may subsequently lead to reduced LUTS.

\section{Short-term effects (chapter 3)}

As a first step in the evaluation of this hypothesis we carried an uncontrolled follow-up study among 55-75 year old men in which we investigated the effects of a two months daily increase of two litres of water. During these two months we measured maximum urinary flow rate, maximum and average voided volumes (voiding diary) and symptoms regularly. After two months, maximum flow rate had increased by $13 \%(2.3 \mathrm{ml} / \mathrm{s})$, maximum voided volume by $23 \%(93.8$ $\mathrm{ml} / \mathrm{s})$, and average voided by $25 \%(60.1 \mathrm{ml})$, suggesting an increased contractility and functional capacity of the bladder. Moreover, $56 \%$ of the participants reported an improvement of their lower urinary tract function. The International Prostate Symptom Score (IPSS), on the other hand, increased statistically significant with 1.2 points, indicating increased bother.

These results suggest that, just as the animal bladder, the human bladder seems able to adapt to an increased physiological load. In addition, the gradual improvement of the bladder function over the intervention period suggest that the effect was not maximal at two months. Therefore, we conclude that future randomised studies with a longer follow-up period should be performed to study the effectiveness on LUTS further and to determine the upper limit of objective bladder adaptation.

\section{Randomised trial on long term effects (chapter 4)}

We continued our investigations with a randomised controlled trial. We invited 5923 men between 55-75 years of age to participate in the study. 1911 men, who wanted to participate and returned the screening questionnaire, were subsequently screened for moderate symptoms 
severity (IPSS: 8-19) and low fluid intake (self reported intake below two litres per day), resulting in a study population of 141 men. These men were assigned to either the advice to increased their daily water intake by 1.5 litres, or to placebo ( $8 \mathrm{ml}$ inactive syrup).

At six months, the effects on isovolumetric bladder pressure, bladder wall tension and average voided volume were small but statistically significant (respectively: $20 \mathrm{cmH}_{2} \mathrm{O} ; \mathrm{p}=0.007,1.9 \mathrm{~N} / \mathrm{cm}^{2}$; $\mathrm{p}=0.02,26 \mathrm{ml} ; \mathrm{p}=0.04$ ). There were no effects on maximum flow rate, bladder wall thickness, residual volume and maximum voided volume (respectively: $0.9 \mathrm{ml} / \mathrm{s} ; \mathrm{p}=0.2,0.03 \mathrm{~mm} ; \mathrm{p}=0.6,-5 \mathrm{ml} ; \mathrm{p}=0.8,44 \mathrm{ml}$; $\mathrm{p}=0.05$ ). Subjective effect parameters improved in both groups, but there were no statistically significant differences between the two groups.

From this trial, also taking into consideration the effects that we observed in the pilot study, we conclude that the bladder seems able to improve its functioning in response to increased urine output. However, the amount of extra fluid intake/urine output must probably be very large, beyond what is feasible, to achieve animal-like and/or clinically relevant effects.

\section{Validity and ethics of our randomised placebo design (chapter 5)}

A placebo control group is often the best option and is still the standard in effectiveness research, but finding a proper control group is difficult when one wants to study the effects of a lifestyle advice such as "drink more water". A potential control group, hearing of a promising new advice, could easily implement the experimental advice into daily life, resulting in contamination bias. In our study on the effects of drinking more water on bladder function, we used an unusual design to overcome this potential problem; the experimental group was given the instruction to drink more water, the control group received placebo medication. The participants were not informed that there was a $50 \%$ change of receiving placebo. However, differences in prior expectations of treatment efficacy, unmasking of the placebo during the study period and ethical aspects could hinder the applicability of this design. Hence, we carefully evaluated this design with regards to its validity and ethicality.

It turned out that, prior to randomisation, patients had higher 
expectations of the efficacy of the experimental intervention. However, the participants did not seem to have a preference for the experimental intervention. During the study period only two out of 71 patients in the control group unmasked the placebo. In general, both groups fully agreed with the informed consent procedure. Therefore, we concluded that this design can be considered when the effects of a non-pharmacological intervention are studied.

\section{Risks and benefits of increased water intake on general (elderly) health (chapter 6)}

A second aspect that we evaluated more thoroughly in the trial was the effect of drinking more water on general health. This was done because much is claimed, but little is known on the benefits and risks of hydration in an elderly population.

It showed that blood pressure, sodium level, renal glomerular filtration rate (GFR) and general quality of life remained constant during the intervention period. In addition, the cases reporting a worsening on the effect measures were equally distributed over the two study groups. In men with a GFR lower than $80 \mathrm{ml} / \mathrm{min}$ there was a statistically significant longitudinal effect of drinking water on diastolic $(-5.6 \mathrm{~mm}$ $\mathrm{Hg}$; 95\% CI: -9.1 to -2.1$)$ and systolic $(-8.6 \mathrm{~mm} \mathrm{Hg}$; $95 \% \mathrm{CI}:-16.3$ to -0.9$)$ blood pressure.

This evaluation showed that the advice to increase the daily fluid intake by 1.5 litres had no negative long term effects in reasonably healthy, 55-75 year old men. The observed effects on blood pressure in patients with decreased GFR should be studied more carefully in future research.

\section{Water and headache (chapter 7)}

One participant in the study on the short term effects of water on bladder function (chapter 3 ) reported that his migraine complaints had improved after he had increased his water intake. This observation was the basis of another pilot study which we carried out among 18 migraine patients. In this study we also used the placebo randomised design.

It turned out that the group that had increased their daily fluid intake during three months, reported a reduction in total hours of 
headache in two weeks by 21 hours (95\% CI: -48 to 5 ). Mean headache intensity decreased by $13 \mathrm{~mm}$ (95\% CI: -32 to 5 ) on a visual analogue scale (VAS) with a range of $100 \mathrm{~mm}$. The effects on quality of life, number of headache episodes, and medication seemed to be small.

Although not statistically significant, these data seem to justify larger scaled research on the effectiveness of increased water intake in headache patients.

\section{General discussion (chapter 8)}

The general discussion focuses on three aspects: the effects in relation to the feasibility of drinking extra water as a preventive intervention for LUTS; future research on improving the bladder function; and future research in hydration research.

As regards the trainability of the human elderly bladder, the most important issue is that we have probably failed to achieve a sufficiently large increase in urine output to achieve animal-like effects. This may also explain the differences between the large effects in the pilot study, and the much smaller effects that were observed in the trial. We put very much effort into achieving a maximum increase in urine output in the trial. Still, it was very difficult to achieve the required impact of the intervention. Therefore, we conclude that the effects are too small to justify implementation. Future research on the bladder training hypothesis should - in our opinion - focus on achieving sufficient power. This may be achieved by increasing the impact of the intervention or by increasing the size of the study population. We also do not exclude the possibility to use diuretics for a short period in order to increase the impact of the intervention.

Two other potentially effective approaches to improve bladder function are: to improve the blood flow through the bladder with for example $\alpha$-adrenergic antagonists, or low-dose aspirin; and to reduce the overactivity of the bladder with for example prostaglandin synthetase inhibitors. These approaches might be considered in combination with increased urine output, because the improved blood flow might increase the trainability of the bladder and the positive effect of prostaglandin synthetase inhibitors on the functional capacity of the bladder might reduce the inconvenience of drinking more water. 
Our research on the general health effects of increased fluid intake is preliminary and far from conclusive. Very few researchers are involved in hydration research, and as a consequence, surprisingly little is known about the effects of fluid intake on health; fluid intake and fluid homeostasis seem forgotten aspects in medical science. Our preliminary data on the effects of water on headache and blood pressure warrant future research. 
. 


\section{Samenvatting}




\section{Samenvatting}

\section{Inleiding (Hoofdstuk 1)}

In dit proefschrift wordt het onderzoek beschreven naar een preventieve interventie - te weten het drinken van extra water - voor lower urinary tract symptoms (LUTS) bij oudere mannen. Een verminderd functioneren van de lagere urinewegen manifesteert zich in symptomen zoals: zwakke straal, niet volledig uitplassen, (urge) incontinentie en vaak moeten plassen overdag en 's nachts. LUTS zijn zelden levensbedreigend, maar kunnen zeer hinderlijk zijn en een aanzienlijk negatieve impact hebben op het dagelijks leven. Daarbij kan een vergevorderde mate van dysfunctie leiden tot achterblijven van urine in de blaas, wat op zijn beurt kan leiden tot nierproblematiek.

\section{Hypothese (hoofdstuk 2)}

LUTS worden vaak toegeschreven aan een vergroting van de prostaat. In de afgelopen decennia zijn daarom talloze studies uitgevoerd waarin de relatie tussen symptomen, prostaatgrootte en plaskracht is onderzocht. Deze studies hebben de prostaathypothese echter onvoldoende kunnen bevestigen.

Een andere pathofysiologische factor, die in toenemende mate aandacht krijgt, is het functioneren van de blaas. De lagere urinewegfunctie bestaande uit het opslaan en uitplassen van urine, is een systeem dat grotendeels afhankelijk is van de blaasfunctie. Het is daarom logisch te veronderstellen dat de blaasfunctie een cruciale rol speelt bij het ontstaan van LUTS. Het feit dat veel mannen met een evidente urethrale obstructie niet klagen over LUTS, en het feit dat veel vrouwen vaak dezelfde symptomen hebben als mannen, pleit verder voor deze hypothese.

Verschillende factoren, waaronder urethrale obstructie, ouderdom en inactiviteit van de blaas kunnen de contractiliteit en de compliantie van de blaas - en zodoende de functionaliteit van de blaas - negatief beïnvloeden.

Het lijkt mogelijk om de blaasfunctie te verbeteren. Dierstudies hebben aangetoond dat de blaas in staat is zich aan te passen aan een 
grotere belasting. In dit opzicht lijkt de blaas veel op skeletspierweefsel. Deze overeenkomst impliceert dat training van de blaas door een grotere belasting de functionaliteit zou moeten verbeteren. Mensen kunnen de belasting van de blaas vergroten door meer water te drinken, waardoor de urine output toeneemt. Daarom veronderstellen wij dat meer water drinken op termijn zou moeten leiden tot een beter blaasfunctie. Dit zou op haar beurt moeten leiden tot een vermindering van de LUTS.

\section{Korte termijn effecten (hoofdstuk 3)}

Als eerste stap in de evaluatie van deze hypothese deden wij een ongecontroleerde follow-up studie bij mannen tussen de 55 en 75 jaar waarin we de effecten onderzochten van twee maanden lang twee liter extra water drinken. Gedurende deze twee maanden beoordeelden we regelmatig de maximale plaskracht, het maximum en gemiddeld geplast volume per plas en de symptomen. Na twee maanden was de maximale plaskracht met $13 \%(2,3 \mathrm{ml} / \mathrm{s})$, het maximaal geplaste volume per plas met $23 \%$ (94 ml) en het gemiddeld geplast volume per plas met 25\% (60 $\mathrm{ml}$ ) toegenomen, wat suggereert dat de contractiliteit en de capaciteit van de blaas waren toegenomen. Daarbij rapporteerde $56 \%$ van de deelnemers een verbetering van 'het plassen'. De International Prostate Symptom Score (IPSS) nam toe met 1.2 punten, wat eerder wijst op een toename van de symptomen.

Deze resultaten doen vermoeden dat, net als de dierenblaas, de menselijke blaas in staat is zich aan te passen aan een toegenomen belasting. Daarbij doet de geleidelijke verbetering van de blaasfunctie vermoeden dat het effect nog niet maximaal was na twee maanden. Daarom concluderen wij dat toekomstig gerandomiseerd effectiviteitonderzoek met een langere follow-up periode nodig is om de effecten op symptomen verder te onderzoeken. Daarbij zal tevens beoordeeld moeten worden tot welke mate de blaasfunctie zich kan aanpassen.

\section{Gerandomiseerde trial naar de langtermijn effecten (hoofdstuk 4)}

De volgende stap was dat we onze hypothese toetsten in een gerandomiseerde trial. In totaal werden voor deze trial 5923 mannen tussen de 55-75 jaar uitgenodigd om deel te nemen. De 1911 mannen die 
wilden deelnemen en die de screeningsvragenlijst hadden teruggestuurd, werden gescreened op het hebben van matige LUTS (IPSS-8-19) en lage vochtinname (zelf gerapporteerde vochtinname van minder dan twee liter per dag). Dit resulteerde in een uiteindelijke studiepopulatie van 141 mannen. Deze mannen werden verdeeld over twee groepen; één groep kreeg het advies om per dag 1.5 liter extra water te drinken, de andere groep kreeg een placebo (8 $\mathrm{ml}$ inactieve siroop per dag).

$\mathrm{Na}$ zes maanden waren er kleine, maar statistisch significante positieve effecten op blaasdruk, blaaswandspanning en gemiddeld geplast volume (respectievelijk: $20 \mathrm{cmH}_{2} \mathrm{O} ; \mathrm{p}=0.007,1.9 \mathrm{~N} / \mathrm{cm} 2$; $\mathrm{p}=0.02,26 \mathrm{ml} ; \mathrm{p}=0.04)$. Er waren geen verschillen tussen de groepen wat betreft de maximale plaskracht, blaaswanddikte, residueel volume en maximaal geplast volume (respectievelijk: $0.9 \mathrm{ml} / \mathrm{s} ; \mathrm{p}=0.2,0.03 \mathrm{~mm}$; $\mathrm{p}=0.6,-5 \mathrm{ml} ; \mathrm{p}=0.8,44 \mathrm{ml} ; \mathrm{p}=0.05$ ). Beide groepen rapporteerden na zes maanden een vooruitgang op de subjectieve maten, maar er waren geen statistisch significante verschillen tussen de groepen onderling.

Uit de resultaten van de trial en pilot studie concluderen wij dat het er op lijkt dat de menselijke blaas in staat is zich aan te passen aan een toegenomen urine output. Echter, om klinisch relevante effecten te bewerkstelligen moet zoveel water worden gedronken dat het niet haalbaar lijkt deze interventie op grote schaal toe te passen.

\section{Validiteit en ethiek van het placebo design bij een leefstijladvies (hoofdstuk 5)}

Een placebo controlegroep is vaak de beste optie, en is nog altijd de standaard, bij effectiviteitonderzoek. Het vinden van een geschikte controlegroep is echter moeilijk als men het effect van een leefstijl advies - zoals "drink meer water" - wil onderzoeken. De controlegroep kan namelijk, als men op de hoogte is van de interventie in de experimentele groep, eenvoudig het leefstijladvies overnemen en gaan toepassen in het dagelijks leven, resulterend in contaminatie bias. In onze studie naar de effecten van het drinken van extra water op de blaasfunctie gebruikten we een onconventioneel design om dit probleem op te lossen: de experimentele groep kreeg het advies om extra water te drinken, de controlegroep kreeg placebo medicatie. De deelnemers werden niet op de hoogte gesteld dat er een 50\% kans was op het krijgen van een placebo. 
Het gevaar bestond dat er verschillen zouden ontstaan in de verwachtingen van de deelnemers met betrekking tot de effectiviteit van de interventies. Daarbij was het mogelijk dat de placebo gedurende de onderzoeksperiode ontmaskerd zou worden en dat het onderzoek ethisch onaanvaardbaar zou worden geacht. Daarom hebben we de validiteit en de ethiek van dit design gedurende het onderzoek geëvalueerd.

Het bleek dat de deelnemers, voordat zij gerandomiseerd waren, hogere verwachtingen hadden ten aanzien van de effectiviteit van het drinken van extra water. Echter, de deelnemers hadden geen voorkeur voor het krijgen van deze behandeling. Gedurende het onderzoek hadden slechts twee van de 71 deelnemers in de placebogroep het idee dat het siroop een placebo was. Over het algemeen ondersteunden de deelnemers de informed consent procedure volledig.

We concluderen dat dit design overwogen kan worden, als men de effecten van een niet-medicamenteuze interventie wil onderzoeken.

\section{Risico's en voordelen van extra water drinken op de algemene (oudere) gezondheid (hoofstuk 6)}

Een tweede aspect waar we extra aandacht aan hebben besteed in de trial was het effect van het drinken van extra water op de algemene gezondheid. Dit werd gedaan omdat er veel gesuggereerd wordt, maar weinig bekend is over de risico's en voordelen van extra water drinken op de algemene gezondheid.

Het bleek dat bloeddruk, natrium gehalte, renale glomerulaire filtratie snelheid (GFR) en algemene kwaliteit van leven constant bleven gedurende de interventie periode. Tevens bleek dat de mensen die het meest achteruit gingen op deze effectmaten, gelijk verdeeld waren over de beide groepen. Bij mannen met een GFR lager dan $80 \mathrm{ml} / \mathrm{min}$ was er een statistisch significante daling van de diastolische $(-5.6 \mathrm{~mm} \mathrm{Hg}$; 95\% CI: -9.1 to -2.1$)$ en systolische $(-8.6 \mathrm{~mm} \mathrm{Hg} ; 95 \% \mathrm{CI}:-16.3$ to -0.9$)$ bloeddruk te zien.

Deze evaluatie laat zien dat het advies om meer water te drinken op de lange termijn geen nadelige gevolgen heeft in een populatie van redelijk gezonde 55-75 jarige mannen. Verder onderzoek naar de effecten van extra water drinken op de bloeddruk bij mensen met een lage GFR lijkt gerechtvaardigd. 


\section{Water en hoofdpijn}

Een deelnemer aan de follow-up studie naar de korte termijn effecten van water op de blaasfunctie (hoofdstuk 3) meldde ons dat zijn migraine minder was geworden sinds hij meer water was gaan drinken. Deze observatie was voor ons aanleiding tot het doen van een pilot studie naar water drinken bij 18 migraine patiënten. Voor deze studie gebruikten we eveneens het placebogecontroleerde design.

Het bleek dat de patiënten een afname van 21 uur hoofdpijn per twee weken rapporteerden $(95 \% \mathrm{CI}$ : -48 tot 5) nadat zij gedurende drie maanden hun waterinname hadden vergroot. De gemiddelde hoofdpijn intensiteit nam af met $13 \mathrm{~mm}$ (95\% CI: -32 tot 5) op een visual analogue scale (VAS) van totaal $100 \mathrm{~mm}$. Er was slechts een klein effect op kwaliteit van leven, aantal hoofdpijn episodes en medicatiegebruik.

Hoewel niet statistisch significant, lijken deze data toekomstig onderzoek naar het effect van water op hoofdpijn te rechtvaardigen.

\section{Algemene discussie}

In de algemene discussie worden drie hoofdthema's behandeld: de effecten ten opzichte van de haalbaarheid van het drinken van extra water in de preventie van LUTS; toekomstig onderzoek naar verbetering van de blaasfunctie; en toekomstig onderzoek naar de effecten van water op de gezondheid.

Het belangrijkste discussiepunt bij de bespreking van de resultaten van water drinken op de blaas is dat het ons in de trial niet is gelukt om een aanzienlijke toename in de urine output te bewerkstelligen. Dit kan tevens de verschillen verklaren tussen de grote effecten in de pilot studie en de veel kleinere effecten in de trial. We hebben veel moeite moeten doen om een maximaal contrast te krijgen en gebleken is dat het zeer moeilijk is om de gewenste impact van de interventie te bewerkstelligen. Daarom hebben wij moeten concluderen dat de effecten te klein zijn om implementatie van deze interventie te overwegen. Toekomstig onderzoek naar de blaastraining hypothese zou zich naar onze mening moeten richten op het bereiken van voldoende power, hetzij door de impact van de interventie, dan wel de grootte van de onderzoekspopulatie, te vergroten. Ook overwegen wij de mogelijkheid om in toekomstig onderzoek diuretica gedurende een korte periode te gebruiken om de 
impact van de interventie te vergroten.

Twee andere mogelijk effectieve methodes om de blaasfunctie te verbeteren zijn: het verbeteren van de doorbloeding van de blaas door middel van bijvoorbeeld $\alpha$-adrenerge antagonisten, of lage-dosis aspirine; en het verminderen van blaasoveractiviteit bijvoorbeeld met behulp van prostaglandine synthetase remmers. Deze methoden zouden tevens in combinatie met extra water drinken overwogen kunnen worden. De verbeterde doorbloeding van de blaas zou de trainbaarheid van de blaas kunnen verbeteren en de prostaglandine synthetase remmers zouden de functionele blaascapaciteit kunnen verhogen, wat de ongemakken van het drinken van veel water kan verminderen.

Zeer weinig medisch-wetenschappelijke onderzoekers houden zich bezig met hydratieonderzoek en zodoende zijn zelfs de meest elementaire vragen nog niet beantwoord; vocht inname en vocht balans lijken vergeten items binnen het medisch-wetenschappelijke onderzoek. Ook wij kunnen na ons onderzoek naar de effecten van extra water drinken op de algemene gezondheid slechts enkele voorzichtige conclusies trekken. Onze voorlopige resultaten op hoofdpijn en bloeddruk lijken toekomstig onderzoek te rechtvaardigen. 


$$
\text { . }
$$




\section{Dankwoord}




\section{Dankwoord}

\section{Achtergrond}

"Zeg je wel alstublieft en dankjewel", zei mijn moeder mij vroeger als ik als klein jongetje uit logeren ging. Daarbij kreeg ik dan een potje (zelfgemaakte) jam mee om aan de logeermoeder te geven. Het potje jam vergat ik nooit af te geven, maar het kan zijn dat ik niet altijd even consequent was in het bedanken van de betreffende moeder; waarom zou mijn moeder me anders iedere keer weer zo zorgvuldig instrueren? In dit proefschrift kan ik mijn dank schriftelijk vastleggen. Op die manier heb ik een bewijs van goed gedrag, ......... mocht men weer aan mijn goede manieren twijfelen.

\section{Hooggeschoold begeleidingsteam}

Mijn promotietraject begon met de vraag van Onno van Schayck of ik bij hem wilde promoveren. Op een onderzoek naar plasklachten notabene; ik wist niet eens waar de prostaat zich bevond. De andere promotor zou André Knottnerus zijn. Na enig navragen in mijn destijds epidemiologische omgeving bleek mijn onwetendheid niet zo'n probleem, "zeker als je zulke toppers als promotores hebt", werd me nog nageroepen. En toppers zijn het, met alle voor- en nadelen die daarmee gepaard gaan. Een nadeel was dat zij het vaak erg druk hadden, een voordeel was dat zij het vaak erg druk hadden. Op die manier mis je wellicht enige diepgang, maar daartegenover staat een zeer gewenste - en door beide heren geboden - vrijheid, waarbij ik wel altijd kon terugvallen op hun oordeel als dat nodig was. Het is lastig te benoemen wat ik nu precies zo zeer gewaardeerd heb in de jarenlange samenwerking met André en Onno. Feit is dat we nog steeds zeer productieve en gezellige besprekingen hebben en ik hoop dat dit nog een tijdje zo door mag gaan. Vanuit Urologie zijn Cees van de Beek en Philip van Kerrebroeck nauw betrokken geweest bij het onderzoek. Beiden zijn aimabele heren en ik wil ze bij deze bedanken voor hun scherpe commentaar en het geboden vertrouwen in een niet-uroloog. Hopelijk wordt ook deze samenwerking in de toekomst voortgezet.

Neuroloog Jaap Troost en geriater Marcel Olde Rikkert dank ik 
voor hun hulp bij respectivelijk de hoofdpijnstudie (hoofdstuk 7) en de bijwerkingen analyse (hoofdstuk 6).

Paul Knipschild wil ik bedanken voor de direct toegankelijke, altijd scherpe en onvoorwaardelijke hulp. Met zijn rechtlijnige visie op de methodologie van een trial heeft hij me erg geholpen bij het structureren van mijn gedachten, zodat we uiteindelijk om mooie trial hadden.

Samen met Klaas Westerterp en Loek Wouters van de capaciteitsgroep Humane Biologie hebben we middels gemerkt water (deuterium) exact kunnen bepalen hoeveel de deelnemers gedronken hadden. Het moge duidelijk zijn dat deze metingen cruciaal waren voor het project.

Ron van Mastrigt, Johan Pel en John Jhuang van de Erasmus Universiteit Rotterdam hebben apparatuur ontwikkeld waarmee het mogelijk is de blaasdruk non-invasief te meten. Tot voor kort was dit alleen mogelijk via het inbrengen van een drukcatheter in de blaas. Dat zag ik bij mijn gezonde populatie niet zitten, dus toen ik van hun apparatuur hoorde heb ik direct contact met ze opgenomen. Uiteindelijk heb ik met hun hulp deze apparatuur in mijn studie kunnen gebruiken.

\section{Praktisch begeleidingsteam}

In de afgelopen vijf jaar hebben verschillende dames mij in praktische zin geholpen bij de diverse projecten. Binnen de plasklachtenlijn zijn Marga, Susanne, Vinca en Karin met name betrokken geweest bij de "diagnostische studie". Hoewel deze studie nog niet is afgerond en dus niet in dit proefschrift is vertegenwoordigd, hebben we de afgelopen jaren veel samengewerkt. Door hun bijdrage is deze studie nu bijna analyseklaar zodat ik na dit proefschrift door kan gaan met schrijven.

Ellen de Goeij en Anuska Weekers hebben me tijdens de "drinkstudie" bijgestaan. Ellen heeft mij vanaf het begin geholpen bij het uitvoeren van deze studie, inclusief de metingen in het ziekenhuis op de dinsdagavond, vrijdagavond en zaterdag! Met Ellen is het zeer fijn samenwerken omdat het haar, op de één of andere manier, lukt om flexibel en principieel tegelijkertijd te zijn. Haar ruime hart (citaat van een deelnemer) zorgde niet alleen voor een goede band met mij, maar het 
zorgde ook voor een ontzettend enthousiaste deelnemersgroep. Anuska maakte het dreamteam compleet. Zij heeft ervoor gezorgd dat iedere deelnemer de juiste spullen kreeg en dat er met iedere deelnemer contact werd gehouden gedurende de zes maanden van het onderzoek. De inzet van beide dames heeft er uiteindelijk zeker toe bijgedragen dat iedere deelnemer de eindstreep haalde.

Willem, de man van Ellen, heeft vrijwillig voor mij een database opgezet. Dit is makkelijker geschreven dan gedaan, want Willem heeft zelf een zeer drukke baan. Als op zondagavond de telefoon ging kon ik er bijna zeker van zijn dat het Willem was. Na een aantal zeer gerichte vragen ging hij dan weer aan de slag. Uiteindelijk durf ik te stellen dat de database hèt middel was waardoor het hele project vlekkeloos en ontspannen verliep.

\section{Huisartsen en deelnemers}

Voor de artikelen in dit proefschrift hebben zich drie deelnemerspopulaties ingezet. De eerste studie die ik uitvoerde was in Noord-Holland in mijn geboortedorp en het dorp ernaast. Dankzij de hulp van de oud-burgemeester van Wogum, de heer De Nijs, en de huisartspraktijk van Nibbixwoud, lukte het om voldoende deelnemers voor de pilot studie bij elkaar te krijgen. Deze mannen dronken twee maanden lang liters water en verschenen om de twee weken op de metingen, waarvoor mijn dank.

De uiteindelijke trial was door de inzet van 21 huisartspraktijken en de daaruit afkomstige (uiteindelijk) 141 deelnemers een groot succes. Tijdens deze studie zorgden deze 141 mannen voor een geweldige sfeer, waardoor de vele metingen buiten normale werktijden uiteindelijk helemaal niet vervelend waren. Tekenend voor het enthousiasme van de deelnemers, was de deelnemer die voor spek en bonen mee wilde doen. Door een ongelukkig ingevulde vragenlijst was deze man geëxcludeerd, maar hij liet zich niet zo snel afschepen. Alle mannen, inclusief deze man, hebben uiteindelijk de eindmeting volbracht. Voor deze uitzonderlijke blijk van discipline ben ik jullie zeer dankbaar. Iedere Hollènder die de discipline van de Limburger in twijfel durft te trekken werp ik voortaan deze cijfers voor de voeten.

Voor de pilot studie naar water bij hoofdpijn hebben zich 18 
mensen ingezet. Hoewel deze studie klein was, was de gevraagde (en geboden) inzet van de deelnemers groot. Uiteindelijk is dit nu één van de belangrijkste pijlers van mijn mogelijkheden op vervolgonderzoek.

\section{Collega's}

Gedurende mijn promotietraject was ik gestationeerd bij de capaciteitsgroep huisartsgeneeskunde van de Universiteit Maastricht. Bij huisartsgeneeskunde werken veel mensen. Een nadere specificatie van dank, zou daarom onherroepelijk tot een eindeloze lijst met namen of tot zure gezichten leiden, dus daar waag ik me niet aan. Daarom bedankt ik iedereen voor de goede samenwerking. Ook met verschillende collega's van de capaciteitsgroep Epidemiologie heb ik veel te maken gehad, al was het soms alleen tijdens de lunch of in de kroeg (Thembi). Bedankt voor de interessante gesprekken in Thembi en het even naar boven lopen als er gelunched werd.

\section{Vrienden}

Zonder vrienden, geen ontspanning en zonder ontspanning geen proefschrift, dus hun bijdrage is zeker significant. Een aantal wil ik er even uitlichten: Caro, Maurice, Edwin, Freddy, Nico, Joost, Guido, Rogier en Gerard. Met Caro kan ik ongegeneerd over het werk praten bij een glas Erdinger in de Falstaff; met Maurice zou ik wel willen trouwen (als ik homo was); ook Edwin kan ik dagen om me heen hebben zonder dat ik me aan hem erger; hoewel het irritant is dat hij (meestal) harder fietst dan ik; net als Freddy en Nico overigens, van wie ik het achterwiel zo langzamerhand kan uittekenen; maar gelukkig kan ìk Joost en Guido laten lijden; Rogier zorgt voor de rust tijdens de duurlopen en zijn vriendin kan goed kip klaarmaken (inclusief het slachten); Gerard is de oudste vriend die ik ooit heb gehad; met hem (en Edwin, Ron, Ludovic) heb ik op relatief jonge leeftijd toch al een wandelclubje waarmee we al menig 'gast' flinke blaren hebben bezorgd.

De dames: Salmara, Sandrine, Sabrina, Marcelle, Els en natuurlijk alle dames van bovengenoemde mannen, zorgen voor enig tegenwicht voor al het macho gedoe. 


\section{Familie}

Dit zijn er twee, de familie Spigt en de familie Kertzman. De Kertzmannetjes zorgen nu zo'n tweeëneenhalf jaar voor veel gezelligheid. De Spiggies doen dat al veel langer; met ups en downs, maar zeker voor altijd. Een speciaal woord van dank is voor mijn vader wiens medeleven zelfs direct heeft geleid tot een onderzoeksvraag (hoofdstuk 7).

\section{Maud}

Hoe kleiner het stukje hoe groter de liefde. 


\section{De auteur}




\section{De auteur}

Mark Spigt werd geboren op 1 september 1973 in Wervershoof (Noord-Holland). De lagere school volgde hij op de Hieronymus school te Wognum. Na een Lbo-Mavo Cito-toetsadvies ging hij naar de Oscar Romero Scholengemeenschap in Hoorn. In 1990 behaalde hij daar zijn Havo-diploma. In Amsterdam startte hij met de opleiding fysiotherapie; in 1995 ontving hij voor deze opleiding zijn diploma. In datzelfde jaar startte hij met de studie Gezondheidswetenschappen afstudeerrichting bewegingswetenschappen aan de Universiteit Maastricht. Op 31 januari 1999 studeerde hij cum-laude af àan de UM en ontving hij de Catharina Pijls aanmoedingsprijs voor zijn afstudeerscriptie getiteld: "prognostische factoren voor een fysiek trainingsprogramma voor chronische aspecifieke lage-rugpijn".

$\mathrm{Na}$ zijn afstuderen werkte hij korte tijd als onderzoeker bij de capaciteitsgroep Epidemiologie, UM. Sinds juni 1999 tot heden werkt hij bij de capaciteitsgroep Huisartsgeneeskunde, UM. Daar was hij onderzoeker op het project "Diagnostiek van mictieklachten bij oudere mannen", dat gefinancierd werd door het College Voor Zorgverzekeringen (CVZ). Verder was hij werkzaam op het ZonMw project: "Prevention of lower urinary symptoms in elderly males". Dit project vormde de basis voor dit proefschrift. Momenteel is hij werkzaam als Postdoc op een project getiteld: "Increasing the daily water intake for the prophylactic treatment of headache", dat wordt gefinancierd vanuit het ZonMw/NHG programma Alledaagse Ziekten. 